Portland State University

PDXScholar

$5-21-1976$

\title{
The Analysis of the Deflection and Containment of a Hot Plume by Side Draft Exhaust Hooding
}

Douglas H. MacGowan

Portland State University

Follow this and additional works at: https://pdxscholar.library.pdx.edu/open_access_etds

Part of the Applied Mechanics Commons

Let us know how access to this document benefits you.

\section{Recommended Citation}

MacGowan, Douglas H., "The Analysis of the Deflection and Containment of a Hot Plume by Side Draft Exhaust Hooding" (1976). Dissertations and Theses. Paper 2557.

https://doi.org/10.15760/etd.2554

This Thesis is brought to you for free and open access. It has been accepted for inclusion in Dissertations and Theses by an authorized administrator of PDXScholar. Please contact us if we can make this document more accessible: pdxscholar@pdx.edu. 
AN ABSTRACT OF THE THESIS OF Douglas H. MacGowan for the Master of Science in Applied Science presented May 21, 1976.

Title: The Analysis of the Deflection and Containment of a Hot Plume by Side Draft Exhaust Hooding.

APPROVED BY MEMBERS OF THE THESIS COMMITTEE:

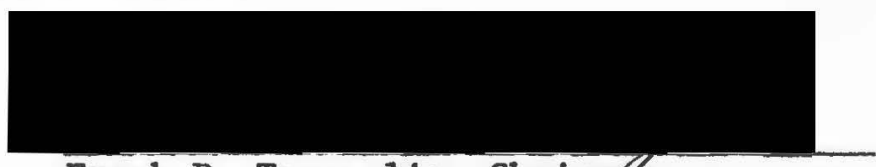

Frank P. Terragl1o, Cha1rmán

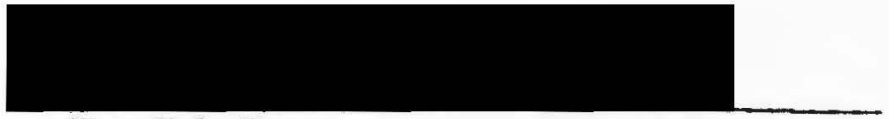

Nan-Teh Hsu

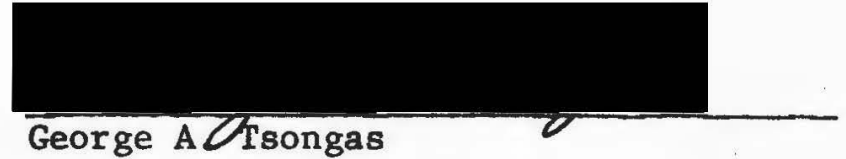

A common industrial ventilation and pollution problem results when a thermally buoyant polluted plume of air must be exhausted away from a work area to allow achievement of air pollution standards. Generally, a close fitting canopy hood is one of the most effective means of exhaust containment; however, physical restrictions or the operation itself often prevent such an arrangement, and a hood located to the side of the operation is required. This arrangement requires the exhaust to bend and contain the vertically rising plume with a horizontal sweep of exhaust alr across the surface of the operation. 
A review of available literature revealed a lack of the necessary theory and data needed to design a side draft hood based on plume dynamics. The purpose of this study, then, is to develop the theory relating the side draft hood size and required exhaust volume to the hot source characteristics and to test the theory in the laboratory.

In making field observations it was noted that the capture of a plume appeared to be a function of the flow volume, velocity and density of the plume. These quantities in turn can be written in terms of the surface area, temperature and location of the hot surface generating the plume. In relating the required exhaust flow to a given plume flow the following relation is proposed:

$$
\rho_{E} Q_{E} \bar{V}_{E}=K_{2} \rho_{P} \rho_{P} \bar{V}_{p}
$$

where $\rho_{E}$ is the exhaust (ambient) density, $Q_{E}$ is the required exhaust volumetric flow, $\bar{V}_{E}$ is the exhaust velocity measured along the hood center line at the plume location, $\rho_{p}$ is the calculated plume density, $Q_{p}$ is the calculated plume volumetric flow, $\bar{v}_{p}$ is the calculated plume velocity at the height of hood center line, and $\mathrm{K}_{2}$ is a coefficient to be experimentally determined. By calculating the plume terms $\left(\rho_{p}, Q_{p}\right.$ and $\bar{V}_{p}$ ) and writing $\bar{V}_{E}$ in terms of $Q_{E}$, the required exhaust can be found for any combination of size, temperature or location of the hot surface generating the plume.

To verify the relationship in Eq.1, equipment was set up in the laboratory to approximate cases of ventilated hot plumes noted in industry. Smoke was introduced over the plate to allow visual observation of the plume flow path. Required exhaust rates were noted as a function of the hot plate size, temperature and location; the data was then 
correlated for use in Eq. 1 with values of $\mathrm{K}_{2}$ noted in each case.

The results of the study verified the relationship seen in Eq.1 for limited horizontal distances from plume to hood. Within this range, $\mathrm{K}_{2}$ was found to be a direct function of distance with values of $0.5,0.7$ and 1.0 resulting for distances of $12 ", 18^{\prime \prime}$ and $24 "$ respectively. Within this range $\mathrm{K}_{2}$ was not found to be a function of the vertical height from hot plate to hood center line. However, at distances greater than $24^{\prime \prime}, \mathrm{K}_{2}$ exceeded expected values, and was found to be dependent upon the hood height. A partial explanation for this discrepancy centers around the geometry of the hooding and equipment specific to this particular experiment. Further testing will be required over a broader range of hot plate sizes, shapes and temperatures, as well as exhaust configurations before this explanation can be verified, or before the theory and results can be applied with confidence in sizing side draft hooding for industrial applications. 
THE ANALYSIS OF THE DEFLECTION AND CONTAINMENT

OF A HOT PLUME BY SIDE DRAFT EXHAUST HOODING

by

DOUGLAS H. MACGOWAN

A thesis submitted in partial fulfillment of the

requirements for the degree of

MASTER OF SCIENCE

in

APPLIED SCIENCE

Portland State University

1976 
TO THE OFFICE OF GRADUATE STUDIES AND RESEARCH:

The members of the Committee approve the thesis of Douglas H. MacGowan presented May 21, 1976.

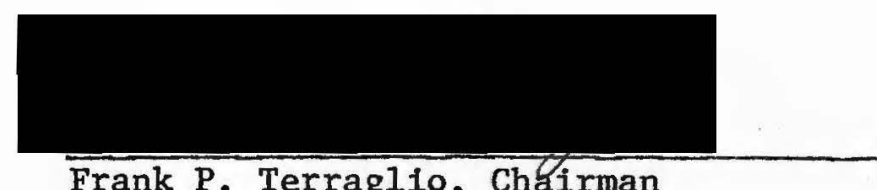

Frank P. Terrag11o, Chairman

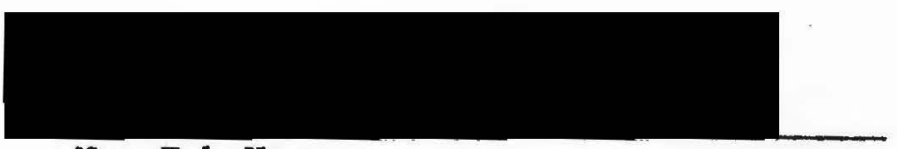

Nan-Teh Hsu

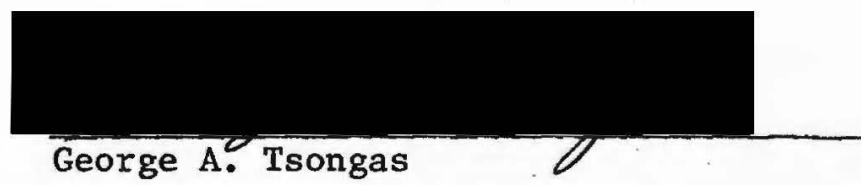

APPROVED:

Fred M. Yeugof Head, Defartment of Engineering and Applied Science

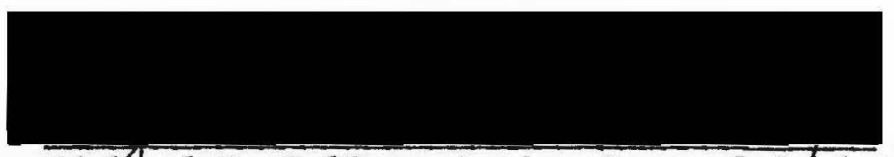

Richard B. Halley, Acting Dean of Gojaduate Studies and Research 
TABLE OF CONTENTS

PAGE

LIST OF TABLES ........................... vi

LIST OF FIGURES $\ldots \ldots \ldots \ldots \ldots \ldots \ldots \ldots \ldots \ldots \ldots \ldots \ldots \ldots \ldots \ldots \ldots \ldots \ldots \ldots$

\section{CHAPTER}

I INTRODUCTION $\ldots \ldots \ldots \ldots \ldots \ldots \ldots \ldots \ldots \ldots \ldots \ldots \ldots$

II BACKGROUND THEORY $\ldots \ldots \ldots \ldots \ldots \ldots \ldots \ldots \ldots \ldots \ldots \ldots$

A. General Overview ................. 5

B. Convective Heat Transfer ............. 8

C. Plume Behavior Due to Natural

Convection ..................... 10

D. Characteristics of Exhaust Hooding ...... 15

E. Analysis of the Effect of Lateral

Exhaust on a Thermal Plume; A

Study by L.V. Kuz'mina............... 21

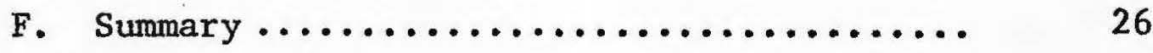

III PROPOSED THEORY ..................... 28

A. Development of Concept $\ldots \ldots \ldots \ldots \ldots \ldots \ldots .28$

B. Development of Equations ........... 35

IV EXPERIMENTAL SET UP .................. 40

A. General $\ldots \ldots \ldots \ldots \ldots \ldots \ldots \ldots \ldots \ldots \ldots \ldots$............... 40

B. Equipment .................... 40

Hot Plate

Hooding and Ductwork

Smoke Generator

Source Stand

Genera1 
CHAPTER

V PROCEDURE

VI RESULTS AND ANALYSIS $\ldots \ldots \ldots \ldots \ldots \ldots \ldots \ldots \ldots$

A. Results of Pre Test Data ...........

B. Results of $12^{\prime \prime} \times 20^{\prime \prime}$ Plate

Tested at $550^{\circ} \mathrm{F} \ldots \ldots \ldots \ldots \ldots \ldots$

C. Results of $12^{\prime \prime} \times 20^{\prime \prime}$ Plate

Tested at $750^{\circ} \mathrm{F}$

68

D. Results of $8^{\prime \prime} \times 10^{\prime \prime}$ Plate

Tested at $615^{\circ} \mathrm{F}$

E. Application of Experimental

Results to Existing Side

Draft Hood Ventilating a

48" Diameter Ladle of Molten

Stee1

86

VII SUMMARY

VIII CONCLUSION

A. Test Equipment List $\ldots \ldots \ldots \ldots \ldots \ldots \ldots$

B. Temperature Calibration, 8" $\times 10^{\prime \prime}$

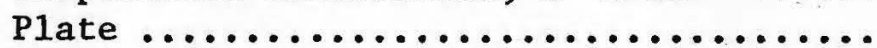

C. Temperature Calibration, $12 "$ × $20^{\prime \prime}$

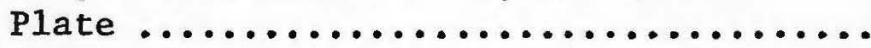

D. Determination of Exhaust Hood Equations

E. Calculated Plate Momentums ..........

F. Tabular Results of $12^{\prime \prime} \times 20^{\prime \prime}$

Plate Tested at $550^{\circ} \mathrm{F} \ldots \ldots \ldots \ldots \ldots \ldots . . . . .108$

G. Tabular Results of $12^{\prime \prime} \times 20^{\prime \prime}$ Plate Tested at $750^{\circ} \mathrm{F} \ldots \ldots \ldots \ldots \ldots \ldots$ 
H. Tabular Results of $8^{\prime \prime} \times 10^{\prime \prime}$ Plate Tested at $615^{\circ} \mathrm{F} \ldots \ldots \ldots \ldots \ldots \ldots \ldots \ldots$

I. Analysis of Existing Side Draft Hood Ventilating a 48" Ladle of Molten Steel 


\section{LIST OF TABLES}

TABLE

PAGE

I Recommended Exhaust Volumes for Foundry Shakeout

Side Draft Hooding $\ldots \ldots \ldots \ldots \ldots \ldots \ldots \ldots \ldots$

II Summary of Calculated P1ume Flow and Velocity Based

$$
\text { on Selected Value of } \bar{h}_{c} \ldots \ldots \ldots \ldots \ldots \ldots \ldots
$$

III Summary of Grashof Number vs Temperature for an

$$
8 " \text { x } 10^{\prime \prime} \text { Plate } \ldots \ldots \ldots \ldots \ldots \ldots \ldots \ldots \ldots \ldots
$$

IV Summary of Grashof Number vs Temperature for a

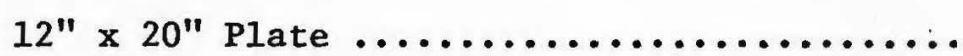

V Resulting Exhaust Velocity Decay Equations at

Three Source Heights $\ldots \ldots \ldots \ldots \ldots \ldots \ldots \ldots \ldots$

VI Application of Plume Momentum Theory to Existing

Side Draft Hood Ventilating a $48^{\prime \prime}$ Diameter

Ladle of Molten Steel

VII Exhaust Volume (CFM) Expressed as a Function of Position for $12^{\prime \prime} \times 20^{\prime \prime}$ P1ate at $550^{\circ} \mathrm{F} \ldots \ldots$.

VIII Ratio of Exhaust Volume to Plume Volume Fxpressed as a Function of Position for $12^{\prime \prime} \times 20^{\prime \prime}$ Plate

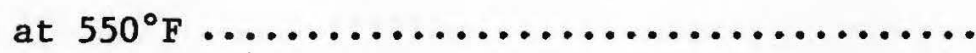

IX Exhaust Momentum Expressed as a Function of Position for a $12^{\prime \prime}$ x $20^{\prime \prime}$ Plate at $550^{\circ} \mathrm{F} \ldots \ldots$ 
X Ratio of Exhaust Momentum to Plume Momentum,

$\mathrm{K}_{2}$, Expressed as a Function of Position

for $12^{\prime \prime} \times 20^{\prime \prime}$ Plate at $550^{\circ} \mathrm{F} \ldots \ldots \ldots \ldots \ldots$

XI An Analysis of Data for the $12^{\prime \prime} \times 20^{\prime \prime}$ Plate at $550^{\circ} \mathrm{F}$ Using the Technique Presented by Kuz mina $\ldots \ldots \ldots \ldots \ldots \ldots \ldots \ldots \ldots \ldots$

XII Exhaust Volume (CFM) Expressed as a Function of Position for $12^{\prime \prime} \times 20^{\prime \prime}$ Plate at $750^{\circ} \mathrm{F} \ldots \ldots$

XIII Ratio of Exhaust Volume to Plume Volume Expressed as a Function of Position for a $12^{\prime \prime}$ x 20 " Plate at $750^{\circ} \mathrm{F} \ldots \ldots \ldots \ldots \ldots \ldots \ldots$

XIV Exhaust Momentum Expressed as a Function of

Position for a $12^{\prime \prime}$ x 20" Plate at $750^{\circ} \mathrm{F} \ldots$

XV Ratio of Exhaust Momentum to Plume Momentum,

$\mathrm{K}_{2}$, Expressed as a Function of Position

for $12^{\prime \prime} \times 20^{\prime \prime}$ Plate at $750^{\circ} \mathrm{F} \ldots \ldots \ldots \ldots \ldots$

XVI An Analysis of Data for the $12^{\prime \prime} \times 20^{\prime \prime}$ Plate at

$750^{\circ} \mathrm{F}$ Using the Technique Developed by

Kuz"mina $\ldots \ldots \ldots \ldots \ldots \ldots \ldots \ldots \ldots \ldots \ldots$

XVII Exhaust Volume (CFM) Expressed as a Function of

Position for an $8^{\prime \prime} \times 10^{\prime \prime}$ Plate at $615^{\circ} \mathrm{F} \ldots$

XVIII Ratio of Exhaust Volume to Plume Volume Expressed

as a Function of Position for an $8^{\prime \prime} \times 10^{\prime \prime}$

Plate at $615^{\circ} \mathrm{F} \quad \ldots \ldots \ldots \ldots \ldots \ldots \ldots \ldots$ 
XIX Exhaust Momentum Expressed as a Function of

Position for an $8^{\prime \prime} \times 10^{\prime \prime}$ Plate at $615^{\circ} \mathrm{F} \ldots$

XX Ratio of Exhaust Momentum to Plume Momentum,

$\mathrm{K}_{2}$, Expressed as a Function of Position

for an $8^{\prime \prime} \times 10^{\prime \prime}$ Plate at $615^{\circ} \mathrm{F} \ldots \ldots \ldots \ldots . \quad 124$

XXI An Analysis of Data for the $8 " x 10 "$ Plate at

$615^{\circ} \mathrm{F}$ Using the Technique Developed by

Kuz "mina

125 


\section{LIST OF FIGURES}

1. Hot Plume of Dusty Air Rising from Foundry

Shakeout

2. Hot Plume of Air Rising from Fuming Ladle of

Molten Metal

3. Two Alternate Methods to Hood a Hot Process ....

3

4. Dimensions Used to Analyze Hot Plume

Characteristics $\ldots \ldots \ldots \ldots \ldots \ldots \ldots \ldots \ldots \ldots$

5. Characteristics of Exhaust Hooding Showing

Velocity Decay as a Function of Distance ...

6. Characteristic Dimensions Required to Analyze

a Slotted Hood...$\ldots \ldots \ldots \ldots \ldots \ldots \ldots \ldots \ldots$

7. Effect of Boundary Conditions on the Slotted

Exhaust Hood

8. Dimensions Required in Analyzing Side Draft

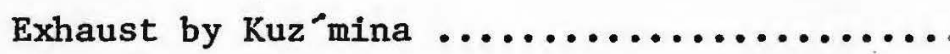

9. Plot Relating Exhaust Flow, $Q_{E}$, to $x_{f}^{\prime}, L$ and

$\mathrm{H}^{\prime}$ as noted by $\mathrm{Kuz}$ "mina $\ldots \ldots \ldots \ldots \ldots \ldots \ldots$

10. Dimensions to be Used in Analyzing Proposed

Side Draft Theory ...................

11. Plume and Exhaust Interaction Analyzed Using

Particle Momentum Approximation .......... 
12. Qualitative Representation of Observed

Plume-Exhaust Interaction $\ldots \ldots \ldots \ldots \ldots \ldots$

13. Plan View of Plume Superimposed on Exhaust

Field $\ldots \ldots \ldots \ldots \ldots \ldots \ldots \ldots \ldots \ldots \ldots \ldots$

14. Adjustable Exhaust Hooding Used in Testing ....

15. Illustration of Smoke, Providing a Visual

Tracer of Air Flow Patterns Over

Hot Plate ......................

16. Adjustable Hot Plate Support Stand Used in

Testing $\ldots \ldots \ldots \ldots \ldots \ldots \ldots \ldots \ldots \ldots \ldots$

17. Test Equipment Ready for Use

18. Relationship of $\mathrm{Q}_{\mathrm{E}} / \mathrm{Q}_{\mathrm{p}}$ to $\mathrm{L}, \mathrm{H}$ for a $12^{\prime \prime} \times 20^{\prime \prime}$

Plate at $550^{\circ} \mathrm{F}$

19. $\mathrm{Q}_{\mathrm{E}} / \mathrm{Q}_{\mathrm{p}}$ vs $\mathrm{L}, \mathrm{H}$ for a $12^{\prime \prime} \times 20^{\prime \prime}$ Plate at $550^{\circ} \mathrm{F} \ldots$

20. $\mathrm{K}_{2}$ Expressed as a Function of Position for

$$
12^{\prime \prime} \times 20^{\prime \prime} \text { Plate at } 550^{\circ} \mathrm{F} \ldots \ldots \ldots \ldots \ldots \ldots
$$

21. $\mathrm{K}_{2}$ vs $\mathrm{L}, \mathrm{H}$ for a $12^{\prime \prime} \times 20^{\prime \prime}$ Plate at $550^{\circ} \mathrm{F} \ldots \ldots$

22: $Q_{E} /\left[\left(H^{\prime}\right)^{1 / 3} L^{5 / 3}\right]$ vs $\left(x_{f}^{\prime} / L\right)^{5 / 3}$ for a $12^{\prime \prime} \times 20^{\prime \prime}$

Plate at $550^{\circ} \mathrm{F}$

23. Effect of Changing Boundary Conditions on

Exhaust Velocity Field as Distance

Increases from $24^{\prime \prime}$ to $30^{\prime \prime}$ for a

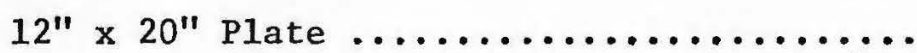

24. Relationship of $Q_{E} / Q_{p}$ to $L, H$ for a $12^{\prime \prime} \times 20^{\prime \prime}$

Plate at $750^{\circ} \mathrm{F}$ 
25. $Q_{E} / Q_{p}$ vs $L, H$ for $12 "$ × 20" Plate

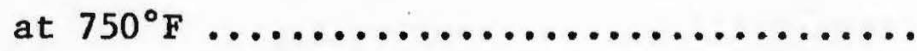

26. $\mathrm{K}_{2}$ Expressed as a Function of Position for

a $12^{\prime \prime}$ x $20^{\prime \prime}$ Plate at $750^{\circ} \mathrm{F} \ldots \ldots \ldots \ldots \ldots$

27. $\mathrm{K}_{2}$ vs $\mathrm{L}, \mathrm{H}$ for a $12^{\prime \prime} \times 20^{\prime \prime}$ Plate

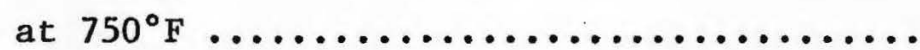

28. $Q_{E} /\left[\left(H^{\prime}\right)^{1 / 3} L^{5 / 3}\right]$ vs $\left(x_{f}^{\prime} / L\right)^{5 / 3}$ for a $12^{\prime \prime} \times 20^{\prime \prime}$

Plate at $750^{\circ} \mathrm{F} \ldots \ldots \ldots \ldots \ldots \ldots \ldots$

29. Relationship of $Q_{E} / Q_{p}$ to $L, H$ for an $8^{\prime \prime} \times 10^{\prime \prime}$

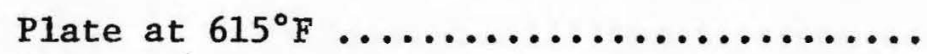

30. $\mathrm{Q}_{\mathrm{E}} / \mathrm{Q}_{\mathrm{p}}$ vs $\mathrm{L}, \mathrm{H}$ for an $8^{\prime \prime} \times 10^{\prime \prime}$ Plate

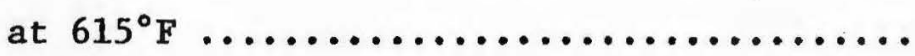

31. $\mathrm{K}_{2}$ Expressed as a Function of Position for

an $8^{\prime \prime} \times 10^{\prime \prime}$ Plate at $615^{\circ} \mathrm{F} \ldots \ldots \ldots \ldots \ldots . \ldots$

32. $\mathrm{K}_{2}$ vs $\mathrm{L}, \mathrm{H}$ for an $8^{\prime \prime} \times 10^{\prime \prime} \mathrm{Plate}$ at $615^{\circ} \mathrm{F} \ldots \ldots \quad 80$

33. $\mathrm{Q}_{\mathrm{E}} /\left[\left(\mathrm{H}^{\prime}\right)^{1 / 3} \mathrm{~L}^{5 / 3}\right]$ vs $\left(\mathrm{x}_{\mathrm{f}}^{\prime} / \mathrm{L}\right)^{5 / 3}$ for an $8^{\prime \prime} \times 10^{\prime \prime}$

Plate at $615^{\circ} \mathrm{F} \ldots \ldots \ldots \ldots \ldots \ldots \ldots \ldots$

34. Effect of Changing Boundary Conditions on

Exhaust Velocity Field as Distance

Increases From $18^{\prime \prime}$ to $24^{\prime \prime}$ for the

$8 " \times 10^{\prime \prime}$ Plate $\ldots \ldots \ldots \ldots \ldots \ldots \ldots \ldots \ldots \ldots$ 


\section{CHAPTER I}

\section{INTRODUCTION}

A common industrial ventilation and pollution problem results when a thermally buoyant polluted plume of air must be exhausted away from a work area to meet air pollution regulations, as well as to protect the working environment. A typical example might be found in a foundry shakeout operation as illustrated in Figure 1. After castings are poured and solidified in sand molds, they are subjected to a jolt table or shakeout where the sand is removed from the casting and flask. During this operation, casting temperatures of up to $1800^{\circ} \mathrm{F}$ create thermal updrafts which entrain dust particles. Adequate ventilation is a necessity.

Another example of an industrial hot polluted plume is given in Figure 2 which illustrates a ladle of molten metal typical in any primary or secondary metals industry. Fuming occurs at the bath surface where the metal is vaporized, and then condensed to a sub micron particle size. Because of their relatively small size, the particles are easily entrained in the hot plume, and become permanently suspended in the atmosphere if they escape exhaust containment.

In both of the above examples, close fitting canopy hooding is one of the most effective means of exhaust containment as shown in Figure 3 . often, physical restrictions or the operation itself prevent such an arrangement and a hood located to the side of the operation is warranted 


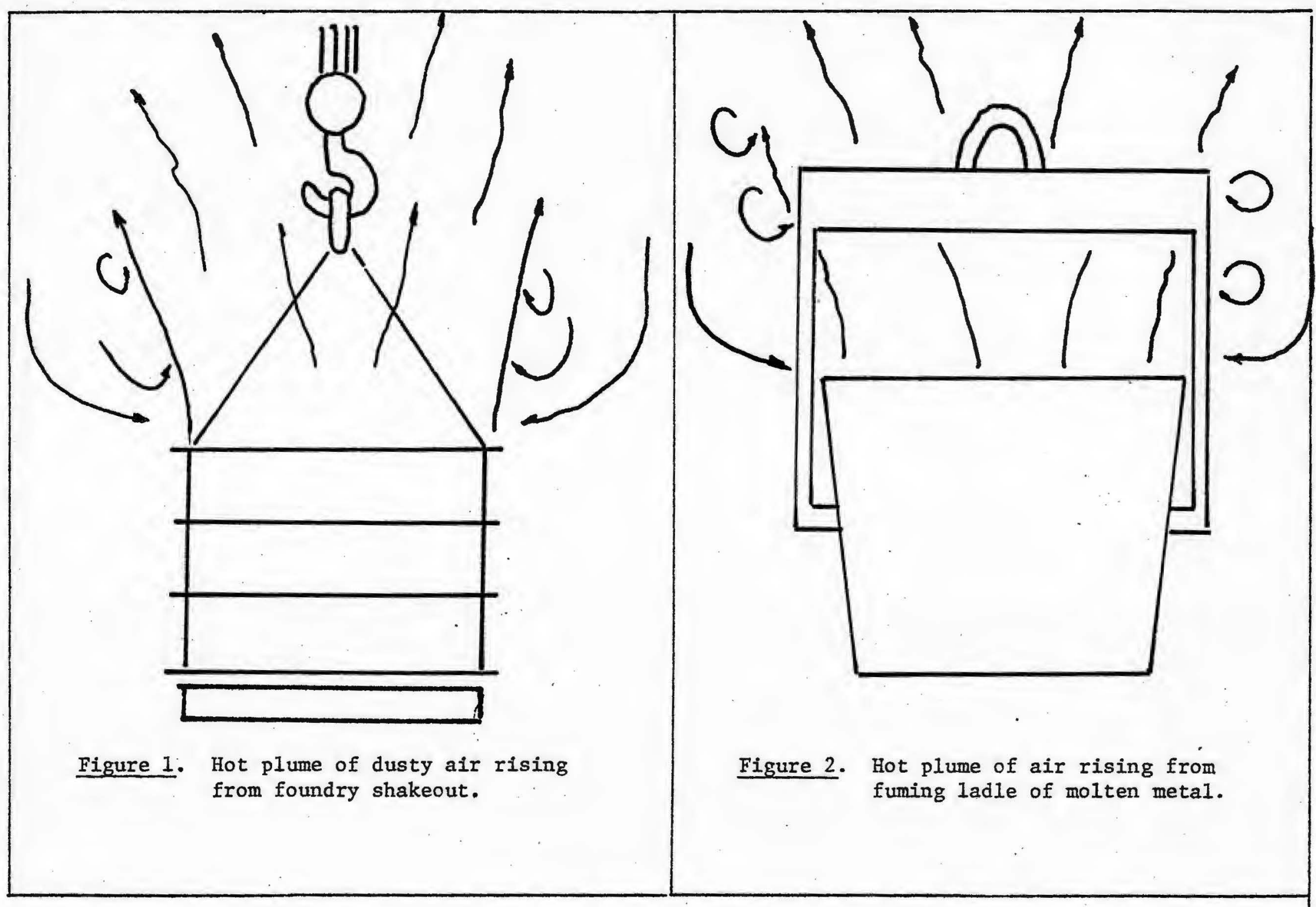




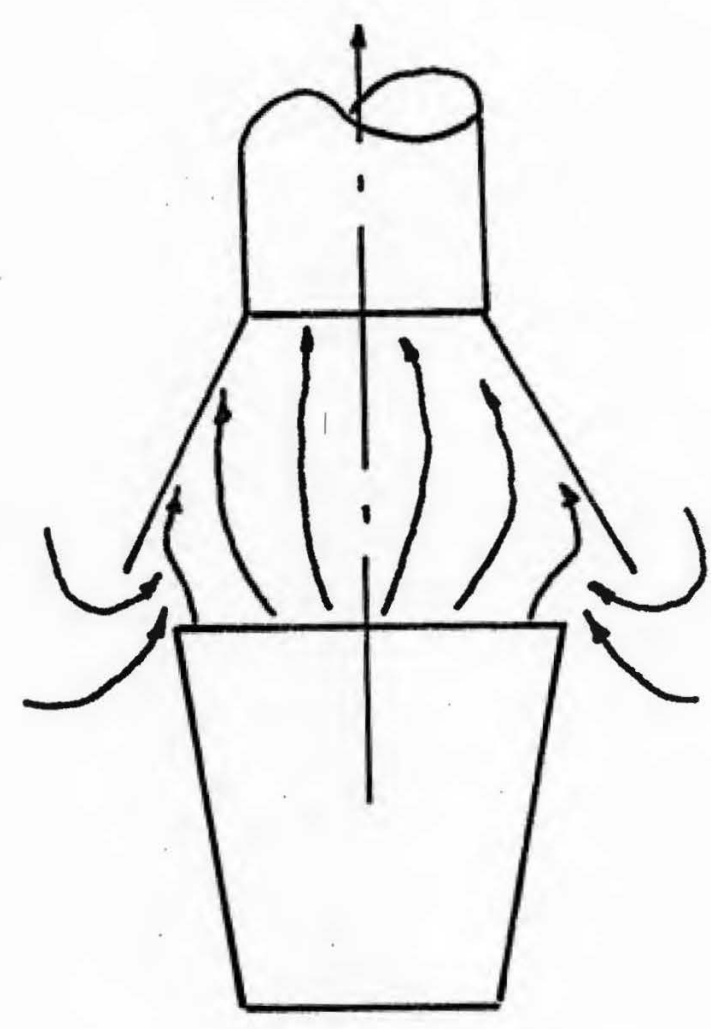

overhead canopy

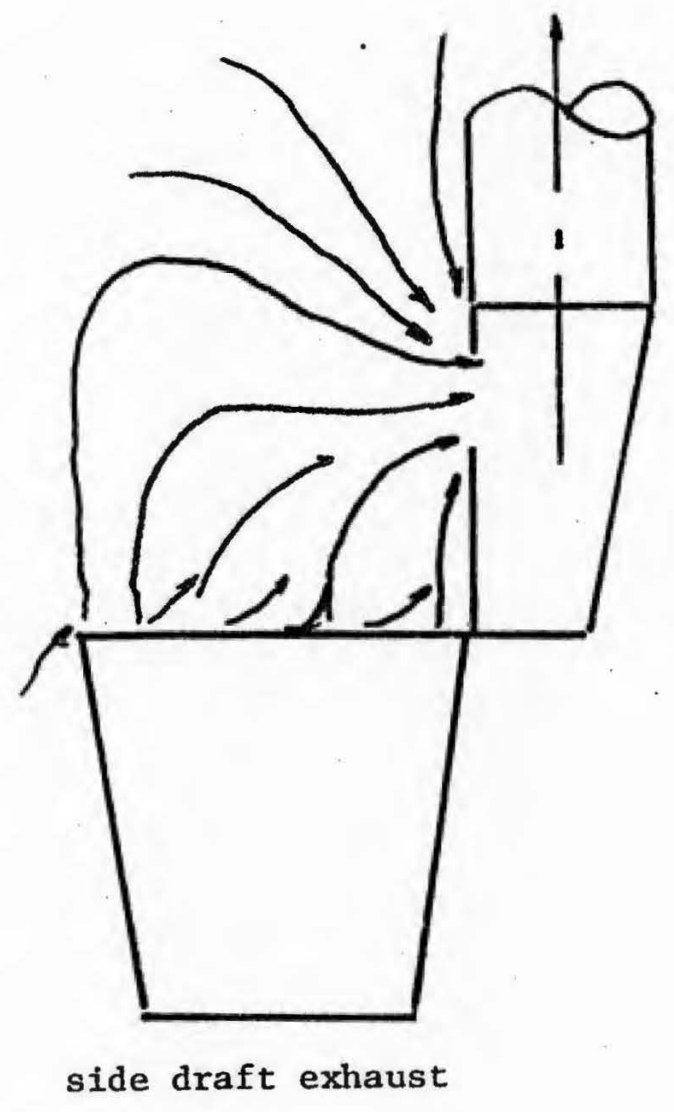

Figure 3. Two alternate methods to hood a hot process. 
as seen in Figure 3. Such an arrangement requires the exhaust hood to bend and contain the buoyant plume with a horizontal sweep of air across the surface of the operation.

This study is devoted to the analysis of the above described operation. A potential analytical solution is developed and tested as described in the chapters to follow. 
CHAPTER II

\section{BACKGROUND THEORY}

\section{A. GENERAL OVERVIEW}

The containment of high temperature plumes by side draft hooding is commonly referenced in the 1iterature. The American Foundryman's Society (1) recommends the exhaust values given in Table I for application to foundry shakeouts. The U.S. Department of Health, Education and Welfare (2) as well as the American Conference of Governmental Industrial Hygienists (3) also recommend the data given in Table I.

Concerning the problem of fuming ladles, the following equation is recommended commonly in the literature $(2,3)$ :

$$
\begin{aligned}
& Q=200\left(10 L^{2}+A_{H}\right) \quad Q=\text { exhaust volume, cfm } \\
& \mathrm{L}=\text { horizontal distance } \\
& \text { of hood to hot source, } \\
& \text { ft } \\
& A_{\mathrm{H}}=\text { hood area, } \mathrm{ft}^{2}
\end{aligned}
$$

It will be shown in subsequent sections that this equation, as well as Table I, is too general to fit all cases.

W.C.L. Hemeon (4) states that the relationships between lateral exhaust and hot plume have not been quantitatively investigated. However, he states that deflection of the plume may occur due to viscous drag of the exhaust air streaming toward the hood, or it may result from turbulent mixing of the hood stream with the hot air, or a combination of both. In addition Hemeon states that the side draft hood exhaust rate 
TABLE I

RECOMMENDED EXHAUST VOLUMES FOR FOUNDRY

SHAKEOUT SIDE DRAFT HOODING

$$
\begin{aligned}
& \text { Hot Castings } \\
& 400-500 \mathrm{cfm} / \mathrm{sq} . \mathrm{ft} \text {. } \\
& \text { of grate area }
\end{aligned}
$$

\section{Cool Castings}

350-400 cfm/sq.ft. of grate area 
is a function principally of

$$
\mathrm{L} ; \mathrm{Ap} ;\left[\left(\mathrm{T}_{\mathrm{H}}-\mathrm{T}_{\mathrm{C}}\right) / \mathrm{T}_{\mathrm{H}}\right]^{1 / 2}
$$

where $\mathrm{L}$ is the horizontal distance of plume to hood, Ap is the area of hot air column, $T_{H}$ is the temperature of hot air, and $T_{C}$ is ambient temperature. One last qualitative conclusion by Hemeon is that the exhaust volume must be greater than plume volume by the amount of air required to supply the deflecting force.

The American Society of Heating, Refrigerating and Air Conditioning Engineers (5) (ASHRAE) comments briefly in comparing side draft to overhead canopy hooding and notes that "the required exhaust for lateral air flow is very much more than for a hood that simply captures the upward flow of heated air." A further statement is made that "ASHRAE has recognized the need for design criteria for determining exhaust ventilation requirements for hot processes in industry...".

Although none of the above cited references provide any quantitative means for describing the side draft - hot plume interaction, a Russian study by L.V. Kuz'mina, described in a translated volume by Baturin entitled "Fundamentals of Industrial Ventilation", (6) provides an initial step in explaining the phenomena. An analysis of the resultIng theory is made in subsequent sections of this paper.

First, however, an analysis of convective heat transfer, plume characteristics and exhaust hood theory is required to allow equations to be developed which describe the thermodynamic relationships between the elements involved. 


\section{B. CONVECTIVE HEAT TRANSFER}

The following section summarizes convective heat transfer theory; limited to the natural convection associated with hot horizontal flat plates. As the hot surface temperature rises, the adjacent air warms causing it to rise vertically as shown in Figure 1 . The hot air column entrains surrounding air, and thus expands. Cooler air surrounding the hot source moves in toward the plate to close the loop.

Convective heat transfer is often described in terms of dimensionless parameters. Two common units used in dealing with natural convection are the Grashof number and Prandtl number. The Grashof number

$$
G r=\rho^{2} g B(T-T) L^{3} / \mu^{2}
$$

represents a ratio of buoyant to viscous forces. Consistent units would be as follows:

$$
\begin{array}{lr}
\rho=\text { density }-1 \mathrm{bm} / \mathrm{cu} . \mathrm{ft} . & \mathrm{L}=\begin{array}{l}
\text { length of heat transfer } \\
\text { surface }-\mathrm{ft} .
\end{array} \\
\mu=\text { viscosity }-1 \mathrm{bm} / \mathrm{sec} . \mathrm{ft} . & \left(\mathrm{T}-\mathrm{T}_{\infty}\right)=\text { temperature difference }-{ }^{\circ} \mathrm{F} \\
\begin{array}{l}
\beta=\text { volumetric coefficient } \\
\text { of thermal expansion }-1 /{ }^{\circ} \mathrm{R}
\end{array} & \mathrm{g}=\begin{array}{l}
\text { acceleration due to } \\
\text { gravity }-\mathrm{ft} . / \mathrm{sec} .
\end{array}
\end{array}
$$

The Prandtl number, $\operatorname{Pr}=C_{P} \mu / K$, represents a ratio of velocity gradient to temperature gradient. The following are consistent units:

$$
\begin{aligned}
\mathrm{K}= & \begin{array}{l}
\text { coefficient of } \\
\text { thermal conductivity }- \\
\text { Btu/hr.- ft. }-{ }^{\circ} \mathrm{F}
\end{array}
\end{aligned} \mathrm{C}_{\mathrm{p}}=\begin{aligned}
& \text { heat capacity - } \\
& \text { Btu/1bm }-{ }^{\circ} \mathrm{F}
\end{aligned}
$$

The Grashof number in particular is of significance when dealing 
with natural convection. Two fluid streams have similar velocity fields if their Grashof numbers are similar (7); if the Prandtl numbers are similar, the temperature profiles closely relate. For air the Prandt1 number equals $0.69-0.72$ over a wide range of temperatures, thus, flow is described by $\mathrm{Gr}$ alone. In analyzing the fluid flow regime, the following criterion is observed according to Kreith (7):

$$
\begin{aligned}
& \text { Gr }<10^{8} \quad \text { Laminar } \\
& \mathrm{Gr}>10^{10} \quad \text { Turbulent }
\end{aligned}
$$

Baturin (6), on the other hand, states that turbulence is achieved if

$$
\operatorname{GrPr} \geq 2 \times 10^{7}
$$

The characteristic equation describing convective heat loss is

$$
H^{\prime}=\bar{h}_{c} A_{s} \Delta T
$$

where $H^{\prime}$ is given in Btu/hr., $A_{s}$ is the source area in $f t .^{2}, \bar{h}_{c}$ is the surface film coefficient in $\mathrm{Btu} / \mathrm{hr} .-\mathrm{ft} .^{2}-{ }^{\circ} \mathrm{F}$, and $\Delta \mathrm{T}$ is the temperature difference between hot plate and ambient in ${ }^{\circ} \mathrm{F}$. Much of the literature is devoted to describing $\bar{h}_{c}$ and Kreith (7) gives the following equations for horizontal hot plates operating in air:

$$
\begin{array}{ll}
\overline{\mathrm{h}}_{\mathrm{c}}=0.18 \Delta \mathrm{T}^{1 / 3} & 10^{9}<\mathrm{Gr}<10^{12} \\
\overline{\mathrm{h}}_{\mathrm{c}}=0.27\left(\Delta \mathrm{T} / \mathrm{D}_{\mathrm{s}}\right)^{1 / 4} & 10^{3}<\mathrm{Gr}<10^{9}
\end{array}
$$

Marks (8), however, references the following equations

$$
\begin{array}{ll}
\overline{\mathrm{h}}_{\mathrm{c}}=0.27\left(\Delta \mathrm{T} / \mathrm{D}_{\mathrm{s}}\right)^{1 / 4} & 10>\mathrm{L}^{3} \Delta \mathrm{T}>0.1 \\
\overline{\mathrm{h}}_{\mathrm{c}}=0.22 \Delta \mathrm{T}^{1 / 3} & 10^{4}>\mathrm{L}^{3} \Delta \mathrm{T}>10
\end{array}
$$

Stanier (9) confirms the relations given by Marks. It is noted that $\mathrm{L}^{3} \Delta \mathrm{T}$ does not completely correspond to the Grashof number since 


$$
\rho^{2} g \beta / \mu^{2}
$$

Is also temperature sensitive. Hemeon (4) defines the surface film coefficient as

$$
\overline{\mathrm{h}}_{\mathrm{c}}=0.38 \Delta \mathrm{T}^{1 / 4}
$$

and this equation is used by other sources (2) when describing plume behavior. It is noted that much of the original experimentation describing plume flow by meteorologist Sutton, $(2,4)$ was based on this latter value for $\bar{h}_{c}$. Since much of this paper will be based on Sutton's results, this latter value for $\bar{h}_{c}$ is preferred by this author.

\section{PLUME BEHAVIOR DUE TO NATURAL CONVECTION}

Sutton's analysis of plume behavior is cited in the literature $(2,4)$, and is described based on the quantities shown in Figure 4. A plume in the absence of cross drafts is contained by a cone rising from a point source located a distance, $z$, below the hot surface. Sutton determined the following relationships $(2,4)$ :

$$
\begin{aligned}
& Z=\left(2 D_{s}\right)^{1.138} \mathrm{ft} . \\
& x_{f}=H+Z \quad \mathrm{ft} . \\
& D_{p}=1 / 2 x_{f}^{0.88} \mathrm{ft} .
\end{aligned}
$$

By assuming natural convection described by Eq. 3 and Eq. 8, Sutton found the plume velocity

$$
v_{p}=37\left(H^{\prime}\right)^{1 / 3} / x_{f}^{0.29}
$$

where $\mathrm{V}_{\mathrm{p}}$ is the velocity in $\mathrm{fpm}, \mathrm{H}^{\prime}$ is the convective heat loss in $B t u / m i n$. and $x_{f}$ is the distance from point source to given plume height 


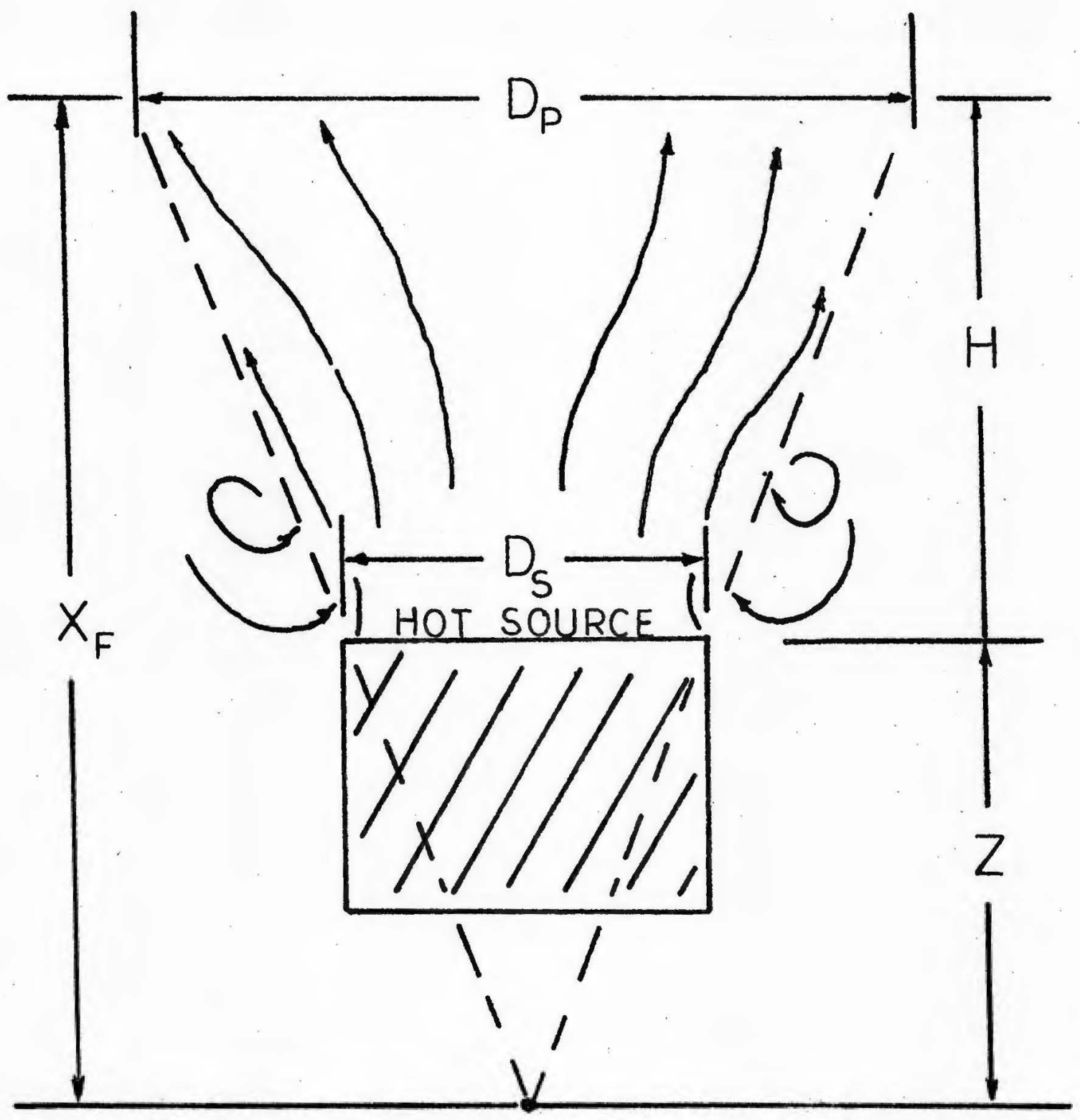

Figure 4. Dimensions used to analyze hot plume characteristics. 
in ft. By substituting Eq. 3 and Eq. 8 into Eq. 12, velocity is given by

$$
v_{p}=8 A_{s}^{1 / 3} \Delta T^{5 / 12} / x_{f} 0.29 f p m
$$

where $A_{S}$ is the source area in $\mathrm{ft}^{2}$ and $\Delta \mathrm{T}$ is the difference between source and ambient temperatures in ${ }^{\circ} \mathrm{F}$. It is noted that a safety factor of $15 \%$ is included in this equation, the resulting velocities being slightly higher than the theoretical values. Hemeon references similar material to that above with only a minor difference in results (4)

$$
v_{p}=37\left(H^{\prime}\right)^{1 / 3} / x_{f} 1 / 4
$$

In a separate study by Shepelev (6), the following results were noted for velocity and flow

$$
\begin{aligned}
& v_{p}=2.32\left(H^{\prime} / x_{f}^{\prime}\right)^{1 / 3} \text { meters/hour } \\
& Q_{p}=.098\left(H^{\prime} x_{f}^{\prime}\right)^{1 / 3} \text { meters }{ }^{3} / \text { hour }
\end{aligned}
$$

where $H^{\prime}$ now is given in $\mathrm{KCAL} / \mathrm{hr}$ and $\mathrm{x}_{f}^{\prime}$ is given in meters. Elterman (6) assumed the hypothetical point source to be located a distance, $\mathrm{D}_{\mathbf{s}}$, below the hot surface with the following results for velocity and flow:

$$
\begin{aligned}
& V_{p}=0.136\left(H^{\prime}\right)^{1 / 3}\left(x_{f}^{\prime}\right)^{-1 / 3} \\
& Q_{p}=19\left(H^{\prime}\right)^{1 / 3}\left(x_{f}^{\prime}\right)^{5 / 3}
\end{aligned}
$$

Comparisons for similarity can be made between Eq. 13, Eq. 14 and Eq. 16 and Eq. 18. Starting with Sutton's assumptions, the plume area is given as

$$
A_{p}=\pi / 4\left(D_{p}\right)^{2}
$$


By substituting Eq. 11

$$
\begin{aligned}
A_{p} & =\pi / 4\left[1 / 2 x_{f} 0.88\right]^{2} \\
& =0.2 x_{f}^{1.76} \mathrm{ft} .^{2}
\end{aligned}
$$

for a circular source and plume. Flow would then be given as

$$
\begin{aligned}
Q_{p} & =V_{p} A_{p} \\
& =\left[37\left(H^{\prime}\right)^{1 / 3} / x_{f}^{0.25}\right]\left[0.20 x_{f}^{1.76}\right] \\
& =7.4\left(H^{\prime}\right)^{1 / 3} x_{f}^{1.51} \mathrm{cfm}
\end{aligned}
$$

This result can be compared with Eq. 16 or Eq. 18 where

$$
Q_{p} \propto\left(H^{\prime}\right)^{1 / 3} x_{f}^{1.66}
$$

thus giving a reasonably good cross check.

In evaluating the velocities and flows, a single estimate for $\bar{h}_{c}$ was used. As noted in Chapter II, subsection B., values for $\bar{h}_{c}$ vary throughout the literature. An estimate of plume flow based on other $\bar{h}_{c}$ values is needed to evaluate the potential error in using one value over another. Equation 12 will be used in each case, and is restated as

$$
v_{p}=37\left(H^{\prime}\right)^{1 / 3} / x_{f} \cdot 29
$$

where $V_{p}$ is given in $f_{p m}, H^{\prime}$ is given in Btu/min. and $x_{f}$ is given in $f t$. In addition Eq. 3 is rewritten to maintain consistent units

$$
\mathrm{H}^{\prime}=\overline{\mathrm{h}}_{\mathrm{c}} \mathrm{A}_{\mathrm{s}} \Delta \mathrm{T} / 60 \mathrm{Btu} / \mathrm{min} \text {. }
$$

where $A_{s}$ is given in $\mathrm{ft}^{2}$ and $\Delta \mathrm{T}$ is given in ${ }^{\circ} \mathrm{F}$.

Case $\mathrm{I} \quad \overline{\mathrm{h}}_{\mathrm{c}}=0.38 \Delta \mathrm{T}^{1 / 4}$ 
The velocity is computed as

$$
\begin{aligned}
& {\left[37 / \mathrm{x}_{f}{ }^{0.29}\right]\left[0.38 \Delta \mathrm{T}^{1 / 4} \mathrm{~A}_{s} \Delta \mathrm{T} / 60\right]^{1 / 3}} \\
& =7 \mathrm{~A}_{\mathrm{s}}^{1 / 3} \Delta \mathrm{T}^{5 / 12} / \mathrm{x}_{\mathrm{f}}{ }^{0.29}
\end{aligned}
$$

By adding a $15 \%$ safety factor,

$$
v_{p}=8 A_{s}^{1 / 3} \Delta T^{5 / 12} / x_{f}{ }^{0.29} f f_{p m}
$$

Flow is given by

$$
\begin{aligned}
Q_{p} & =V_{p} A_{p}=\left[8 A_{s}^{1 / 3} \Delta T^{5 / 12} / x_{f}^{0.29}\right]\left[0.20 x_{f}^{1.76}\right] \\
& =1.60 \mathrm{~A}_{s}^{1 / 3} \Delta T^{5 / 12} x_{f}^{3 / 2} \mathrm{cfm}
\end{aligned}
$$

Case II $\quad \bar{h}_{c}=0.22 \Delta T^{1 / 3}$

The velocity is computed as

$$
\begin{aligned}
\mathrm{V}_{\mathrm{p}} & =\left[37 / \mathrm{x}_{\mathrm{f}}{ }^{0.29}\right]\left[\left(.22 \Delta \mathrm{T}^{1 / 3}\right) \mathrm{A}_{\mathrm{s}} \Delta \mathrm{T} / 60\right]^{1 / 3} \\
& =6.5 \mathrm{~A}_{\mathrm{s}}^{1 / 3} \Delta \mathrm{T}^{4 / 9} / \mathrm{x}_{\mathrm{f}}{ }^{.29} \mathrm{fpm}
\end{aligned}
$$

Flow is given by

$$
Q_{p}=1.31 \mathrm{~A}_{\mathrm{s}}^{1 / 3} \Delta \mathrm{T}^{4 / 9} \mathrm{x}_{\mathrm{f}}^{3 / 2} \mathrm{cfm}
$$

Case III $\quad \bar{h}_{c}=0.27\left(\Delta T / D_{s}\right)^{1 / 4}$

Velocity is computed as

$$
\mathrm{v}_{\mathrm{p}}=\left[37 / \mathrm{x}_{\mathrm{f}}^{0.29}\right]\left[\left(.27\left(\Delta \mathrm{T} / \mathrm{D}_{\mathrm{s}}\right)^{1 / 4}\right) \mathrm{A}_{\mathrm{s}} \Delta \mathrm{T} / 60\right]^{1 / 3}[1.15]
$$

Source diameter is expressed as

$$
D_{s}=1.12 \mathrm{~A}_{s}^{1 / 2} \mathrm{ft} \text {. }
$$

for a circular source.

Therefore, velocity becomes

$$
v_{p}=\left[37 / x_{f}^{0.29}\right]\left[.27 \Delta T^{1 / 4}\left(1.12 A_{s}^{1 / 2}\right)^{-1 / 4} A_{s}-\Delta T / 60\right]^{1 / 3}
$$




$$
=\left[7 / \mathrm{x}_{\mathrm{f}}^{0.29}\right]\left[\mathrm{A}_{\mathrm{S}}^{7 / 24} \Delta \mathrm{T}^{5 / 12}\right] \mathrm{fpm}
$$

F1 ow is given by

$$
Q_{p}=1.4 A_{s}^{7 / 24} \Delta T^{5 / 12} x_{f}^{3 / 2} \mathrm{cfm}
$$

A summary of Eq. 23 through Eq. 28 is given in Table II.

As illustrated in Table II, it is seen that the choice of $\bar{h}_{c}$ effects the resulting plume flow and velocity; however, the primary effect is to alter the numerical coefficient attached to each term. The relationship to $A_{S}, \Delta T$, and $x_{f}$ is approximately the same in all three cases. Since Sutton based his work on the assumptions found in Case I, it appears likely that any error in numerical coefficient would have been accounted for in adjusting experimental data and developing the theory. Therefore, the assumptions and results derived in Case I will be used throughout the remainder of this study.

\section{CHARACTERISTICS OF EXHAUST HOODING}

Exhaust or suction hooding is required to capture contaminents dispersed in the air, and therefore, a description of exhaust behavior is in order. A typical circular hood is illustrated in Figure 5 where velocity contours are plotted as a function of distance, L, away from the hood. If the hood were square, rectangular, possessed flanges, or were bounded by adjacent planes, then the streamlines would be altered; these effects are noted in the literature $(1,2,3,4)$. At relatively close distances (less than three diameters), the hood has a considerable effect on the velocity profile due to its physical size. Further out, the exhaust hood can be described as a point sink. Velocity radially in toward the sink can be related to exhaust flow as 
TABLE II

SUMMARY OF CALCULATED PLUME FLOW AND VELOCITY

BASED ON SELECTED VALUE OF $\bar{h}_{c}$

\begin{tabular}{|c|c|c|c|}
\hline \multicolumn{2}{|c|}{$\overline{\mathrm{h}}_{\mathrm{c}}\left(\mathrm{Btu} / \mathrm{ft} \mathrm{t}^{2}-{ }^{\circ} \mathrm{F}-\mathrm{hr}_{.}\right)$} & $Q_{p}(\mathrm{cfm})$ & $v_{p}(f p m)$ \\
\hline I & $0.38 \Delta \mathrm{T}^{1 / 4}$ & $1.6 \mathrm{~A}_{\mathrm{s}}^{1 / 3} \Delta \mathrm{T}^{5 / 12} \mathrm{x}_{\mathrm{f}}^{3 / 2}$ & $8 \mathrm{~A}_{\mathrm{s}}^{1 / 3} \Delta \mathrm{T}^{5 / 12} / \mathrm{x}_{\mathrm{f}}{ }^{0.29}$ \\
\hline & . & & \\
\hline II & $0.22 \Delta \mathrm{T}^{1 / 3}$ & $1.31 \mathrm{~A}_{\mathrm{s}}^{1 / 3} \Delta \mathrm{T}^{4 / 9} \mathrm{x}_{\mathrm{f}}{ }^{3 / 2}$ & $6.5 \mathrm{~A}_{\mathrm{s}}^{1 / 3} \Delta \mathrm{T}^{4 / 9} / \mathrm{x}_{\mathrm{f}}{ }^{0.29}$ \\
\hline III & $0.27\left(\Delta \mathrm{T} / \mathrm{D}_{\mathrm{s}}\right)^{1 / 4}$ & $1.40 A_{s}{ }^{7 / 24} \Delta T^{5 / 12} x_{f}^{3 / 2}$ & $7 \mathrm{~A}_{\mathrm{s}}{ }^{7 / 24} \Delta \mathrm{T}^{5 / 12} / \mathrm{x}_{\mathrm{f}} 0.29$ \\
\hline
\end{tabular}



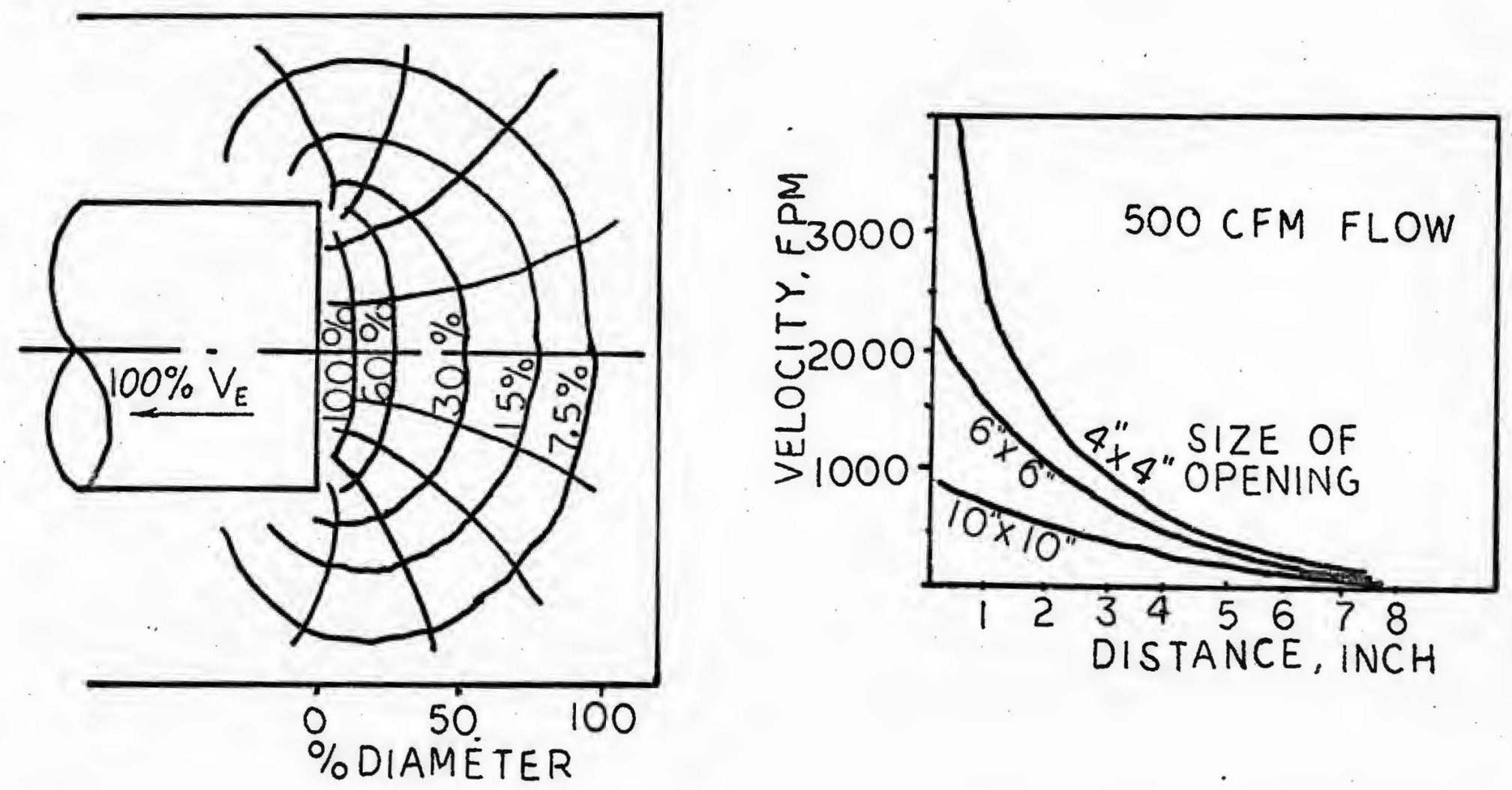

Figure 5. Characteristics of exhaust hooding showing velocity decay as a function of distance. 


$$
\mathrm{V}_{\mathrm{E}}=\mathrm{Q}_{\mathrm{E}} / 4 \mathrm{KL}^{2}
$$

in a spherical, unbounded field, where $V_{E}$ is the velocity in $f p m, Q_{E}$ is the exhaust flow in $\mathrm{cfm}$, and $4 \mathrm{IL}^{2}$ represents the surface area of a sphere in $\mathrm{ft.}^{2}$. Rearranging terms, flow can be written as

$$
Q_{E}=12.6 V_{E} L^{2}
$$

It is noted that for a given flow rate, two given velocities are related to their respective distances by the inverse square law

$$
\mathrm{V}_{\mathrm{E}^{1}} / \mathrm{v}_{\mathrm{E}^{2}}=\left(\mathrm{L}_{2} / \mathrm{L}_{1}\right)^{2}
$$

if the boundary conditions don't change between these two distances, and both distances are great enough to allow the hood effect to be neglected. To illustrate the effect of boundary conditions, it is noted that a hood bounded by a plane would possess velocity contours over a hemisphere, in which case

$$
\mathrm{V}_{\mathrm{E}}=\mathrm{Q}_{\mathrm{E}} / 2 \mathrm{HL}{ }^{2}
$$

or by rearranging terms

$$
Q_{E}=6.3 V_{E} L^{2}
$$

It is seen that boundary analysis plays a critical role in determining flow-velocity relationships.

Dalla Valla $(1,2,3,4)$ proposed equations which describe a rectangular unbounded hood where the width to length ratio is greater than 0.2 .

$$
Q_{E}=V_{E}\left(10 L^{2}+A_{H}\right)
$$

It is noted that when distance is small, the hood area term, $A_{H}$, predominates, and when distance equals zero 


$$
Q_{E}=V_{E} A_{H} \text {. }
$$

When distance is large, the hood area term loses significance and thus Eq. 34 approximates Eq. 30. If the hood were bounded by a single plane

$$
Q_{E}=V_{E}\left(5 L^{2}+A_{H}\right)
$$

according to Dalla Valla $(1,2,3,4)$.

A point to note in all of the exhaust equations is that velocity drops off rapidly with distance, thereby reducing its effect greatly in capturing contaminents. For a circular hood the velocity drops off to $5 \%$ of its value in the hood at a distance of $1.05 \times$ hood diameter (4). One method to reduce rapid velocity decay is to design the hood in the form of a slot where the width to length ratio is less than 0.2 (4). Here, the exhaust profile may be approximated as a line sink where end leakage from the hood can be neglected. The illustration in Figure 6 supports exhaust equations

$$
\mathrm{V}_{E O^{b L}}=\mathrm{V}_{E L} \mathrm{LeL}_{s}
$$

where $V_{E O}$ is the velocity in the slot in $f_{p m}, b$ is the slot width in $f t$. , $V_{E L}$ is the velocity at distance $L$ in $\mathrm{fpm}, L$ is the distance in $\mathrm{ft.}, \theta$ is the angle between boundary planes in radians, and $L_{s}$ is the slot length in $\mathrm{ft}$. As shown in Figure 6, if

$$
\theta=180^{\circ}=\Pi \text { radians }
$$

then velocities are related as

$$
\mathrm{V}_{\mathrm{EL}} / \mathrm{v}_{\mathrm{EO}}=\mathrm{b} / \mathrm{ML}
$$

thus,

$$
\mathrm{v}_{\mathrm{E} 1} / \mathrm{v}_{\mathrm{E}} 2=\mathrm{L}_{\overline{2}} / \mathrm{L}_{1}
$$




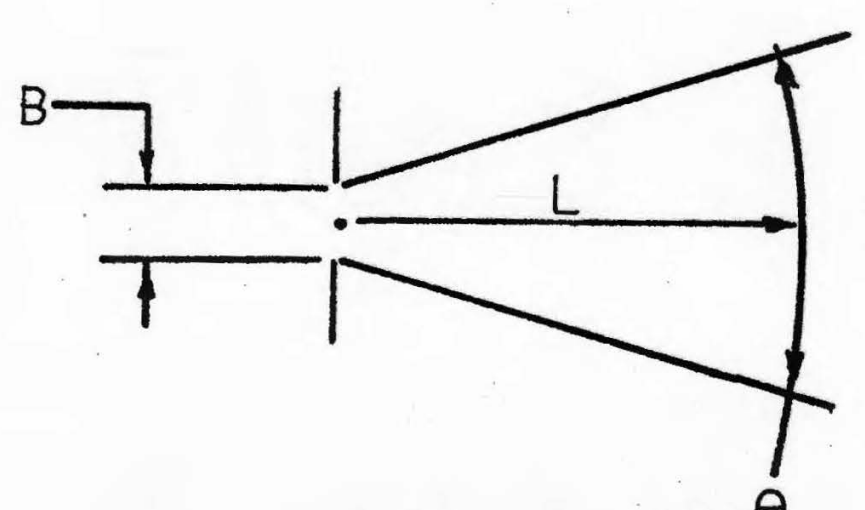

GENERAL CASE

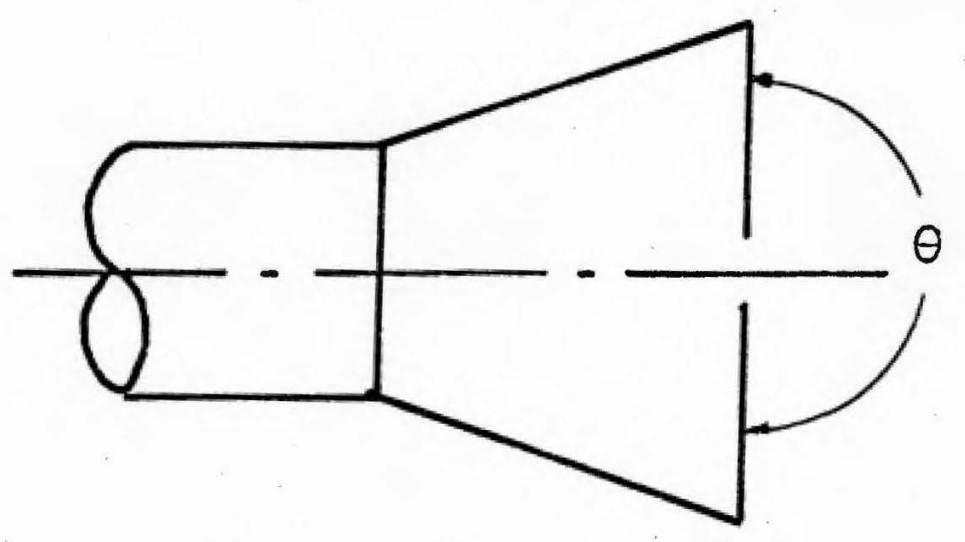

$\theta=180^{\circ}$

Figure 6. Characteristic dimensions required to analyze a slotted hood. 
assuming boundary conditions are constant from $L_{1}$ to $L_{2}$. Thus, when end leakage can be neglected, velocity drops off as a function of distance to the first power. Hemeon (4) notes, however, that this approximation loses validity for a distance greater than one third the slot length away from the hood, regardless of hood demensions. Since most side draft problems occur outside this range, the hood equations, Eq. 30 - Eq. 35, are generally used. However, where appropriate, slotted hood exhaust flow can be written as

$$
Q_{E}=K L L_{S} V_{E}
$$

where $\mathrm{K}$ is a numerical coefficient dependent on boundaries. Figure 7 illustrates the effect of boundary conditions for bounding planes of $270^{\circ}, 180^{\circ}$ and $90^{\circ}$ (4).

In analyzing the interaction between side draft exhaust field and plume jet, the above equations will be referenced along with the conclusions found in section B. and section $C$.

E. ANALYSIS OF THE EFFECT OF LATERAL EXHAUST ON A THERMAL PLUME A Study by L.V. Kuz'mina

As noted earlier, a study was made at the Moscow Institute of Labor Protection to correlate exhaust requirements to plume thermodynamics. In developing the theory, researcher Kuz'mina assumed that the exhaust volume was a direct function of the plume volume, that is

$$
\mathrm{Q}_{\mathrm{E}}=\mathrm{KQ}_{\mathrm{p}} \text { meters }^{3} / \text { hour }
$$

where $\mathrm{K}$ is a numerical coefficient. As noted in section $B$, Shepelev defines plume volume as 


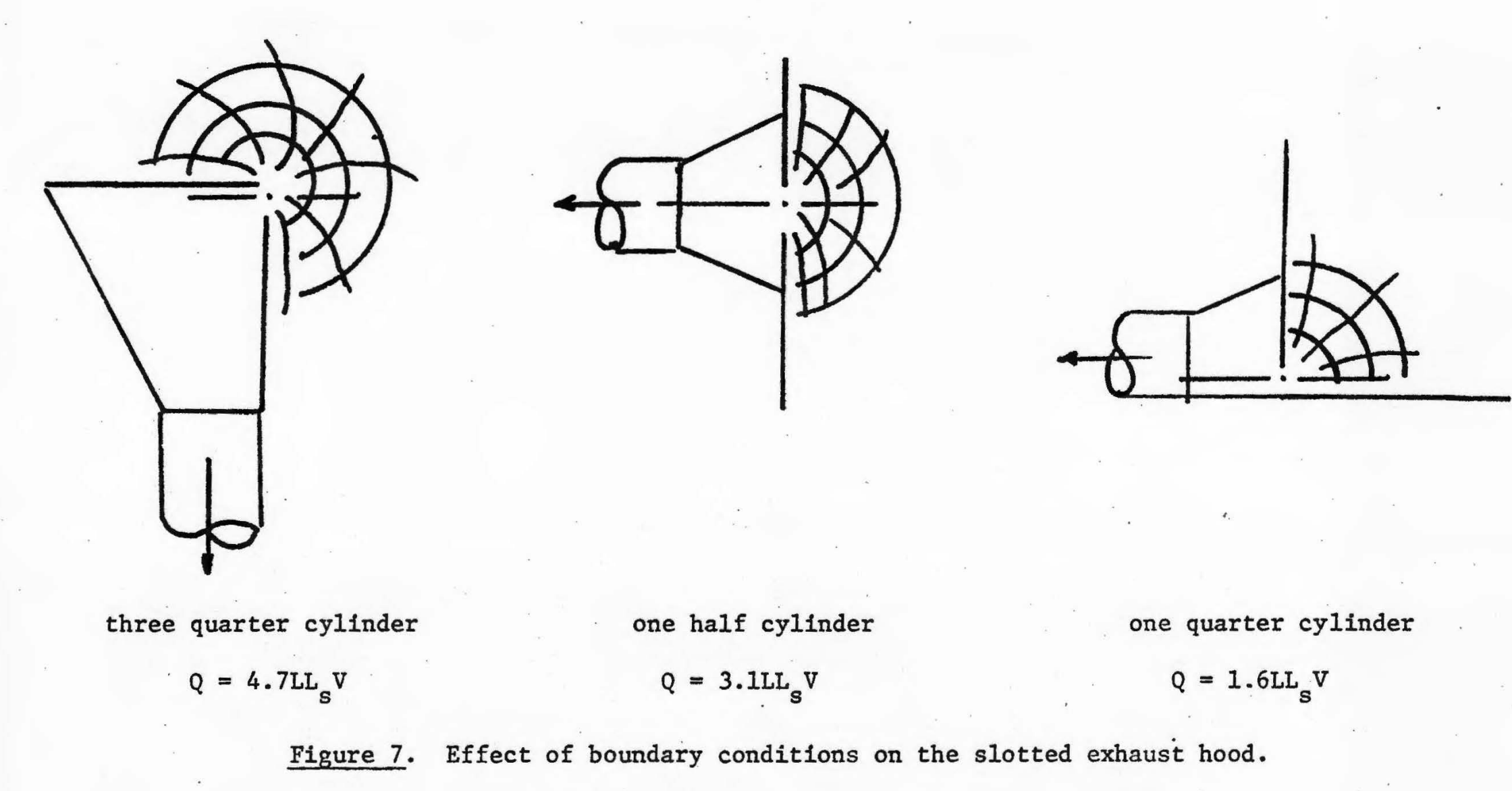




$$
Q_{p}=19\left(H^{\prime}\right)^{1 / 3}\left(x_{f}^{\prime}\right)^{5 / 3} \text { meters }{ }^{3} / \text { hour }
$$

where $H^{\prime}$ is the heat loss in $\mathrm{KCAL} / \mathrm{hr}$. and $\mathrm{x}_{f}^{\prime}$ is the distance from plume height to point source in meters, a distance B below the surface. These relationships are illustrated in Figure 8 . It is noted that the definition of $x_{f}^{\prime}$ differs from that used by Sutton. shown in Figure 4, Eq. 9 and Eq. 10. The value for $x_{f}^{\prime}$ is then shown in Figure 8 to be

$$
x_{f}^{\prime}=H+B
$$

and exhaust flow can be expressed as

$$
Q_{E}=K\left(H^{\prime}\right)^{1 / 3}\left(x_{f}^{\prime}\right)^{5 / 3}
$$

By rearranging terms

$$
Q_{E} /\left(H^{\prime}\right)^{1 / 3}=K\left(x_{f}^{\prime}\right)^{5 / 3}
$$

The distance, L, out from the hood is not contained in the equations, and in fact according to Eq. 40, the defining assumption states that exhaust volume is only a function of plume volume, regardless of location. In order to include distance into the development, both sides of Eq. 43 were multiplied by $(1 / L)^{5 / 3}$ by Kuz'mina, thus giving

$$
Q_{E} /\left[\left(H^{\prime}\right)^{1 / 3} L^{5 / 3}\right]=K\left(x_{f}^{\prime} / L\right)^{5 / 3}
$$

In this manner, the dimensionless character of $\mathrm{K}$ was maintained. Experimental data was taken in the laboratory with the results illustrated in Figure 9. To determine $\mathrm{K}$ from Figure 9, the abscissa is divided by the ordinate.

In analyzing the graph, it is seen that $K$ is not constant, but Increases from a value of 200 at the lower left hand corner to 120 at the upper end of the curve. By definition and Eq. 40, these results 


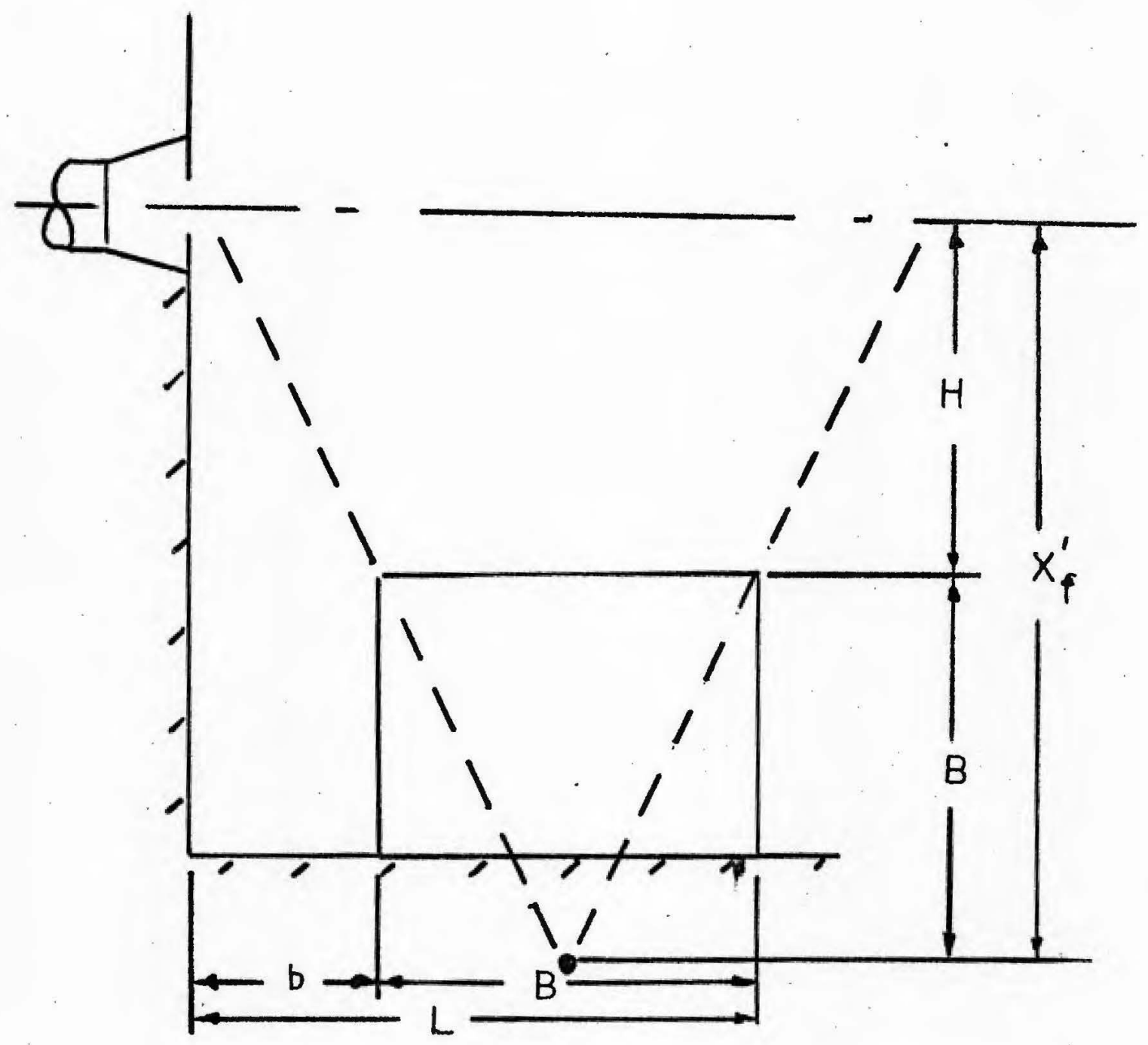

Figure 8. Dimensions required in analyzing side draft exhaust by Kuz'mina. 


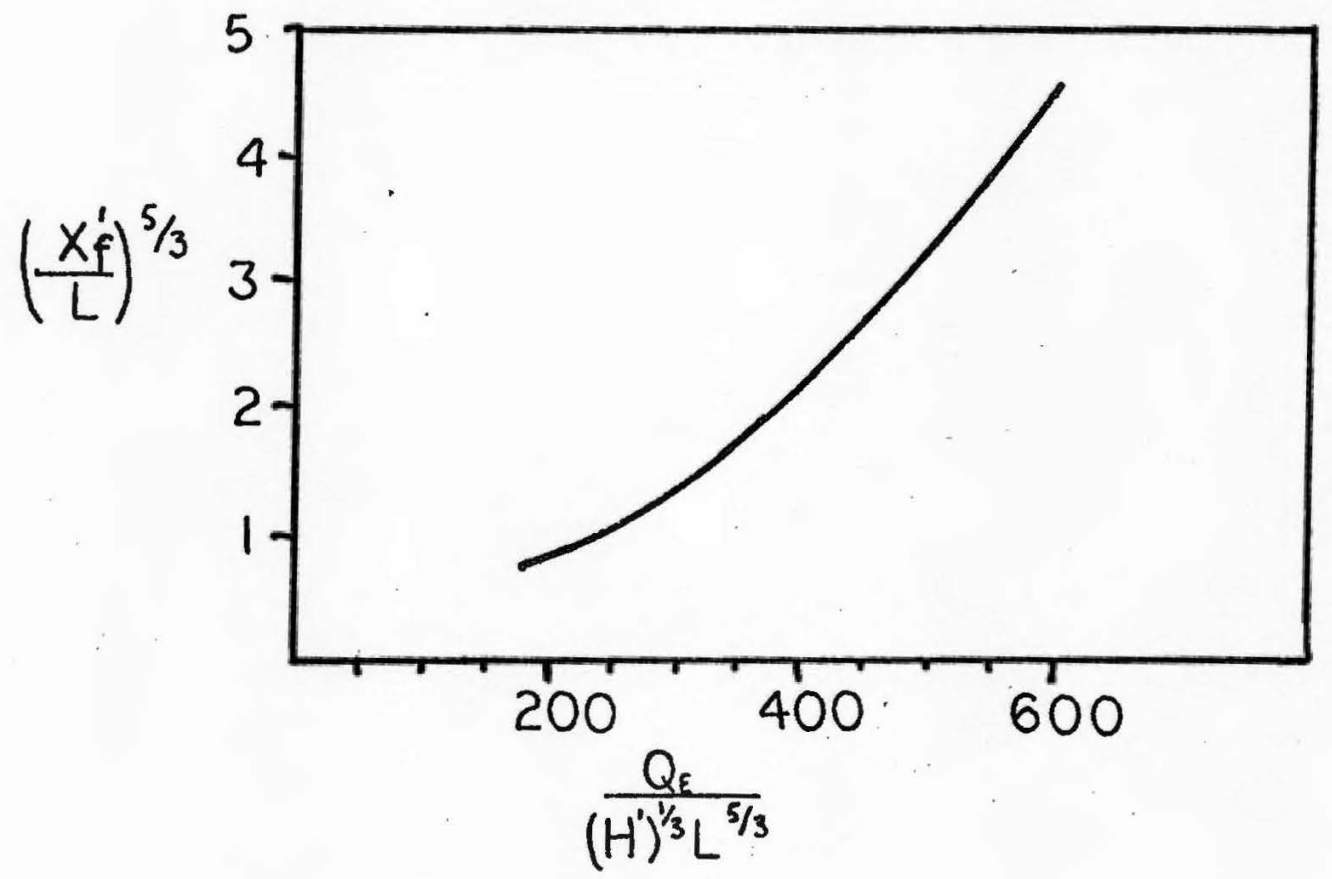

Figure 9. Plot, relating exhaust flow, $Q_{E}$, to $x_{f}^{\prime}, L$ and $H^{\prime}$ as noted by Kuz"mina. 
predict required exhaust flow to be 120 to 200 times calculated plume volume within the ranges investigated. However, as the theory was developed through Eq. 42, it is noted that $\mathrm{K}$ absorbed the numerical coefficient contained in Eq. 18. Therefore, the coefficient, $\mathrm{K}$, determined in Eq. 44 is apparent1y equal to $19 \mathrm{~K}$ defined in Eq. 40, and the predicted ratio of exhaust to plume flow would then range from 5 to 10.

The above results show that $\mathrm{K}$ is highest in the lower left portion of the curve. This may be explained, since this area is characterized by a large distance $L$, or relatively low height $x_{f}^{\prime}$. It is recalled that velocity decays as a function of $1 / \mathrm{L}$ or $1 / \mathrm{L}^{2}$, therefore the plume would be increasingly difficult to deflect with increasing distance. Low values of $x_{f}^{\prime}$ would indicate a relatively high plume velocity (see Eq. 13), and intuitively, a given flow rate at high velocity would be more difficult to deflect than one at low velocity. It is interesting to note that the defining theory, Eq. 40, does not recognize this last point, nor does it make any mention of the exhaust coefficient as a function of distance. In addition none of the above theory places importance on plume temperature and therefore, density; intuitively, a given plume flow of high mass would be more difficult to deflect than one of low mass.

In conclusion, it would appear that exhaust volume is more than a function of plume volume; that factors such as distance, plume velocity and density should be acknowledged and analyzed in the Initial defining theory.

\section{F. SUMMARY}

To summarize this chapter, the sections concerning heat transfer, 
plume characteristics and exhaust flow were presented to reference existing theory cited in the literature and to be used for the development of proposed theory describing the side draft exhaust-plume flow interaction. The results of the Kuz'mina study, as well as those noted in the section concerning the general overview, point out the need for further investigation of the problem. A new analytical presentation is given in Chapter III. 
CHAPTER III

PROPOSED THEORY

A. DEVELOPMENT OF CONCEPT

The purpose of this section is to develop equations or graphs which describe the side draft exhaust-thermal plume interaction in terms of basic, measurable quantities. Much of the symbology to be used is illustrated in Figure 10. Intuitively, one would expect the required exhaust flow

$$
Q_{E}=f\left(A_{S}, T_{S}, L, x_{f}\right)
$$

The hood area may effect $Q_{E}$ where the distance is small as noted in Eq. 34, but generally side draft applications become a problem when the distance is large and the hood can be represented by a point sink. In addition, the hood size would become important when considering the negative effect of cross drafts in the bullding which tend to interfere with collection efficiency. The theory will be developed assuming interaction between the hood and plume only; the results would be adjusted in practice by increasing hood size and exhaust rate to account for unusual interference.

In analyzing the deflectability of a plume, one may initially envision a parcel of air, acting like a particle, in its upward travel. The plume particle is acted upon by a similar exhaust particle traveling horizontally, and this interaction is depicted in Figure 11 where the 


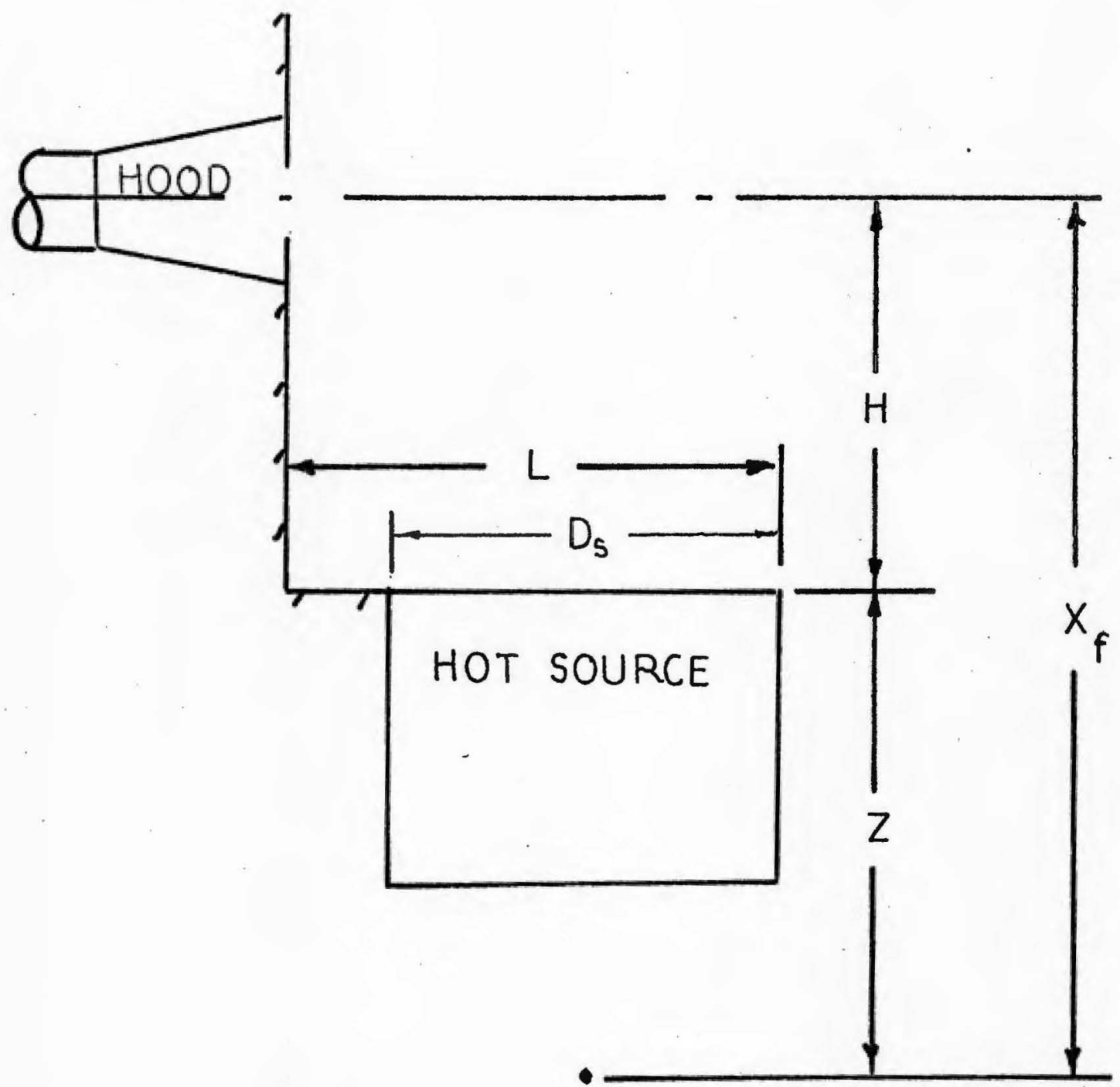

Figure 10. Dimensions to be used in analyzing proposed side draft theory. 


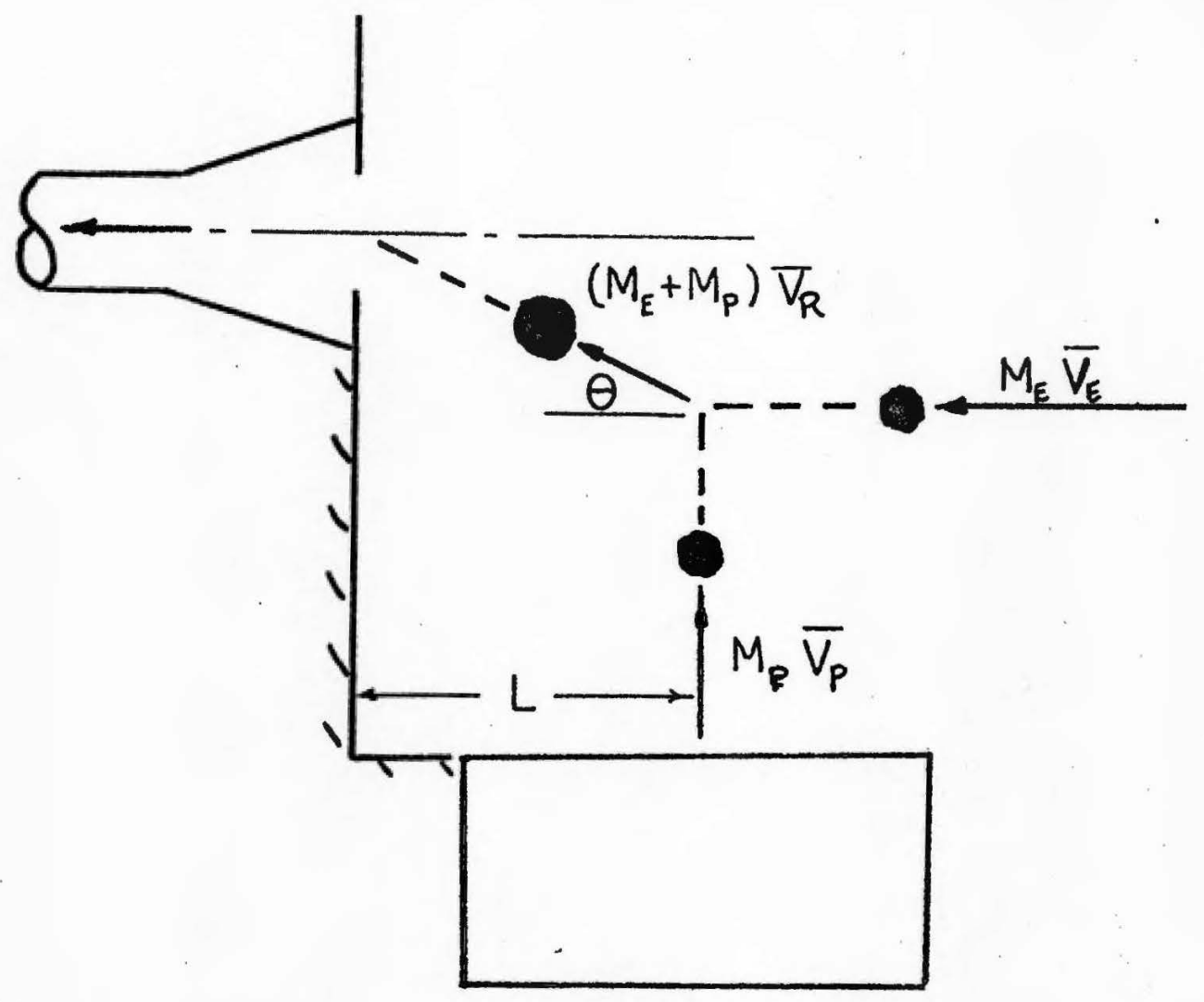

Figure 11. Plume and exhaust interaction analyzed using particle momentum approximation. 
analogy illustrates a particle momentum interchange.

$$
M_{P} \bar{V}_{p}+M_{E} \bar{V}_{E}=\left(M_{P}+M_{E}\right) \bar{V}_{R}
$$

where $M_{p}$ is the mass of plume particle, $\bar{V}_{p}$ is the plume velocity, $M_{E}$ is the mass of the exhaust particle, $\bar{V}_{E}$ is the velocity of exhaust and $\bar{v}_{R}$ is the resulting velocity after impact, acting at an angle $\theta$. It is noted that the magnitude of $\theta$ is a function of the relative strengths of mass and velocity for both the plume and exhaust particles. If the plume is too strong, the $\left(M_{p}+M_{E}\right) \bar{V}_{R}$ vector will not intercept the hood, but rather escape. In practice, however, the deflected vector would not take a straight path to the hood, since the exhaust field becomes stronger as $\mathrm{L}$ decreases. A qualitative illustration of observed exhaust-plume interaction is shown in Figure 12. It is noted that to completely contain a plume, the deflection must be adequate at the plumes furthest distance out from the hood. As the plume gains relative strength over the exhaust, the first sign of escape will occur at the outer edge as shown in Figure 12.

Although the particle momentum analogy is useful in describing deflectability, in reality one deals with the interaction of two gas streams, which in themselves, are not similar. As pointed out by Hemeon, (4), the deflection is a result of turbulent mixing, viscous drag, or both. Furthermore, although the plume tends to be a concentrated, well defined jet of air, the exhaust field is spread out over considerable area with exhaust velocity varying over the diameter of the plume. This relationship is shown in Figure 13 where the majority of the exhaust field does not intercept or effect the plume. Finally, much of the exhaust air travels not horizontally to the hood, but descends in a 


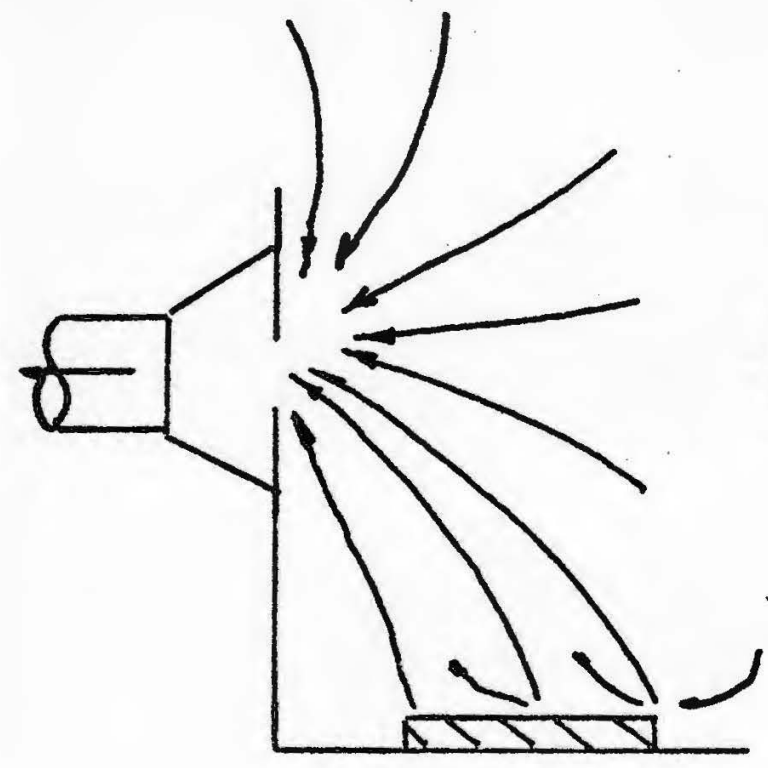

weak plume

strong exhaust

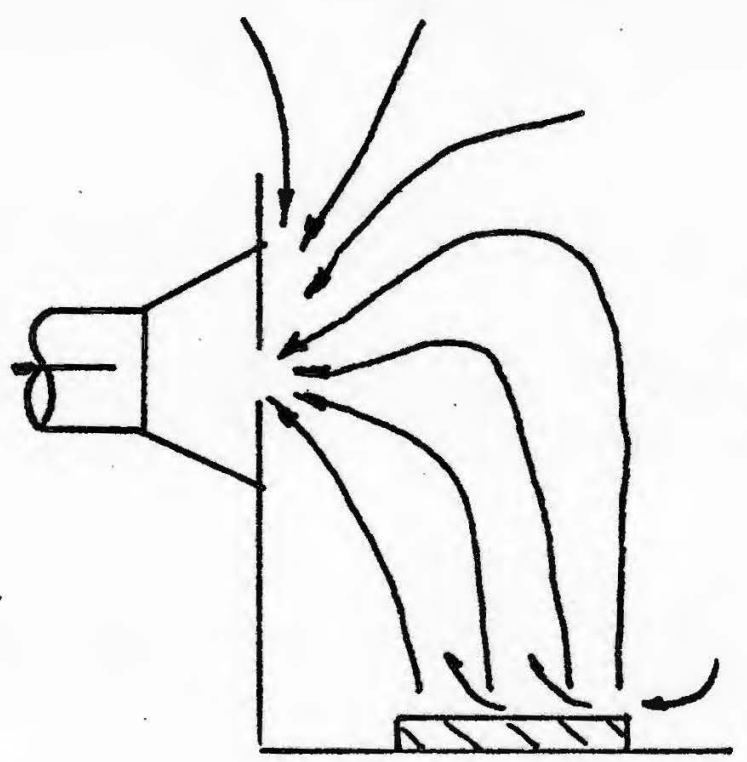

stronger plume

marginal collection

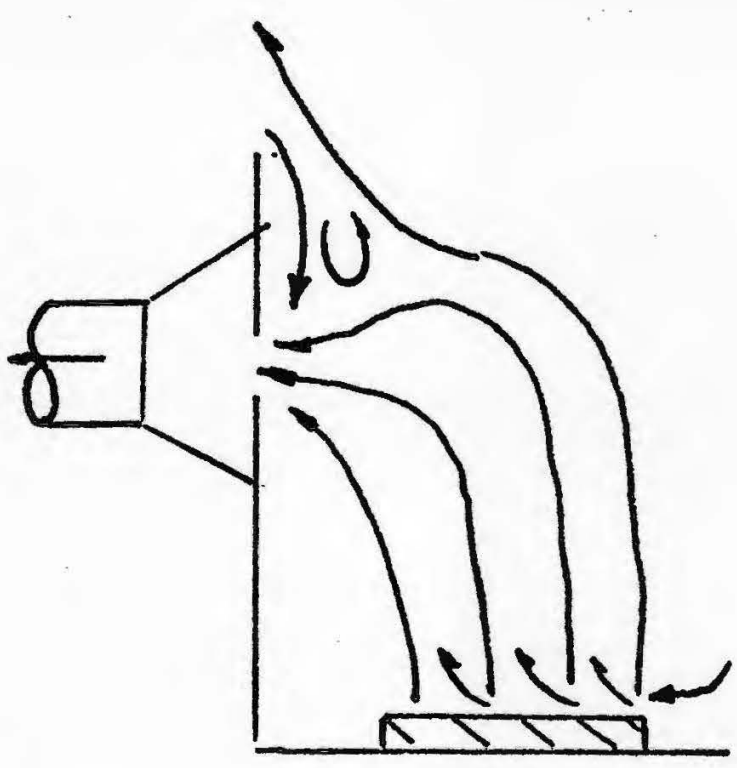

additional plume strength causes losses at outer edge

Figure 12. Qualitative representation of observed plume-exhaust interaction.

$\stackrel{\omega}{\omega}$ 


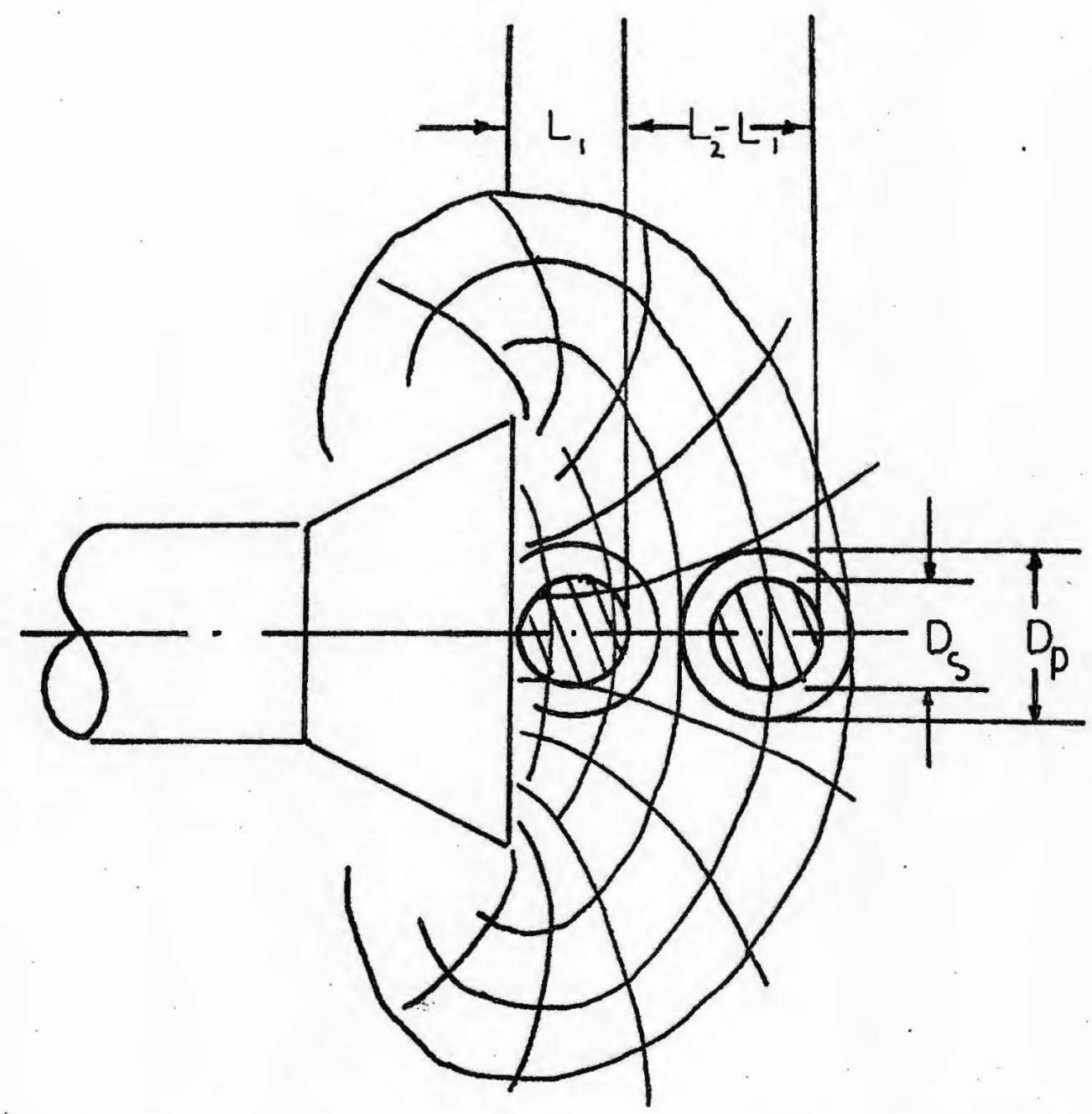

Figure 13. Plan view of plume superimposed on exhaust field. 
radial direction; in fact, only streamlines located on the hood center line travel horizontally. With all of the stated variances from the particle momentum analogy, it is evident that the relationship is more complex.

Conservation of momentum in fluid flow theory takes the following form(8)

$$
\Sigma F_{x}=\rho Q\left(v_{2}-v_{1}\right)=\dot{M}\left(v_{2}-v_{1}\right)
$$

where $F_{x}$ is the result of all forces acting in the $x$ direction, $\rho$ is the fluid density, $Q$ is fluid flow, $v_{1}-v_{2}$ is the velocity change in the $x$ direction, and $\dot{M}$ is mass flow.

With the exhaust velocity vector changing magnitude and direction as a function of location, it would be difficult to mathematically evaluate the sum of all such vectors over the field. On the other hand, a term, $\dot{M}$, related to fluid force, could be defined for the plume, and a similar term could be written for that portion of the exhaust which intercepts the plume with velocity defined along the center line of the hood axis, a distance away equal to the maximum plume distance, L. The resulting terms for exhaust and plume would be

$$
\begin{aligned}
& \dot{\mathrm{M}}_{\mathrm{E}} \mathrm{V}_{\mathrm{E}}=\rho_{\mathrm{E}} \mathrm{Q}_{\mathrm{E}} \mathrm{V}_{\mathrm{E}} \\
& \dot{\mathrm{M}}_{\mathrm{p} \mathrm{V}_{\mathrm{p}}}=\rho_{\mathrm{p}} \mathrm{Q}_{\mathrm{p}} \mathrm{V}_{\mathrm{p}}
\end{aligned}
$$

where $\dot{M}_{E}$ is exhaust mass flow, $v_{E}$ is exhaust velocity at the outer edge of the plume, $\rho_{E}$ is exhaust density, $Q_{E}$ is exhaust flow, $\dot{M}_{p}$ is plume mass flow, $V_{p}$ is plume velocity, $\rho_{p}$ is plume density; and $Q_{p}$ is plume flow. It could then be postulated that

$$
\dot{\mathrm{M}}_{\mathrm{E}} \mathrm{V}_{\mathrm{E}}=\mathrm{K}_{1} \dot{\mathrm{M}}_{\mathrm{p}} \mathrm{V}_{\mathrm{p}}
$$


or alternately

$$
\rho_{\mathrm{E}} \mathrm{Q}_{\mathrm{E}} \mathrm{V}_{\mathrm{E}}=\mathrm{K}_{1} \rho_{\mathrm{p}} \mathrm{Q}_{\mathrm{p}} \mathrm{V}_{\mathrm{p}}
$$

where $K_{1}$ is a dimensionless coefficient.

It is recognized that both the exhaust and plume momentum terms are ficticious quantities during actual operation. The exhaust field is altered by the presence of the plume, and the equations describing plume dispersion and flow would certainly be altered by the exhaust field. Still, the above theory is analogous to the particle momentum example, and provides a mechanism for analysis which is based on physical observation. That is, a high density, high velocity plume with a given flow rate is no longer equally deflected as one with the same flow at low density and velocity.

\section{B. DEVELOPMENT OF EQUATIONS}

In simplifying Eq. 50 it is remembered that $Q_{p}$ and $v_{p}$ are given as

$$
\begin{aligned}
& Q_{p}=1.6 A_{s}^{1 / 3} \Delta T^{5 / 12} x_{f}{ }^{3 / 2} \\
& v_{p}=8 A_{s}^{1 / 3} \Delta T^{5 / 12} / x_{f} 0.29
\end{aligned}
$$

for a circular source.

It is therefore seen that

$$
\rho_{p} V_{p} Q_{p}=13 \rho_{p} A_{s}^{2 / 3} \Delta T^{5 / 6} x_{f}^{5 / 4}
$$

For a rectangular source (2), the plume is evaluated by Eq. 9, 10 and 11 except that the short side dimension is substituted for $D_{s^{*}}$. After $D_{p}$ is calculated, the area of the plume is set equal to

$$
\left(D_{p}\right)\left(D_{p}-W+L\right)
$$


where $\mathrm{W}$ is the width of source and $\mathrm{L}$ is the source length (2). Plumes rising from square sources can be assumed to be circular in most cases (2).

In evaluating Eq. 51 , it is seen that plume momentum increases with source area, temperature and height. Although plume flow, $Q_{p}$, increases quickly with height, and is a function of $x_{f}{ }^{3 / 2}$, the corresponding decrease in velocity counterbalances this effect, so that momentum increases less dramatically, a function of $x_{f}^{5 / 4}$.

In analyzing the exhaust momentum, the proper exhaust equation must be selected based on boundaries and proximity of the hood. A summary of equations is given as follows:

$$
\begin{aligned}
& \text { Equation Source Limitations } \\
& Q_{E}=V_{E}\left(10 L^{2}+A_{H}\right) \quad \text { Dalla Valla no boundaries } \\
& Q_{E}=V_{E}\left(5 L^{2}+A_{H}\right) \quad \text { Dalla Valla one plane } \\
& Q_{E}=12.6 \mathrm{~V}_{\mathrm{E}} \mathrm{L}^{2} \quad \text { point sink no boundaries } \\
& Q_{E}=6.3 V_{E} L^{2} \quad \text { point sink one plane } \\
& Q_{E}=K_{S L L} V_{E} \quad \text { line sink } \quad L<1 / 3 L_{s} \\
& \text { width/length }<0.2
\end{aligned}
$$

A hood located near the ground ventilating distances greater than three hood diameters is a common case and represented by Eq. 33. Exhaust momentum in this case would be given by

$$
\rho_{E} Q_{E} V_{E}=\rho_{E} Q_{E}^{2} / 6.3 L^{2}
$$

By equating the terms in Eq. 51 and Eq. 53, the momentum relationship for a circular plume exhausted by this particular hood becomes

$$
\rho_{E} Q_{E}^{2} / 6.3 L^{2}=13 K_{1} \rho_{p} A_{s}^{2 / 3} \Delta T^{5 / 6} x_{f}^{5 / 4}
$$


By rearranging terms

$$
\mathrm{Q}_{\mathrm{E}}^{2}=82 \mathrm{~K}_{1} \rho_{\mathrm{p}} / \rho_{\mathrm{E}} \mathrm{A}_{\mathrm{s}}^{2 / 3} \Delta \mathrm{T}^{5 / 6} \mathrm{x}_{\mathrm{f}}^{5 / 4} \mathrm{~L}^{2}
$$

At this point it is worthy to note that the exhaust volume, $Q_{E}$, has been expressed in terms of $T_{s}, A_{s}, L$, and $x_{f}$ as desired in $E q .45$. The exhaust density term, $\rho_{E}$, is equal to ambient air density, $0.075 \mathrm{lb} / \mathrm{cu} . \mathrm{ft}$. in most cases. The plume density, $\rho_{p}$, is a function of $A_{s}$ and $T_{s}$ and handled in the following manner.

It is first noted that

$$
\rho_{p}=0.75\left(530 / T_{p}\right) 1 b / f t .^{3}
$$

where $T_{p}$ is the plume temperature in ${ }^{\circ} \mathrm{F}$. It is further noted that

$$
\begin{aligned}
H^{\prime} & =\rho_{p} C_{p} Q_{p}\left(T_{p}-530^{\circ} F\right) \text { Btu/min. } \\
& =\rho_{p}(.24)\left(Q_{p}\right)\left[(.075)\left(530 / \rho_{p}\right)-530^{\circ}\right] \\
& =9.54 Q_{p}-127 \rho_{p} Q_{p}
\end{aligned}
$$

The heat loss is also given by

$$
H^{\prime}=0.38 A_{s}\left(T_{s}-530\right)^{5 / 4} / 60 \mathrm{Btu} / \mathrm{min} \text {. }
$$

By solving for $H^{\prime}$ and $Q_{p}, p_{p}$ can be evaluated from Eq. 56. In arriving at Eq. 54, numerous assumptions were made which will be restated at this point.

1. As $\mathrm{L}, \mathrm{H}, \mathrm{T}_{\mathrm{S}}$ and $\mathrm{A}_{\mathrm{S}}$ are varied, it is assumed that a given range of dynamic similarity is maintained as measured by respective Grashof numbers.

2. The coefficient, $\mathrm{K}_{1}$, is dimensionless and relates the plume momentum to that portion of exhaust momentum intercepting the plume.

3. The effect of increasing distance, $L$, is first to reduce $V_{E}$, and 
secondly to reduce the percentage of exhaust intercepting the plume. This latter effect will be discussed further in the next section. 4. The effect of changing height is covered by the presence of $x_{f}$ in the equation.

5. Sutton's equations describing plume behavior are appropriate over a wide range of conditions.

6. Exhaust momentum is defined as that portion of the total exhaust intercepting the plume, with flow and velocity measured at a helght equal to that at the hood centerline and a distance, $L$, defined at the outer plume boundary.

7. External cross drafts are neglected.

One last polnt needs to be made concerning the derivation of Eq. 50 and $\mathrm{Eq} \cdot$ 54. If the assumed relationships are accurate, then the numerical value of $K_{1}$ will be constant for any combination of $\left(A_{s}, T_{s}\right.$, $L, x_{f}$ ) assuming boundary conditions are properly evaluated. It is noted, however, that $\mathrm{K}_{1}$ relates the plume momentum to only that portion of exhaust momentum intercepting the plume. This latter quantity is difficult to measure and in reality, an exhaust system must be sized for the total volume, even though much of it will not be useful. Therefore, a coefficient, $\mathrm{K}_{2}$, is needed which will relate the total exhaust momentum to plume momentum. It is noted that $\mathrm{K}_{2}$ is highly dependent on boundary conditions and will vary with distance, L, as illustrated in Figure 13. In this figure it is noted that the proportion of exhaust intercepting the plume drops off from $100 \%$ at $L=0$ (in which case $K_{1}$ would equal $K_{2}$ ) to increasingly lower values as $\mathrm{L}$ increases. A definition of $\mathrm{K}_{2}$ is given by 


$$
\rho_{E} Q_{E T} V_{E}=K_{2} \rho_{p} Q_{p} V_{p}
$$

where $Q_{E T}$ is total exhaust required. Returning to Figure 13, it is noted that if the boundary conditions remain constant from $L_{1}$ to $L_{2}, K_{2}$ could conceivably increase directly with distance, L. The portion of exhaust intercepting the plume at $L_{1}$ and $L_{2}$ could be given as

$$
\mathrm{D}_{\mathrm{p}} / \mathrm{IL}_{1} \quad \text { and } \quad \mathrm{D}_{\mathrm{p}} / \mathrm{IL}_{2}
$$

where $\pi_{1}$ and $\mathrm{IL}_{2}$ represent hemispherical velocity contours at a distance L. With the above assumptions in mind, the relationship for $\mathrm{k}_{2}$ as a function of distance would be

$$
\mathrm{K}_{2_{2}}=\mathrm{K}_{2_{1}}\left(\mathrm{~L}_{2} / \mathrm{L}_{1}\right)
$$

If boundary conditions remain constant from $L_{1}$ to $L_{2}$. It could also be postulated that

$$
\mathrm{K}_{2}=\mathrm{K}_{1} \Pi \mathrm{L} / \mathrm{D}
$$

for the case shown in Figure 13.

In general, formulae such as Eq. 54, Eq. 59 and Eq. 60 are not particularly useful because they describe only one set of conditions. A better technique would be to go back to Eq. 50 and analyze exhaust and plume flow terms appropriate to the specific case in mind.

The next section of this paper deals with the experimental set up and procedure required to verify Eq. 50, Eq. 58 and to determine the actual relationship of $\mathrm{K}_{2}$ with respect to distance as estimated by Eq. 60 . 
CHAPTER IV

EXPERIMENTAL SET UP

\section{A. GENERAL}

To test the proposed theory developed in Chapter III, a suitable area was selected; one which was well enclosed to minimize building drafts, yet large enough to dissipate room air turbulence caused by the hot plume itself. A detailed description of the required equipment, hot plate, hooding, air flow measuring devices, adjustable source stand, and smoke generator is found in the following section.

\section{B. EQUIPMENT}

\section{Hot Plate}

An adjustable temperature hot plate was required to generate a predictable plume. An electrically heated unit was chosen over a gas fired unit because improved temperature uniformity and controllability was anticipated. In addition, an absence of products of combustion potentially interfering with the plume was deemed desirable. In practice two plates were tested, one commercial unit, $12^{\prime \prime} \times 20^{\prime \prime}$ in size and a specia11y built unit $8^{\prime \prime} \times 10^{\prime \prime}$ in size.

An important consideration in setting up the experiment was to achieve Grashof numbers reasonably close to values achieved in actual practice. This objective was limited somewhat by the capability of available equipment. A typical industrial example might involve a $12^{\prime \prime}$ 
diameter ladle of molten aluminum. It is recalled that the Grashof number,

$$
\mathrm{Gr}=\rho^{2} \mathrm{g \beta} \Delta \mathrm{TL}^{3} / \mu^{2}
$$

would be given as follows

$$
\begin{aligned}
\text { Gr } & =\left(26.5 \times 10^{3}\right)(1,000)(1)^{3} \\
& =2.6 \times 10^{7}
\end{aligned}
$$

A more buoyant plume would be generated by a $48^{\prime \prime}$ diameter ladle of molten steel, in which case, the Grashof number would be

$$
\begin{aligned}
\text { Gr } & =\left(1.2 \times 10^{3}\right)(2,700)(4)^{3} \\
& =2 \times 10^{8}
\end{aligned}
$$

It is noted that $\mathrm{Gr}$ varies greatly in practice, and, as shown above, the values will many times fall within the laminar flow regime.

In setting up the experiment, Grashof numbers were estimated to assure reasonable similarity to those noted above. Typical values for the $8^{\prime \prime} \times 10^{\prime \prime}$ plate and $12^{\prime \prime} \times 20^{\prime \prime}$ plate are given in Table III and Table IV respectively.

\section{Hooding and Ductwork}

The test set up called for an adjustable volume of exhaust and a hood whose face area could also be adjusted. An illustration of the hood actually built is given in Figure 14. Since plate sources from $8^{\prime \prime} \times 10^{\prime \prime}$ to $12^{\prime \prime} \times 20^{\prime \prime}$ were to be used, the hood was designed for a slot height to vary from 0 to $12^{\prime \prime}$ and slot length to vary from 0 to $17^{\prime \prime}$. In actual practice, the slot height was held constant at $4.5^{\prime \prime}$.

Once the hood design was frozen, the maximum required exhaust vo1ume was estimated as 
TABLE III

SUMMARY OF GRASHOF NUMBERS VS TEMPERATURE FOR AN $8^{\prime \prime} \times 10^{\prime \prime}$ PLATE

\begin{tabular}{c|ccc}
$T_{S}$ & $500^{\circ} \mathrm{F}$ & $750^{\circ} \mathrm{F}$ & $1,000^{\circ} \mathrm{F}$ \\
\hline$g \beta p^{2} / \mu^{2}$ & $159 \times 10^{3}$ & $60 \times 10^{3}$ & $26.5 \times 10^{3}$ \\
$\mathrm{Gr}$ & $4.6 \times 10^{7}$ & $2.7 \times 10^{7}$ & $1.5 \times 10^{7}$
\end{tabular}

TABLE IV

SUMMARY OF GRASHOF NUMBERS VS TEMPERATURE

FOR A $12^{\prime \prime} \times 20^{\prime \prime}$ PLATE

\begin{tabular}{l|ccc}
$\mathrm{T}_{\mathrm{S}}$ & $500^{\circ} \mathrm{F}$ & $750^{\circ} \mathrm{F}$ & $1,000^{\circ} \mathrm{F}$ \\
$\mathrm{gB \beta} \rho^{2} / \mu^{2}$ & $159 \times 10^{3}$ & $60 \times 10^{3}$ & $26.5 \times 10^{3}$ \\
$\mathrm{Gr}$ & $3.68 \times 10^{8}$ & $2.1 \times 10^{8}$ & $1.23 \times 10^{8}$
\end{tabular}



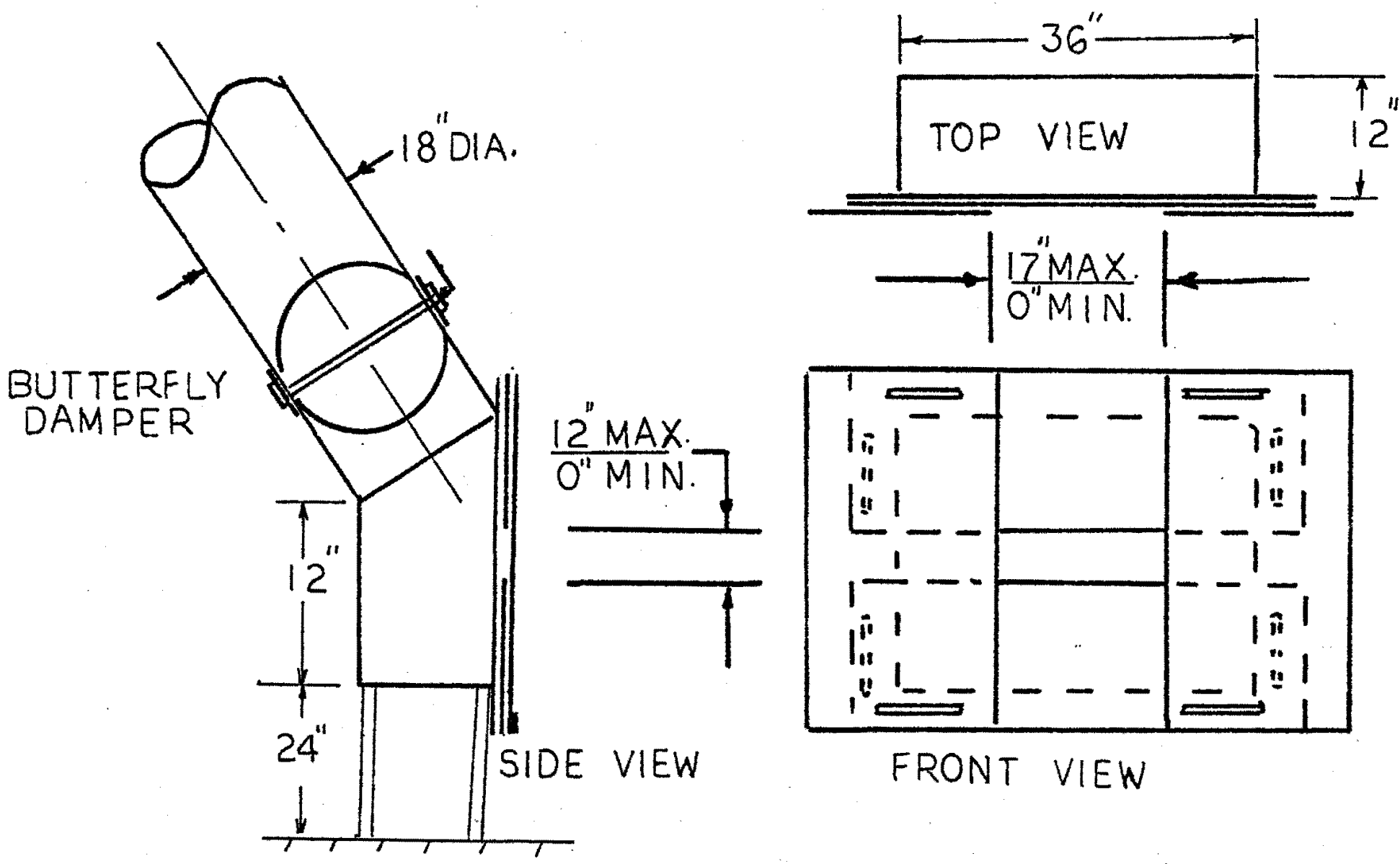

Figure 14. Adjustable exhaust hooding used in testing. 


$$
Q_{E}=100\left(5 L^{2}+A_{H}\right)
$$

A maximum anticipated hood area of $6^{\prime \prime} \times 17^{\prime \prime}$ and distance of $48^{\prime \prime}$ defined the required exhaust at $8,000 \mathrm{cfm}$. An existing nearby exhaust ventilation system provided more than enough capacity and was, therefore, used for an exhaust source with a butterfly damper installed to modulate flow.

\section{Smoke Generator}

The method of testing involved varying $T_{s}, A_{s}, L$, and $H$ while observing the exhaust required to marginally contain a visible plume of smoke injected at the plate. By adjusting the exhaust to a marginal level, the same degree of collection could be measured in each case to insure consistency of results. The criteria for smoke generating equipment was that it produce a dense, easily discernable discharge of smoke and yet not alter the thermal plume by its presence. Smoke produced from an exothermic process was unacceptable, because the accompanying heat release would boost the existing thermal plume. Commercial smoke guns were also unacceptable, because the initial velocity imparted to the smoke caused drafts and turbulence directly effecting the plume. Thus, it was decided that the smoke had to be introduced at room temperature at the outer edge of the test plate in such a way that it would be entrained in the plume without effecting it. Such a source was created by placing an open ceramic dish of ammonia adjacent to one of hydrochloric acid. The resulting dense white vapor, as noted in Figure 15, provided a good tracer to air flow patterns. It 1s noted that a partial cover was placed over the dishes to insure that the emerging smoke arose adjacent to the plate only. 


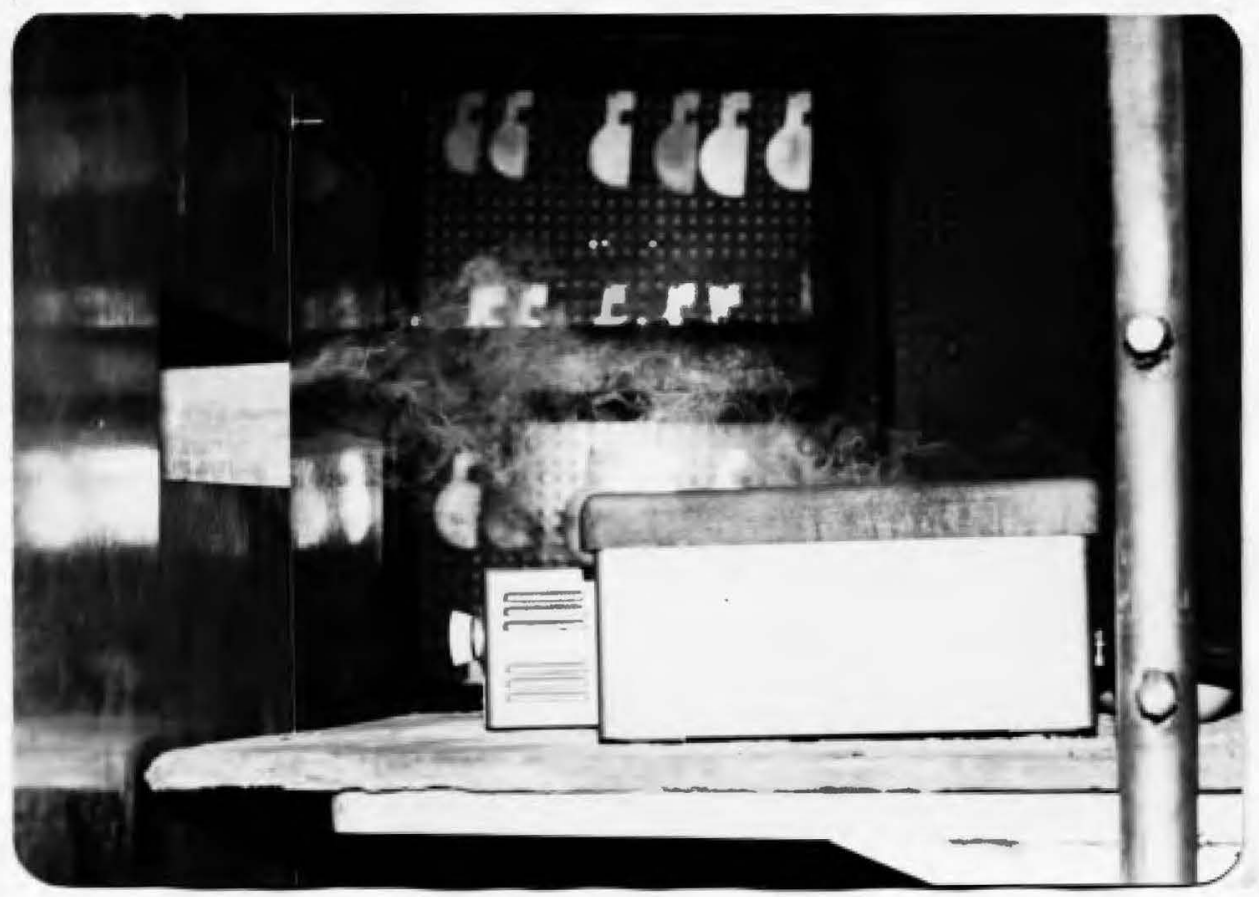

Figure 15. Illustration of smoke providing a visual tracer of air flow pattern over hot plate. 


\section{Source Stand}

In order to adjust the position of the hot plate, an adjustable source stand was built as illustrated in Figure 16. The frame supported the hot plate and smoke generating dishes as well.

\section{General}

The remainder of the equipment consisted of a multipoint thermocouple and recorder to measure plate temperature uniformity, and a pitot tube and vane anemometer to measure exhaust flow. A complete equipment list is given in Appendix A. The photographs shown in Figure 17 11lustrate the test set up ready for use. 


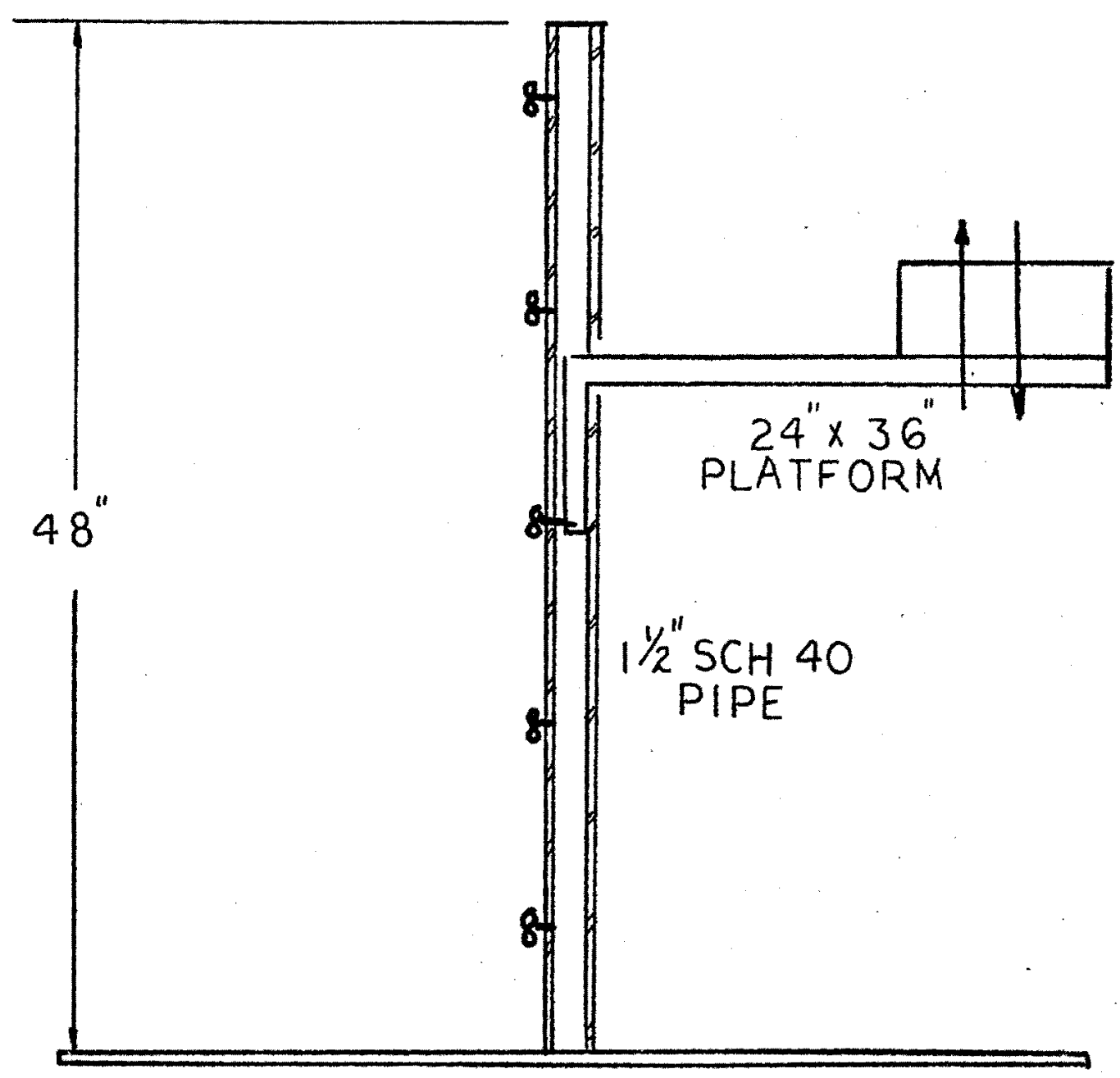

Figure 16. Adjustable hot plate support used in testing. 

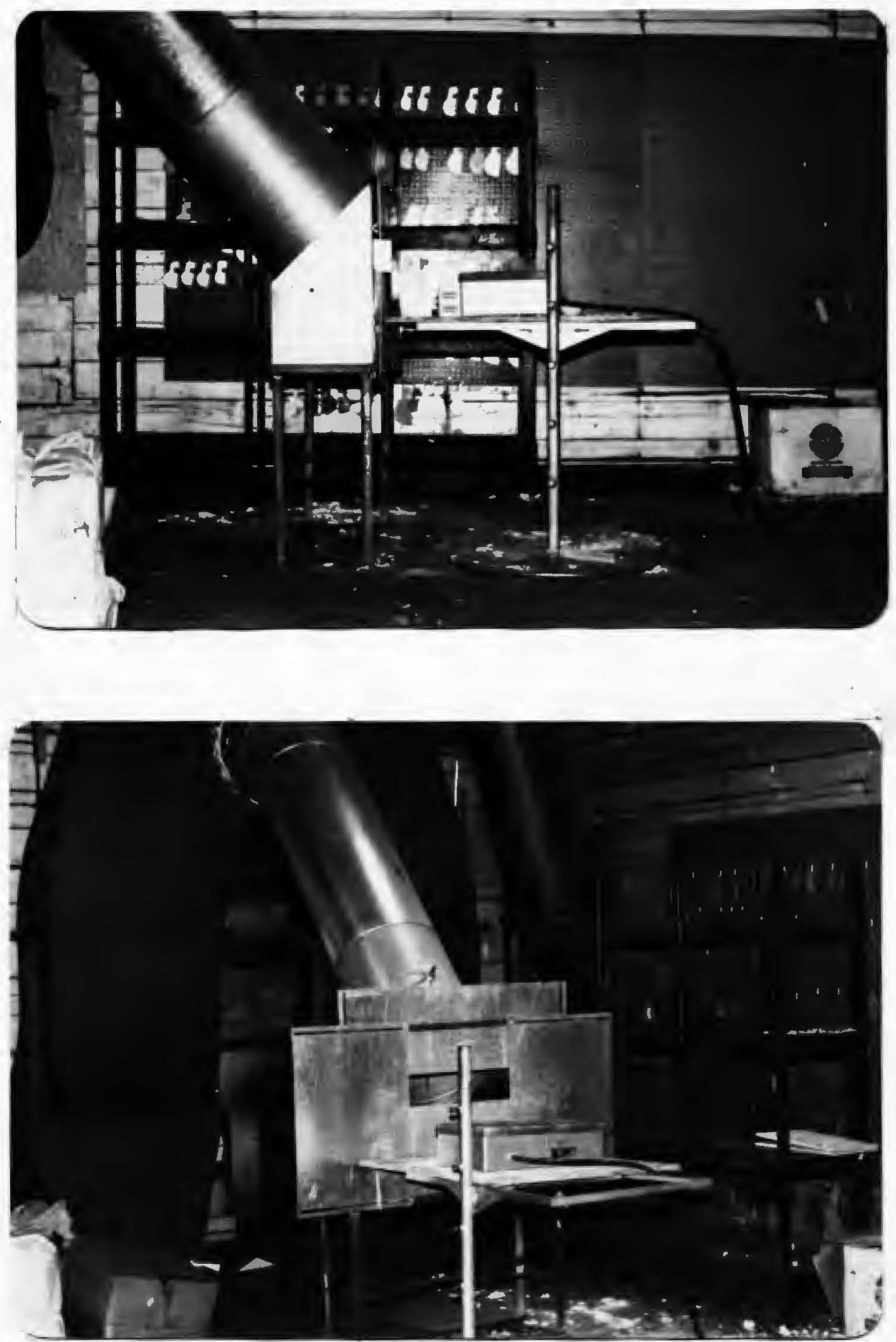

Figure 17. Test equipment ready for use. 
CHAPTER V

\section{PROCEDURE}

With the equipment installed, the first step was to calibrate both plates for temperature uniformity; results are given in Appendix B and Appendix C for the $8^{\prime \prime} \times 10^{\prime \prime}$ plate and $12^{\prime \prime}$ x $20^{\prime \prime}$ plate, respectively. The second step was to select different test heights, $H$, and to measure hood flow versus velocity, as a function of distance. With this data, accurate hood equations with boundary coefficients could be determined. Plate momentums could then be calculated for the $8^{\prime \prime} \mathrm{x} 10^{\prime \prime}$ plate at $615^{\circ} \mathrm{F}$, and the $12^{\prime \prime} \times 20^{\prime \prime} \mathrm{plate}$ at $550^{\circ} \mathrm{F}$ and $750^{\circ} \mathrm{F}$. Exhaust momentums were given by

$$
\rho_{E} Q_{E} V_{E}=.075 Q_{E}^{2} / \mathrm{KL}^{2}
$$

where

$$
Q_{E}=K V_{E} L^{2}
$$

Values of $\mathrm{K}_{2}$ were then calculated by noting the ratio of exhaust to plume momentums.

The specific experimental procedure used in testing the 8 " $\times 10^{\prime \prime}$ plate is as follows:

1. The plate was brought to $615^{\circ} \mathrm{F}$ and allowed to stabilize.

2. The initial plate height was set at $2^{\prime \prime}$ below the hood center line. The hood opening was set at $4.5^{\prime \prime} \times 10^{\prime \prime}$, the $10^{\prime \prime}$ length matching the assumed plume diameter.

3. The required exhaust was measured for a distance of $12^{\prime \prime}$, then the plate was retested at distances of $18^{\prime \prime}, 24^{\prime \prime}$ and $30^{\prime \prime}$. 
4. The height was then readjusted to $7^{\prime \prime}$ below the hood center line, with the hood size being increased to $4.5^{\prime \prime} \times 12^{\prime \prime}$, the 12 " length matching the calculated plume diameter. Readings were again noted at distances of $12^{\prime \prime}, 18^{\prime \prime}, 24^{\prime \prime}$, and $30^{\prime \prime}$.

5. Elevations of $14^{\prime \prime}$ and $20^{\prime \prime}$ were investigated with hood openings set at $4.5^{\prime \prime} \times 15^{\prime \prime}$ and $4.5^{\prime \prime} \times 17^{\prime \prime}$ respectively.

6. In each of the above tests two or three readings of exhaust volume were taken, with the volume first adjusted until smoke leakage was observed, and then gradually increased to the marginal level.

7. It is also noted that at all distances, a horizontal spacer was placed between the hood and plate to maintain constant boundary conditions, as much as possible.

When running tests using the $12^{\prime \prime} \times 20^{\prime \prime}$ plate, a slightly different procedure was followed. It was noted in the preceding theory that hood size should not effect the required exhaust, as long as the plate is relatively distant from the hood. Therefore, to test this theory, one hood size, 4.5" $\times 17$ ", was used for all tested positions of the $12^{\prime \prime} \times 20^{\prime \prime}$ hot plate. Tests were run at $550^{\circ} \mathrm{F}$ and $750^{\circ} \mathrm{F}$; distances of $12^{\prime \prime}, 18^{\prime \prime} ;$, 24", 30", 42". and 48"; and heights of 4", 12" and 18". It was anticipated that values of $\mathrm{K}_{2}$ achieved in the above tests would compare favorably to those noted for the $8^{\prime \prime} \times 10^{\prime \prime}$ plate at similar positions. 


\section{CHAPTER VI}

\section{RESULTS AND ANALYSIS}

In this chapter the results achieved from each hot plate experiment are 1isted; each section is composed of graphical data correlating exhaust flow to plume flow, exhaust momentum to plume momentum, as well as correlating results of the data manipulated using the technique developed by Kuz'mina. An analysis accompanies each set of graphs. Calculations and supporting data are included in the Appendix.

The results of experimental testing are applied to an existing side draft hood ventilating a 48" diameter foundry ladle located at Esco Corporation, Portland, Oregon. The accompanying analysis compares measured results to those predicted, thus showing applicability to experimental data extrapolated to an industrial scale. 
A. RESULTS OF PRETEST DATA 
TABLE V

RESULTING EXHAUST VELOCITY DECAY EQUATIONS

AT THREE SOURCE HEIGHTS

Helght

$4^{\prime \prime}$

$14^{\prime \prime}$

20
Exhaust equation

$$
Q_{E}=3 V_{E} L^{2}
$$

$Q_{E}=5 V_{E} L^{2}$

$$
Q_{E}=5.25 V_{E^{L}}{ }^{2}
$$


Before testing the plate exhaust requirements, checks were run to verify plate temperature uniformity, as well as to determine exhaust velocity decay equations for the specific experimental configuration. Temperature calibrations are noted in Appendix B and Appendix C where average plate temperatures of $615^{\circ} \mathrm{F}, 532^{\circ} \mathrm{F}$ and $744^{\circ} \mathrm{F}$ are noted; these values correspond to values of $615^{\circ} \mathrm{F}, 550^{\circ} \mathrm{F}$ and $750^{\circ} \mathrm{F}$ used in the calculations. Since the recorded temperatures varied slightly over the test duration, any errors incurred from rounding off average temperatures for calculation were deemed to be insignificant.

It is noted that in actual practice in industry the precise temperatures are seldom known, nor are they completely uniform over the surface area. Likewise, in the experiment an average temperature of $615^{\circ} \mathrm{F}$ was calculated from values ranging from $560^{\circ} \mathrm{F}$ to $680^{\circ} \mathrm{F}$. The $550^{\circ} \mathrm{F}$ average temperature resulted from values ranging from $470^{\circ} \mathrm{F}$ to $590^{\circ} \mathrm{F}$, and the $750^{\circ} \mathrm{F}$ temperature resulted from values ranging from $700^{\circ} \mathrm{F}$ to $800^{\circ} \mathrm{F}$. Although the test yielded data and graphs describing relative trends, the results would undoubtedly be improved with achievement of closer temperature tolerance.

The results of the velocity decay equations expressed as a function of height are noted in Table V; supporting data and calculations are given in Appendix D. The velocities were measured using a vane anemometer which possessed a lower measurable limit of $100 \mathrm{fpm}$. Therefore, by setting maximum flow at the hood, velocities could be measured out to a distance of $20^{\prime \prime}$ to $24^{\prime \prime}$, only. It was assumed that boundary conditions remained constant for distances further out. The equations, therefore, were assumed to remain the same. This assumption may have led to errors in 
analysis noted later in this paper.

In analyzing the accuracy of the equations, it is first noted that each equation approximates the point sink theory with numerical coefficients of 3,5 and 5.25 corresponding to heights of $4^{\prime \prime}, 14^{\prime \prime}$ and $20^{\prime \prime}$ respectively. This appears consistent with physical interpretation where a 4" height would approximate a hood bounded directly by two planes, with velocity contours resulting in the shape of quarter spheres. A corresponding numerical coefficient of 3.15 checks well with observations.

At the $14^{\prime \prime}$ height the bounding horizontal plane would be removed from the hood, and only the effects of the hood flange plane would remain. The resulting hemispherical velocity contours would be described by a theoretical numerical coefficient of 6.3 . This value corresponds to an observed and calculated value of 5.0 showing some deviation from assumed to actual boundary restraints. In other words the horizontal plane still had some effect on the contours, thus restricitng flow area, increasing velocity and slightly reducing the flow coefficient at this height. It is noted in Appendix D that the numerical coefficient of 3 is an average of values ranging from 3.07 to 3.3 ; the coefficient of 5 is an average of values ranging from 4.22 to 5.3 ; and the coefficient of 5.25 resulted from values ranging from 4.7 to 6.0 . Therefore, the equations given in Table $\mathrm{V}$ only approximately describe velocity decay; errors in measurement or changing boundary conditions provide some uncertainty.

When running actual exhaust tests on the $12^{\prime \prime} \times 20^{\prime \prime}$ plate, heights of $4 ", 12^{\prime \prime}$ and $18^{\prime \prime}$ were used with corresponding numerical flow coefficients estimated as $3,4.5$ and 5 respectively. For the 8 " $x 10$ " hot 
plate heights of $2^{\prime \prime}, 7^{\prime \prime}, 14^{\prime \prime}$, and $20^{\prime \prime}$ were used, with corresponding numerical flow coefficients estimated at $3,4,5$, and 5.25 . All subsequent analysis of data was based on the above results. 
B. RESULTS OF 12" x 20" PLATE TESTED AT $550^{\circ} \mathrm{F}$ 


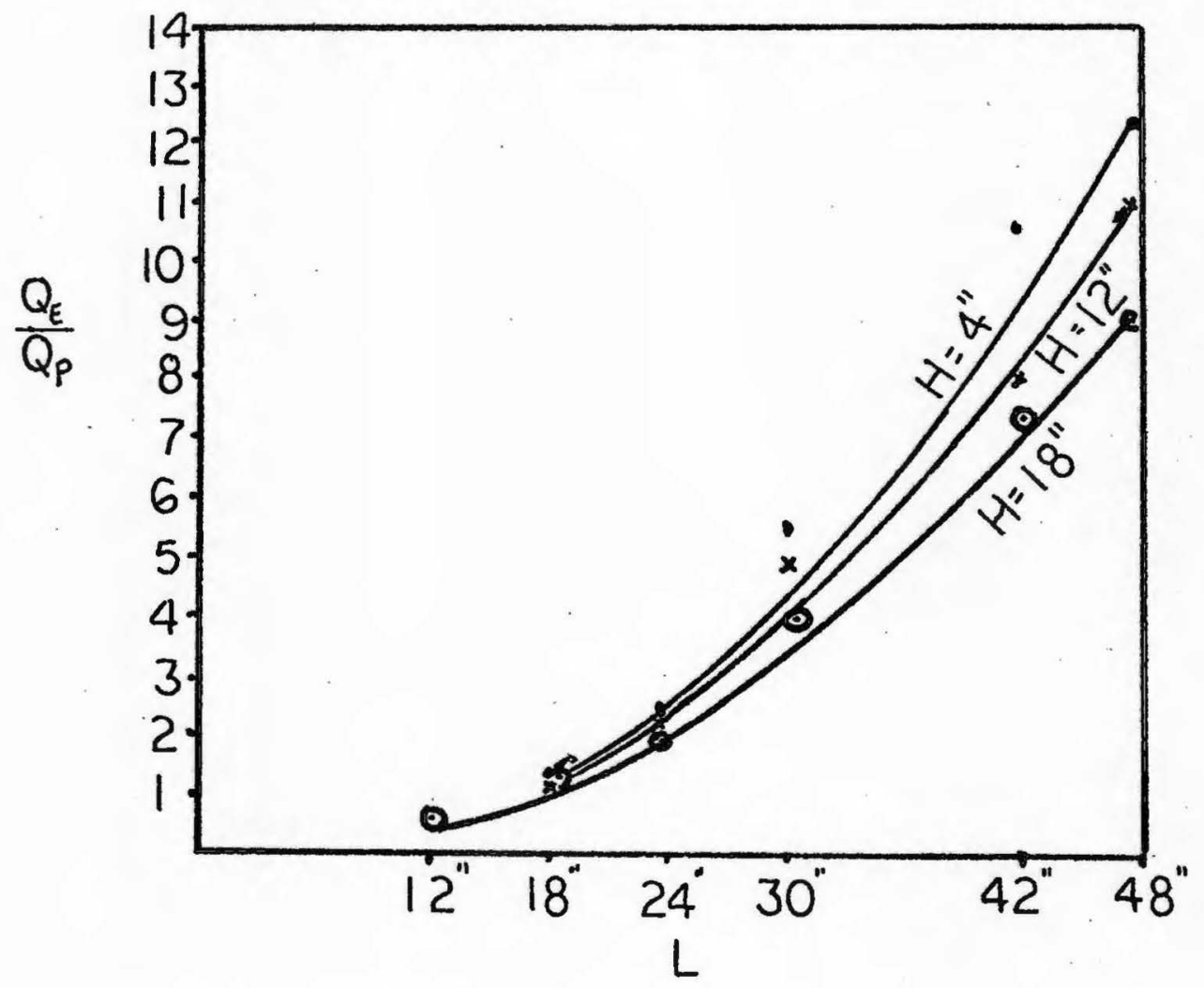

Figure 18. Relationship of $Q_{E} / Q_{p}$ to $\mathrm{L}, \mathrm{H}$ for a $12^{\prime \prime} \times 20^{\prime \prime}$
plate at $550^{\circ} \mathrm{F}$. 


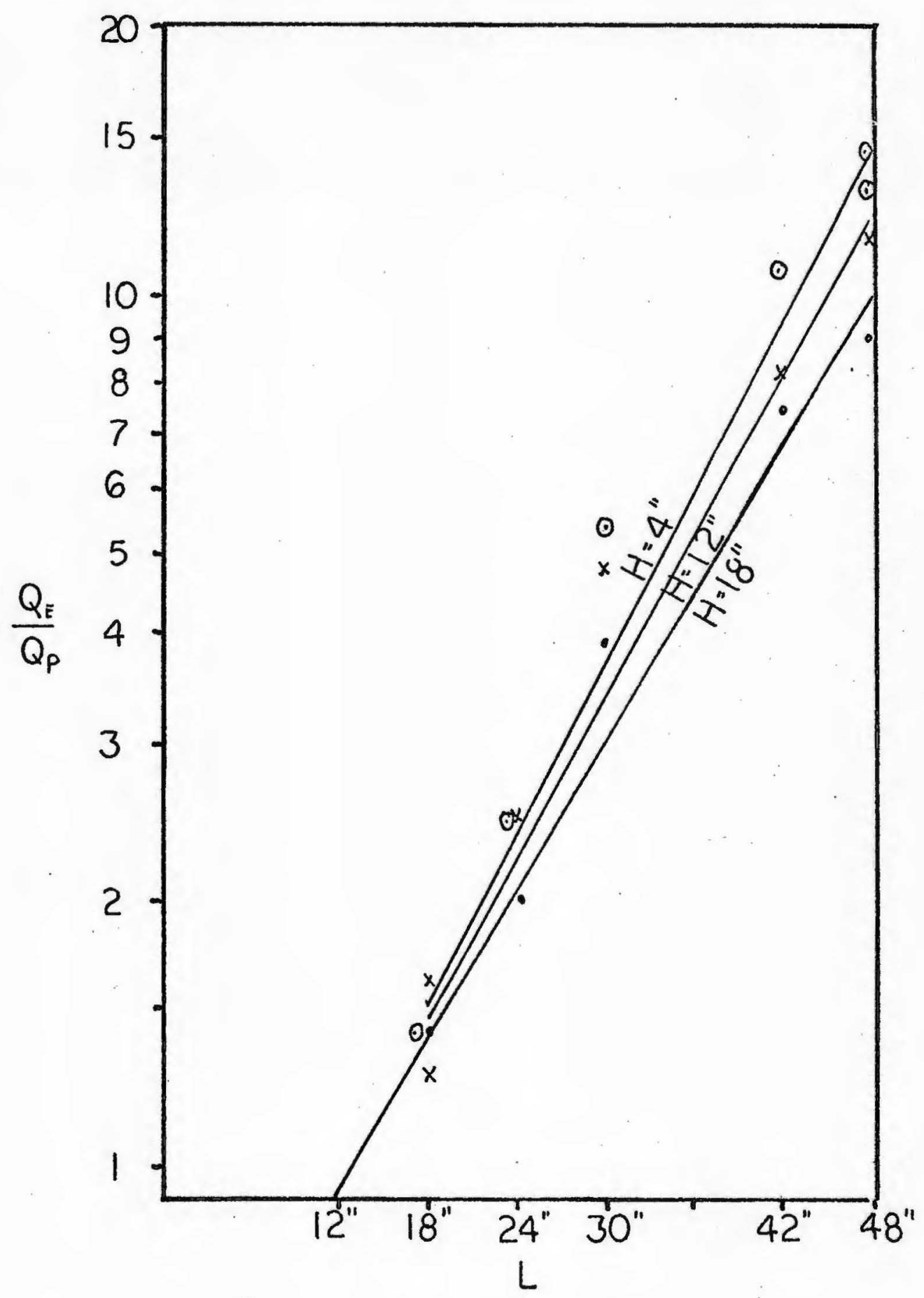

F1gure 19. $Q_{E} / Q_{p}$ vs L,H for $12^{\prime \prime} \times 20^{\prime \prime}$ plate at $550^{\circ} \mathrm{F}$. 


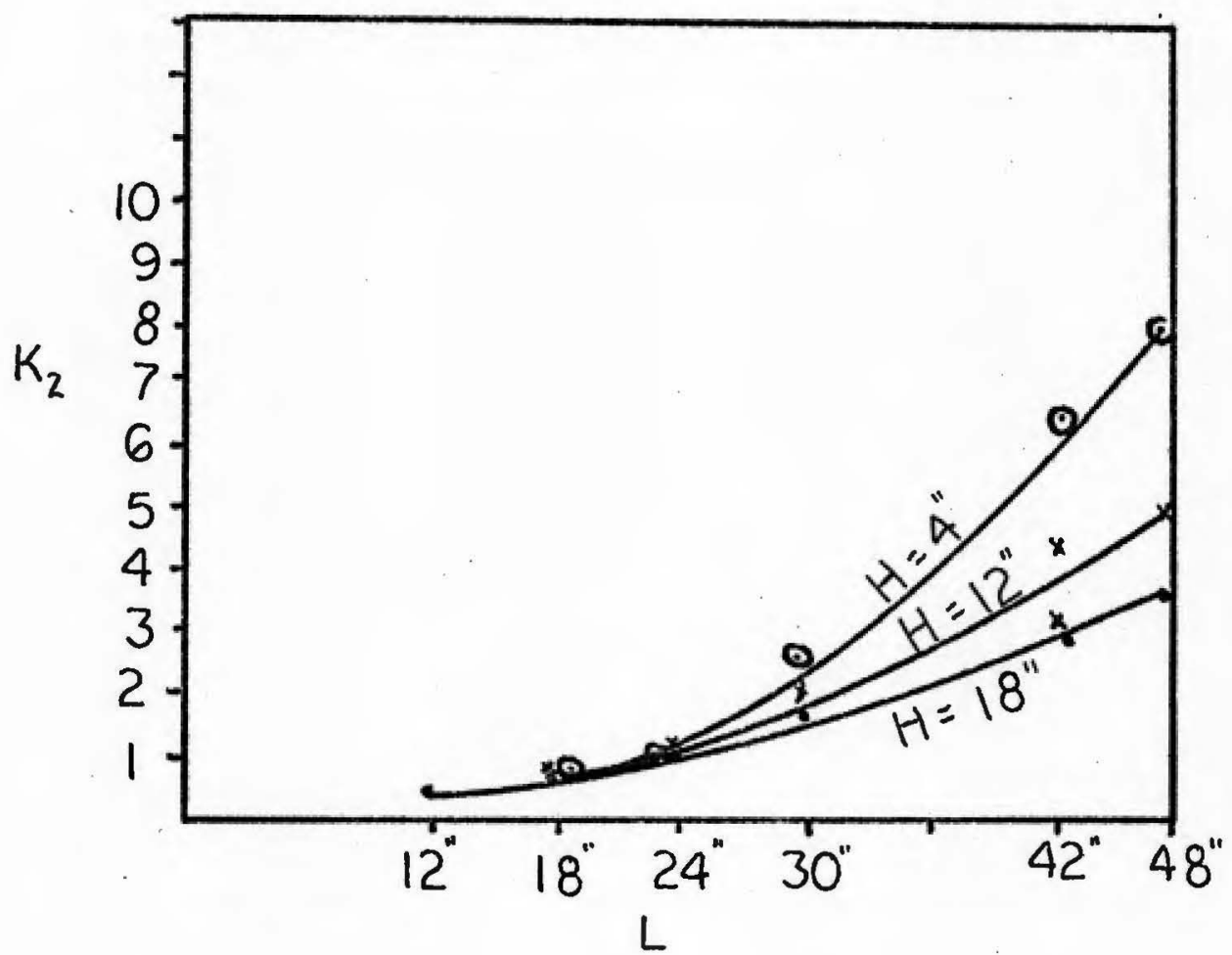

Figure 20. $\mathrm{K}_{2}$ expressed as a function of position for $12^{\prime \prime} \times 20^{\prime \prime}$ plate at $550^{\circ} \mathrm{F}$. 
61

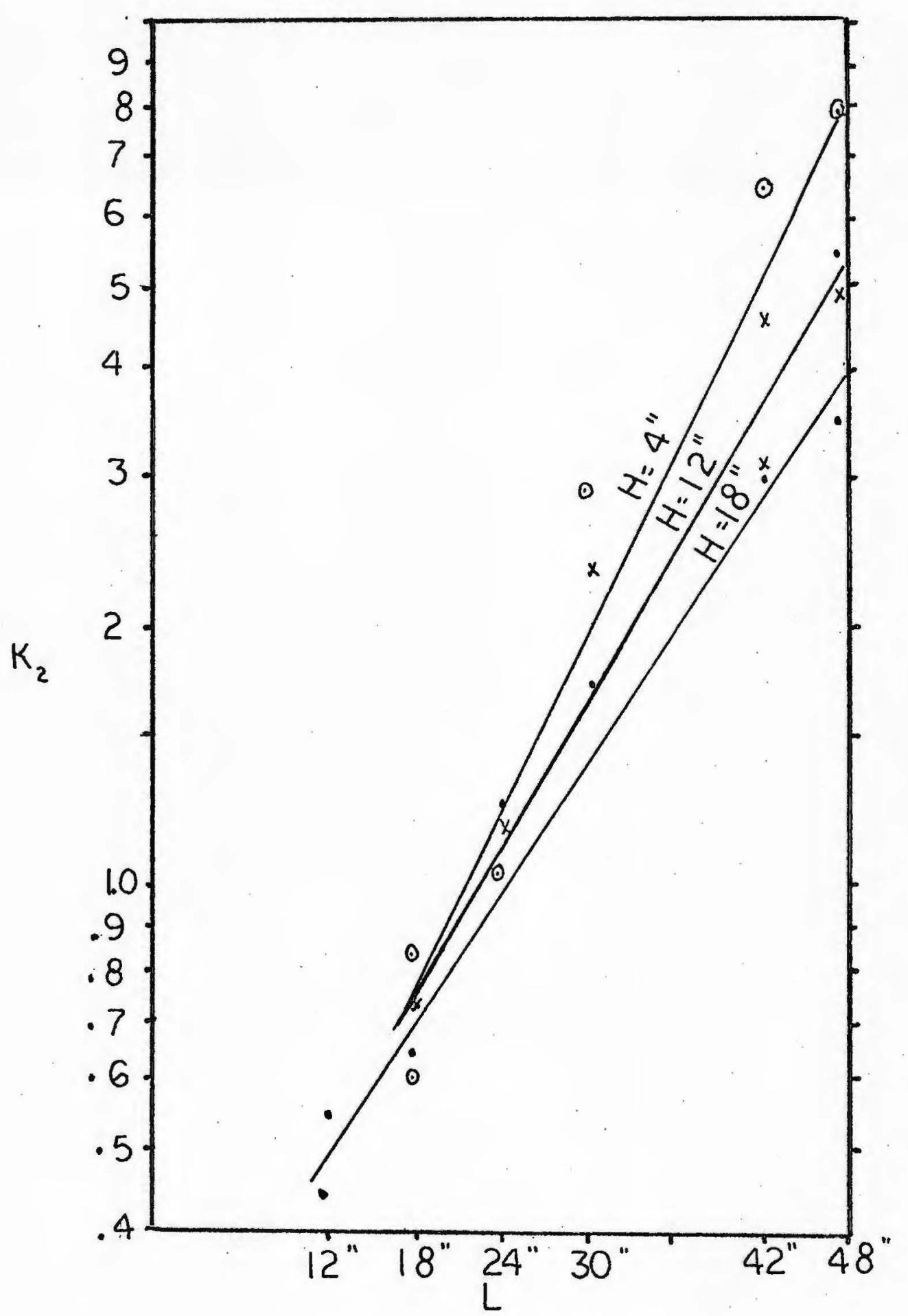

Figure 21. $\mathrm{K}_{2}$ vs $\mathrm{L}, \mathrm{H}$ for $12^{\prime \prime} \times 20^{\prime \prime}$ plate at $550^{\circ} \mathrm{F}$. 


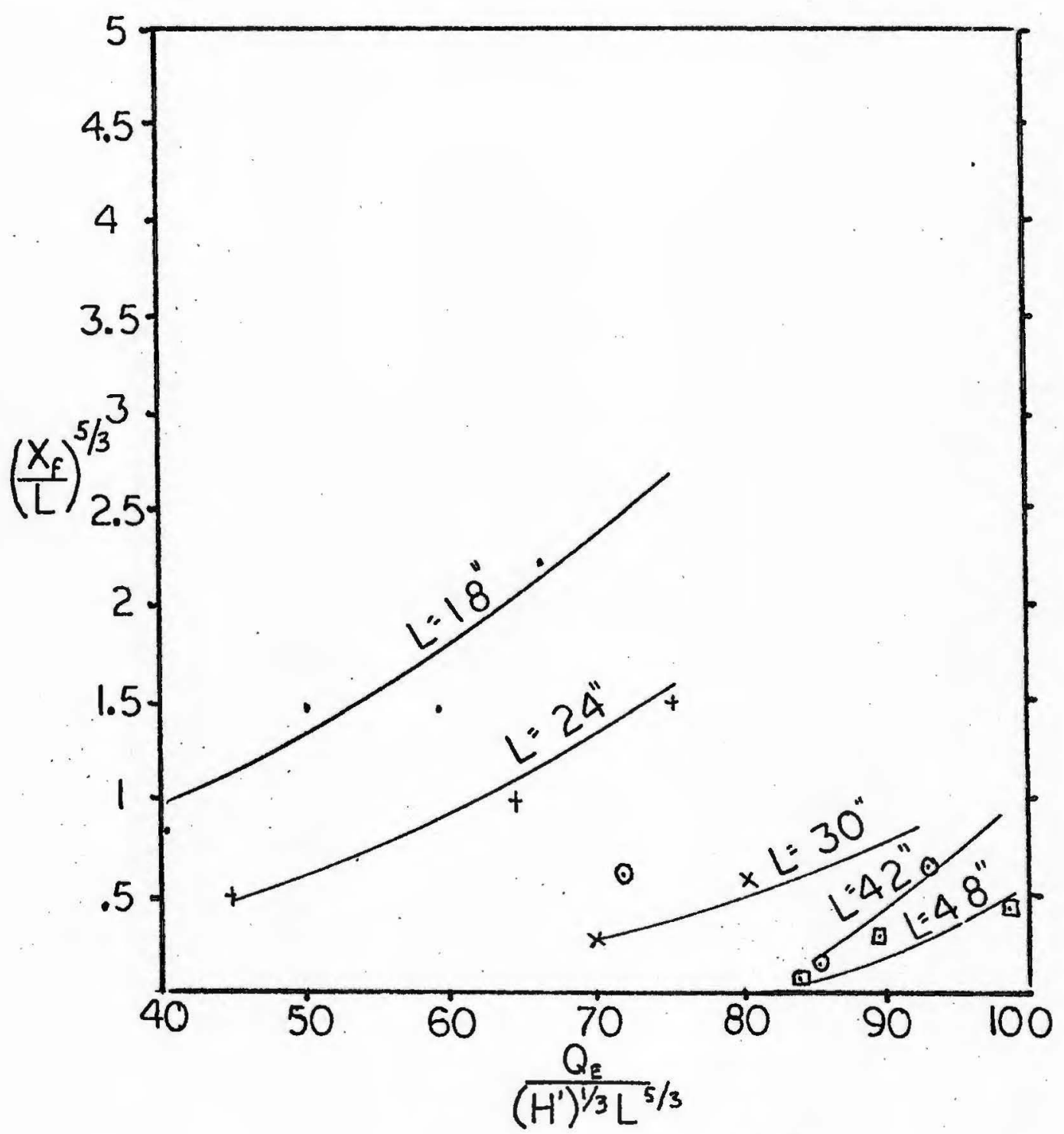

Figure 22. $Q_{E} /\left[\left(\mathrm{H}^{\prime}\right)^{1 / 3}(\mathrm{~L})^{5 / 3}\right]$ vs $\left(\mathrm{x}_{\mathrm{f}}^{\prime} / \mathrm{L}\right)^{5 / 3}$ for a $12^{\prime \prime} \times 20^{\prime \prime}$ plate tested at $550^{\circ} \mathrm{F}$. 
The results correlating exhaust flow to plume flow are given in Figures 18-22; the supporting data is found in tabular form in Appendix F, Tables VII - XI.

It is noted in Table VII that the required exhaust flow values increase both with height and distance as expected, with flow extending up to approximately $3,000 \mathrm{cfm}$ at a distance of $48^{\prime \prime}$ and helght of $18^{\prime \prime}$. A better appreciation of these values is achieved by noting the ratio of exhaust flow to plume flow, $Q_{E} / Q_{p}$; this is illustrated in Figure 18 with values tabulated in Table VIII of Appendix F. During the experiment it was difficult to adjust the system to marginal collection in many cases. Therefore, multiple readings were taken with corresponding qualitative descriptions noted in both Table VII and Table VIII. In plotting the data these notations were taken into account to assure that a consistent degree of collection was compared from one point to another. Although physical restrictions prevented readings being taken at the 12 " distance for all heights; it is noted that values of $Q_{E} / Q_{p}$ at an $18^{\prime \prime}$ and $24 "$ distance equal 1.3 to 1.6 and 2 to 3 respectively, regardless of height. However, as the distance increases beyond $24 "$, the $Q_{E} / Q_{p}$ values become height sensitive with values at a given distance decreasing with increasing height. As seen in Figure 18, three curves correlate these flow ratios, one for each height.

This same data is plotted to logarithmic scale in Figure 19 where data is fitted to straight lines, each a function of height. It is noted that within the experimental range, exhaust flow increases to a maximum of 12 to 14 times the plume flow at a 48" distance and 4" height. The exhaust flows at heights of 12" and 18" equal 11 and 9 times the 
respective plume flows at the $48^{\prime \prime}$ distance, thus illustrating the height effect.

The momentum results are the major interest of this paper; calculated exhaust momentums are noted in Appendix F, Table IX as a function of position. Calculated plume momentums are noted in Appendix $\mathrm{E}$ as a function of height.

The ratio of exhaust momentum to plume momentum, $K_{2}$, is plotted in Figure 20 with supporting data tabulated in Appendix F, Table $X$. It is noted that three separate curves result, each a function of height. However, at distances of $12^{\prime \prime}, 18^{\prime \prime}$ and $24^{\prime \prime}$ this height effect is not noticable and corresponding $\mathrm{K}_{2}$ values of $0.5,0.7$ and 1.1 are attained in al1 cases. Assuming boundary conditions remain constant within these ranges, the above results correlate well as anticipated by

$$
\mathrm{K}_{2}=\mathrm{K}_{2} \mathrm{~L}_{2} / \mathrm{L}_{1}
$$

At a distance of $30^{\prime \prime}, \mathrm{K}_{2}$ jumps from an expected value of

$$
\begin{aligned}
K_{2} & =0.5(2.5 / 1) \\
& =1.25
\end{aligned}
$$

to values of 3.24 to 1.74 as height increases from 4 " to $18^{\prime \prime}$. This result was not anticipated and a possible explanation centers around changing boundary conditions as illustrated in Figure 23. Here, it is noted that the hood flanges extend to a distance of $26.5^{\prime \prime}$. Inside this radius, the velocity contours can be shown as semicircles in the plan view. At a $30^{\prime \prime}$ distance, the contour reaches out beyond the flange tip, thus increasing the contour surface area. The resulting effect would be to alter the exhaust velocity decay equation, and to reduce the percent- 


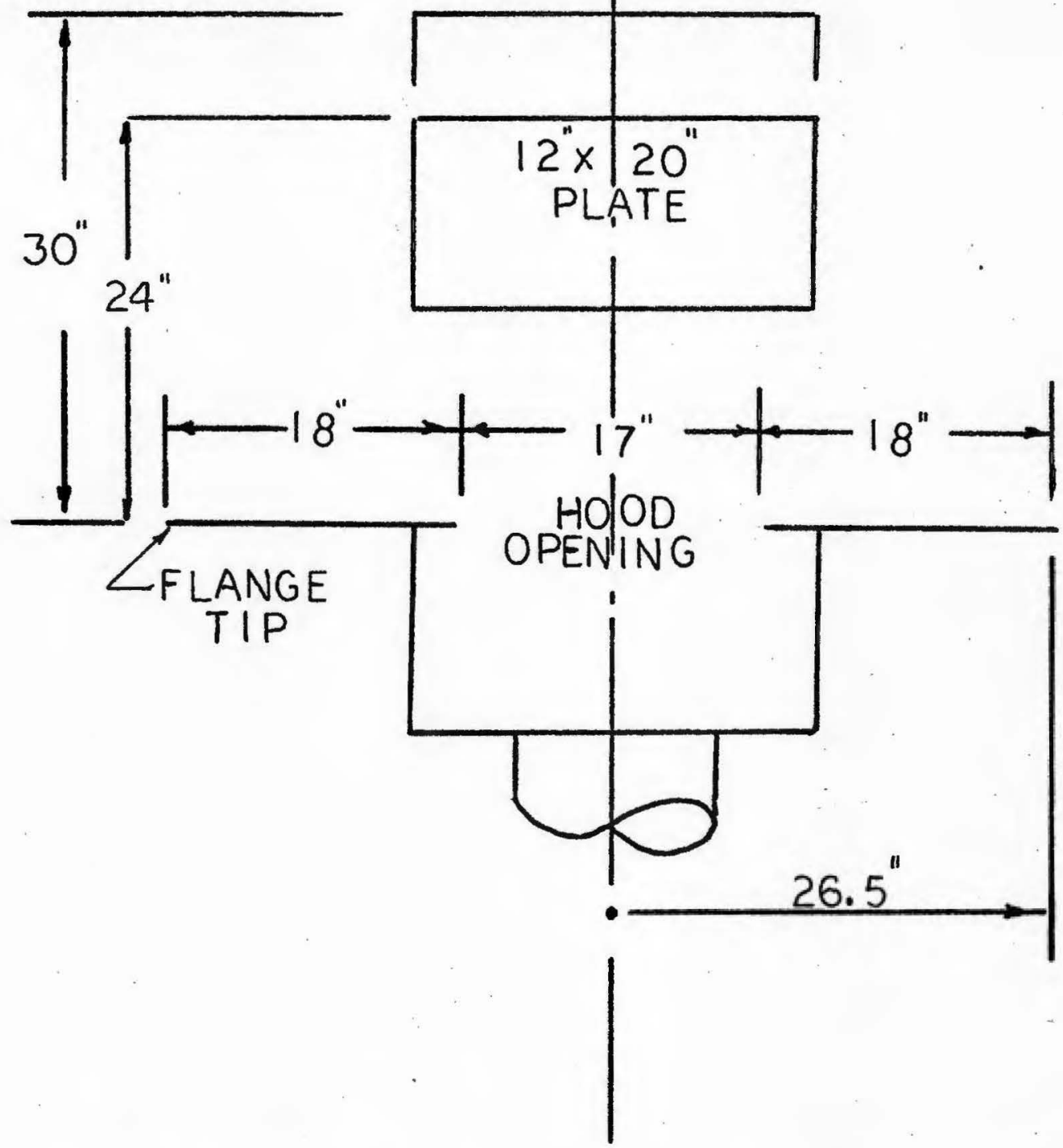

Figure 23. Effect of changing boundary conditions on exhaust velocity field as distance increases from $24^{\prime \prime}$ to $30^{\prime \prime}$ for a 12 " $x$ 20" plate. 
age of exhaust air intercepting the plume dramatically. For example, if the field were to change from a hemisphere to a full sphere, the percentage would be cut in half with $\mathrm{K}_{2}$ doubling. Of course, the physical size of the hood would have an effect on this oversimplification, but an appreciation of the order of magnitude of change is achieved. Unfortunately, the exhaust air velocities at the $30^{\prime \prime}$ distance were too low to measure, so the above explanation has not been experimentally verified.

The decrease of $\mathrm{K}_{2}$ with increasing height at any given distance beyond 24" may also be due to changing boundary conditions, but the explanation is not as clearly demonstrated as done above. An additional explanation may center around the observation that as height is increased, the thermal plume is bent or turned inward less sharply; intuitively, such an effect would appear to lower $\mathrm{K}_{2}$ values. However, this effect is not noted at distances less than $30^{\prime \prime}$, and, therefore, changing boundary conditions would appear to play a role.

The data relating $\mathrm{K}_{2}$ to position is replotted in Figure 21 to logarithmic scale where the data is fitted to straight lines, each a function of height. It is noted that momentum ratios increase up to a maximum value of 6.5 to 8 at a $4^{\prime \prime}$ height and $48^{\prime \prime}$ distance; however, values drop off with increasing height with the effect being more pronounced as distance increases.

An analysis of this data would not be complete without correlating it using the technique developed by Kuz'mina. It is recalled that two dimensionless parameters

$$
Q_{E} /\left[\left(H^{\prime}\right)^{1 / 3} L^{5 / 3}\right] \text { vs }\left(x_{f}^{\prime} / L\right)^{5 / 3}
$$


were plotted as noted in Figure 9. A corresponding analysis is tabulated in Appendix F., Table XI for the $12^{\prime \prime} \times 20^{\prime \prime}$ plate at $550^{\circ} \mathrm{F}$ with the results plotted in Figure 22. It is seen that a loose family of curves results from the data, as opposed to the single curve achieved by Kuz'mina. As noted in Chapter II, this theory was developed with the distance term introduced somewhat arbitrarily into the equations in this author's opinion. The scatter of data noted in Figure 22 may be due to flaws in the initial assumptions. In fact by noting that the $\mathrm{H}^{\prime}$ term is constant at $550^{\circ} \mathrm{F}$, the equations can be written as

$$
\begin{array}{r}
Q_{E} /\left[\left(H^{\prime}\right)^{1 / 3} L^{5 / 3}\right]=K\left(x_{f}^{\prime} / L\right)^{5 / 3} \\
Q_{E} / L^{5 / 3}=K_{3}\left(x_{f}^{\prime} / L\right)^{5 / 3}
\end{array}
$$

By multiplying both sides of the equation by $L^{5 / 3}$

$$
Q_{E}=K_{3}\left(x_{f}^{\prime}\right)^{5 / 3}
$$

and, thus exhaust volume is only a function of height. For each new distance term, then, a new curve relating $Q_{E}$ to $x_{f}^{\prime}$ would be expected and this is exactly the result shown in Figure 22.

Comparison of experimental results to those of Kuz'mina is difficult because no raw data was made available supporting the results of that study. Whether similar source size, temperature range, distances, or heights were used is not known, nor is the experimental procedure known. Suffice to say that considerable variance is found between the results of this study and those noted by Kuz'mina. 
C. REsurts OF $12^{\prime \prime} \times 20^{\prime \prime}$ PLATE TESTED AT $750^{\circ} \mathrm{F}$ 


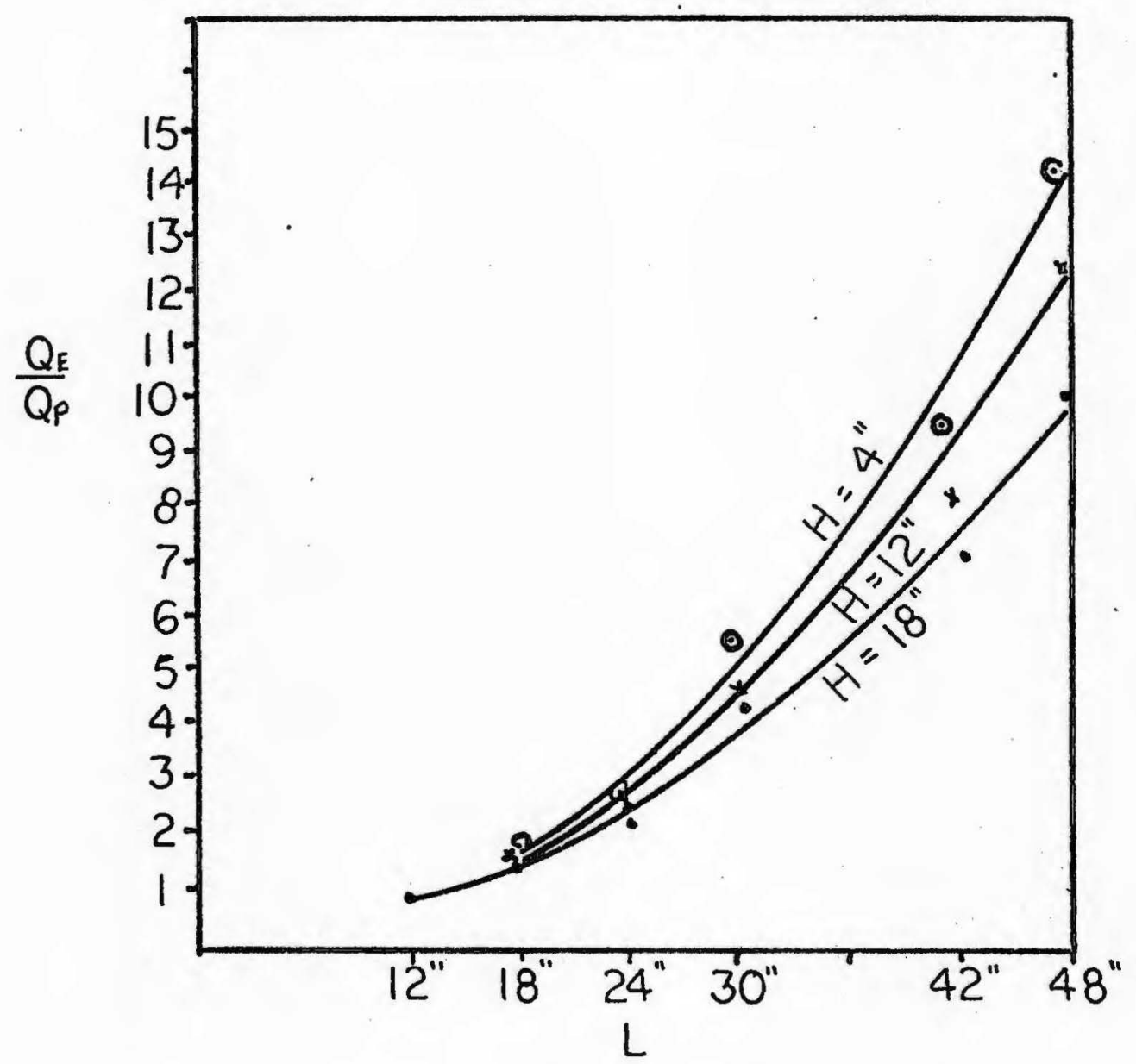

Figure 24. Relationship of $Q_{E} / Q_{p}$ to $L, H$ for $12^{\prime \prime} \times 20^{\prime \prime}$ plate at $750^{\circ} \mathrm{F}$. 


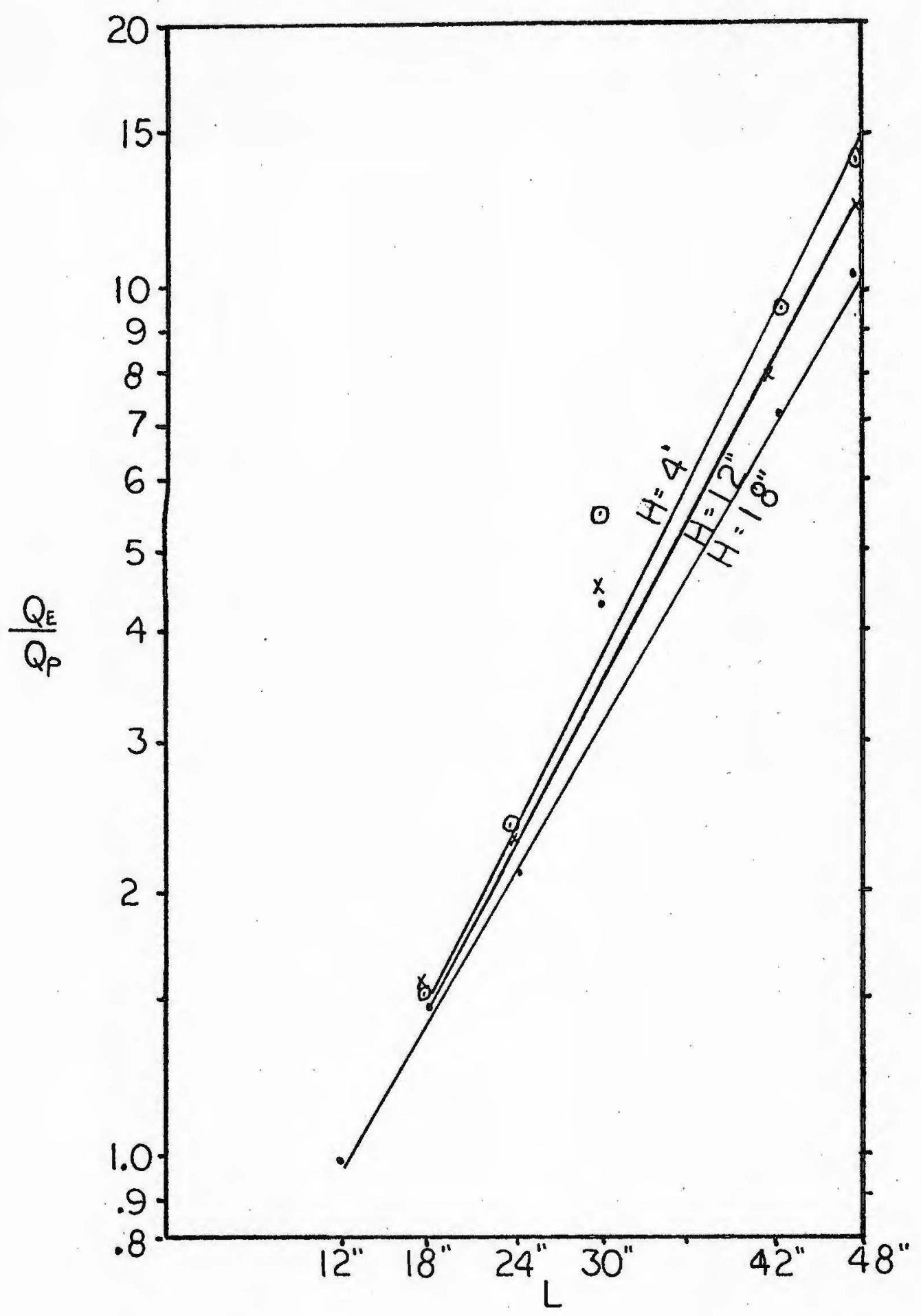

Figure $25 . Q_{E} / Q_{p}$ vs $\mathrm{L}, \mathrm{H}$ for $12^{\prime \prime} \times 20^{\prime \prime}$ plate at $750^{\circ} \mathrm{F}$. 


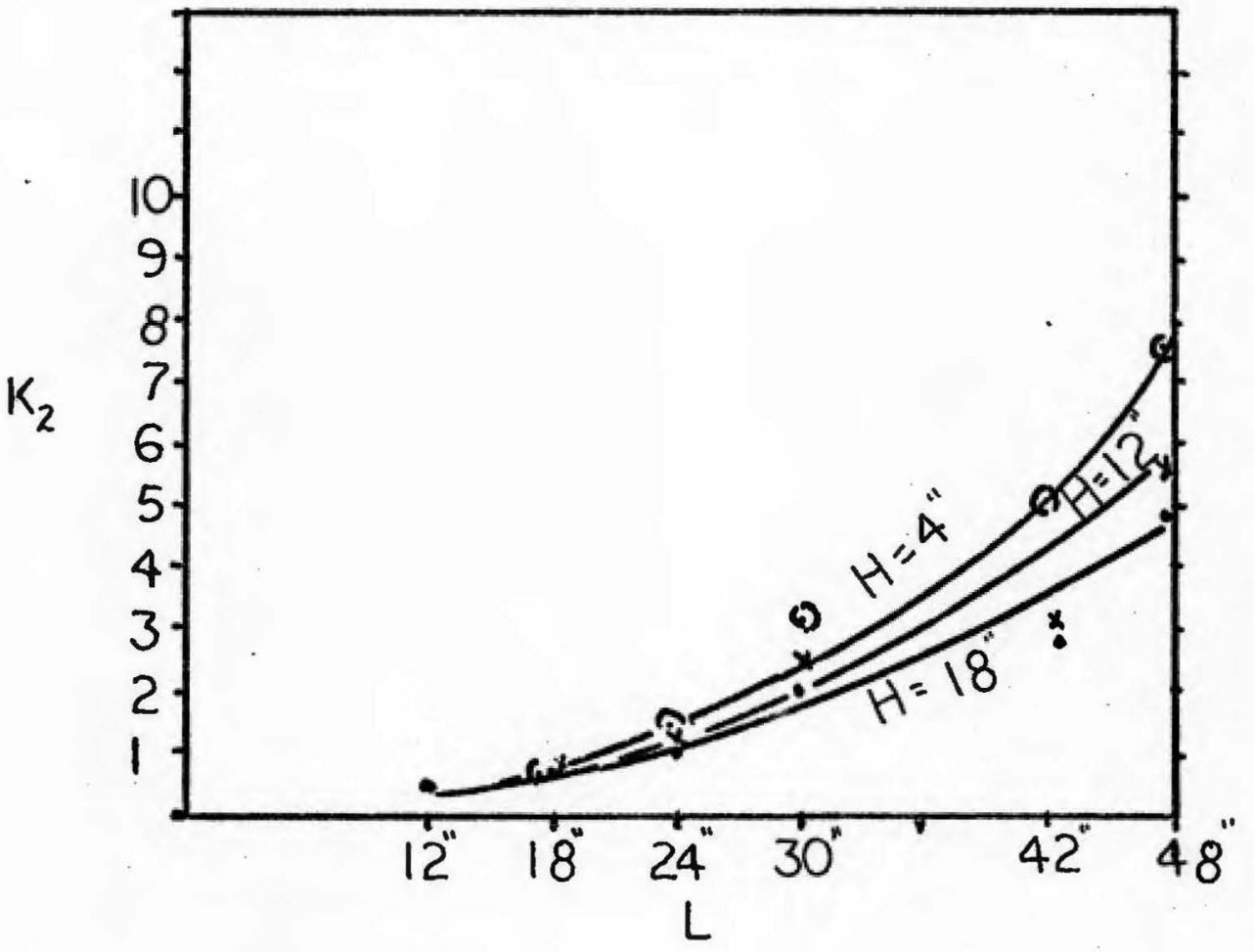

Figure 26. $\mathrm{K}_{2}$ expressed as a function of position for $12^{\prime \prime} \times 20^{\prime \prime}$ plate at $750^{\circ} \mathrm{F}$. 


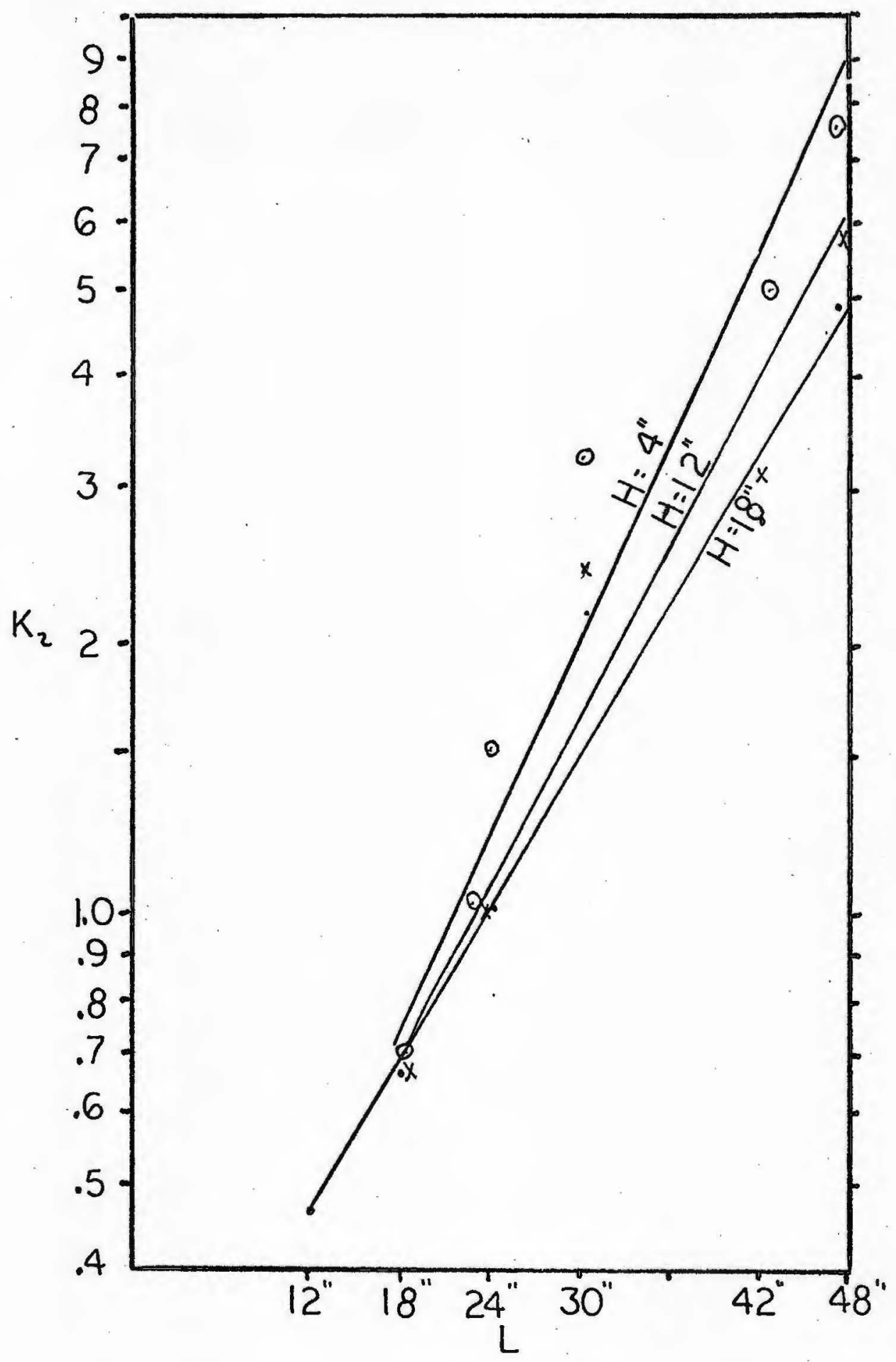

Figure $27 . \mathrm{K}_{2}$ vs $\mathrm{L}, \mathrm{H}$ for a $12^{\prime \prime} \times 20^{\prime \prime}$ plate at $750^{\circ} \mathrm{F}$. 


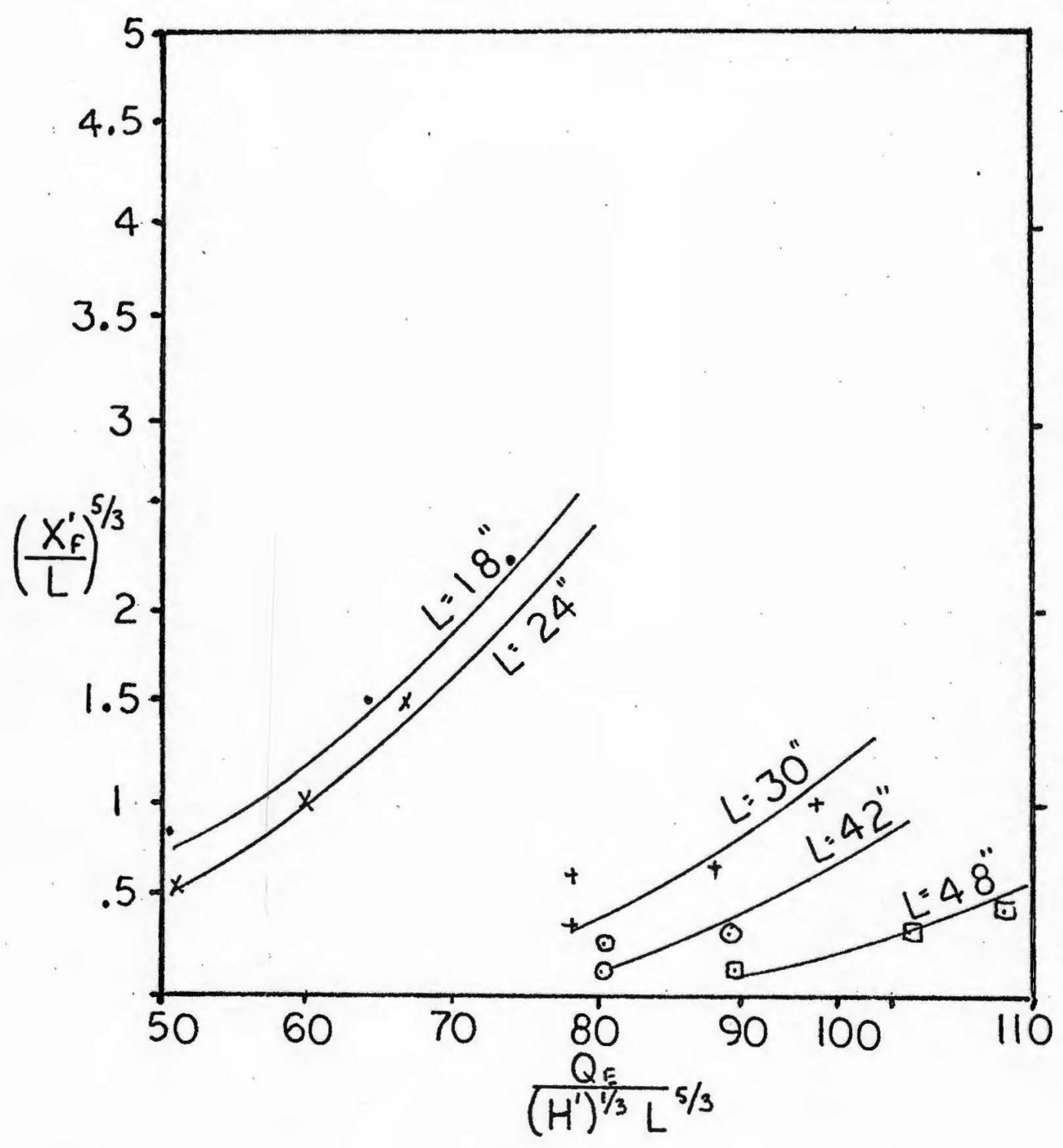

Figure 28. $Q_{E} /\left[\left(H^{\prime}\right)^{1 / 3}(L)^{5 / 3}\right]$ vs $\left(x_{f}^{\prime} / L\right)^{5 / 3}$ for a $12^{\prime \prime} \times 20^{\prime \prime}$ plate tested at $750^{\circ} \mathrm{F}$. 
The results correlating exhaust flow to plume flow are given in Figures 24 to 28; the supporting data is tabulated in Append1x G, Tables XII through XVI.

It is noted in Table XII that the required exhaust flow increases with both distance and height as predicted by the theory. Within the experimental range, exhaust volumes extended to $3,520 \mathrm{cfm}$ at a 48 " distance and $18^{\prime \prime}$ height. This compares with a value of $3,000 \mathrm{cfm}$ noted when the plate was tested at $550^{\circ} \mathrm{F}$ at the same location.

A ratio of exhaust to plume volume, $Q_{E} / Q_{p}$, is shown in Figure 24; supporting data is given in Table XIII. Ranges of values from 1.4 to 1.8 and 2.0 to 3.0 are noted for corresponding distances of $18^{\prime \prime}$ and $24 "$. However, as the distance exceeds $24^{\prime \prime}$, the $Q_{E} / Q_{p}$ ratio becomes height sensitive as was also noted in the results of the plate tested at $550^{\circ} \mathrm{F}$. It is seen in Figure 24 that three curves result corresponding to heights of $4^{\prime \prime}, 12^{\prime \prime}$ and $18^{\prime \prime}$, and that the decrease of $Q_{E} / Q_{p}$ with increase in height becomes more pronounced as distance increases. The same data is plotted to logarithmic scale in Figure 25 and the results are fitted to straight lines. It is noted that within the experimental range, exhaust flow increases up to 14-16 times the corresponding plume flow at a $48^{\prime \prime}$ distance and 4" height. Corresponding values of $Q_{E} / Q_{p}$ at heights of 12 " and $18^{\prime \prime}$ drop to 12.5 and 10.5 respectively illustrating the effect of increased height.

Required exhaust momentums are given in Appendix G, Table XIV. Calculated plume momentums are noted in Appendix E. The ratio of exhaust momentum to plume momentum, $\mathrm{K}_{2}$, is plotted in Figure 26; the data is tabulated in Appendix G, Table XV. It is noted that at distances of 12", 
18 " and 24", values of $\mathrm{K}_{2}$ equal $0.5,0.7$ and 1.0 respectively. At a distance of $30^{\prime \prime}$, values of $\mathrm{K}_{2}$ jump to a range of 3.0 to 2.0 as height increases from $4 "$ to $18^{\prime \prime}$. The explanation for this jump in the data is similar to that noted for the plate when tested at $550^{\circ} \mathrm{F}$. It is seen in Figure 26 that within the experimental range, values of $\mathrm{K}_{2}$ extend to 7.6 at a 48" distance and 4" height with values at 12 " and 18 " decreasing to 6.0 and 4.75 , respectively. The data is plotted to logarithmic scale in Figure 27 and it is seen that the data is represented by straight lines, one for each of the three heights. The significance of this correlation is that it appears the data can be extrapolated, with some degree of risk to distances not covered by this experiment.

A correlation of the data using the technique developed by Kuz'mina is illustrated in Figure 28; the data is referenced in Appendix G, Table XVI. It is noted that a loose family of curves describes the data and a new curve is generated at each new distance, $L$. This result is comparable to that found for the plate when tested at $550^{\circ} \mathrm{F}$ and contrary to that found by Kuz'mina. Thus, it appears from the above results that this technique does not properly describe the exhaust-plume interaction by a single curve as suggested by Figure 9 . 



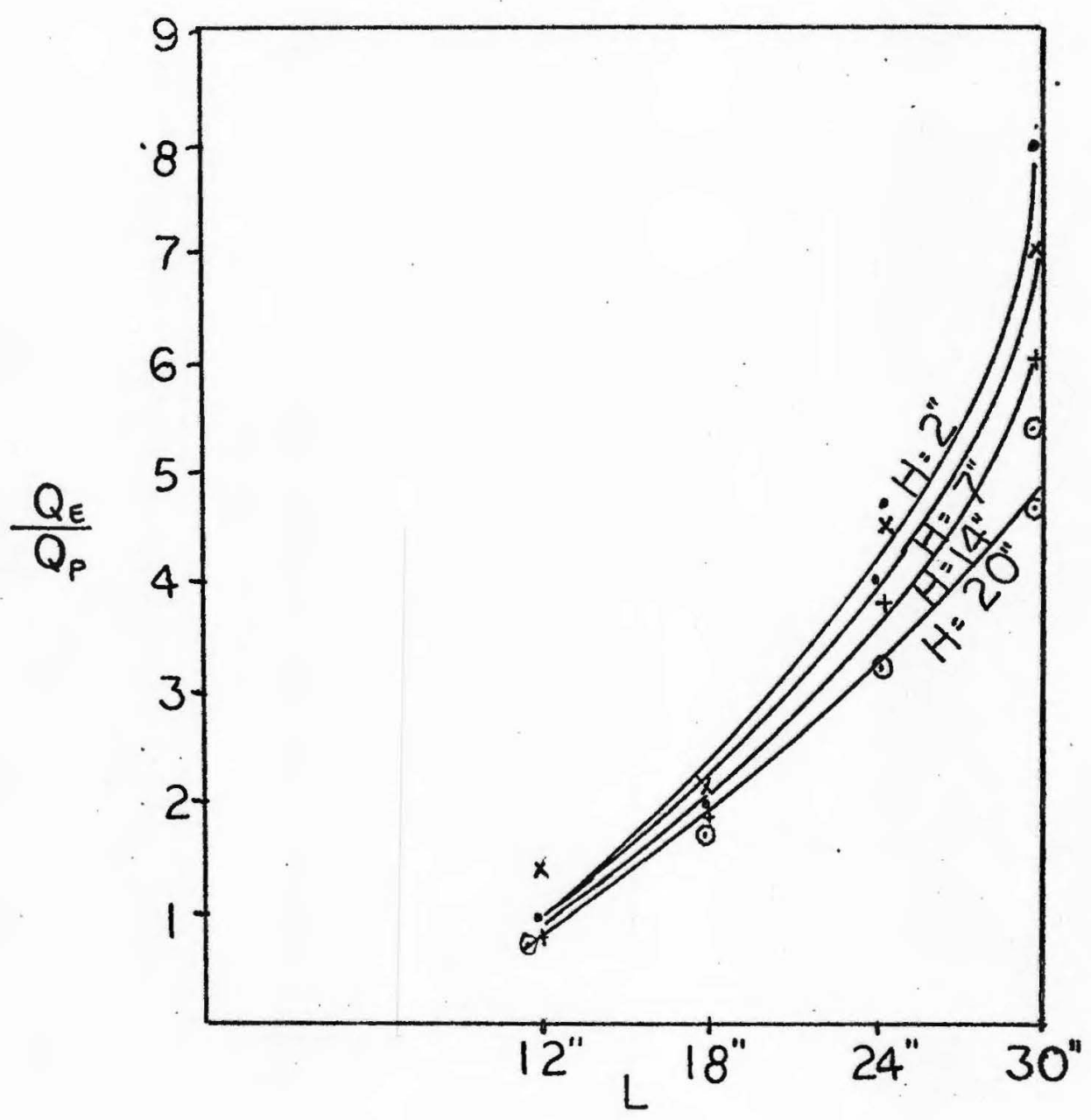

Figure 29. Relationship of $\mathrm{Q}_{\mathrm{E}} / \mathrm{Q}_{\mathrm{p}}$ to $\mathrm{L}, \mathrm{H}$ for an $8^{\prime \prime} \times 10^{\prime \prime}$ plate at $615^{\circ} \mathrm{F}$. 


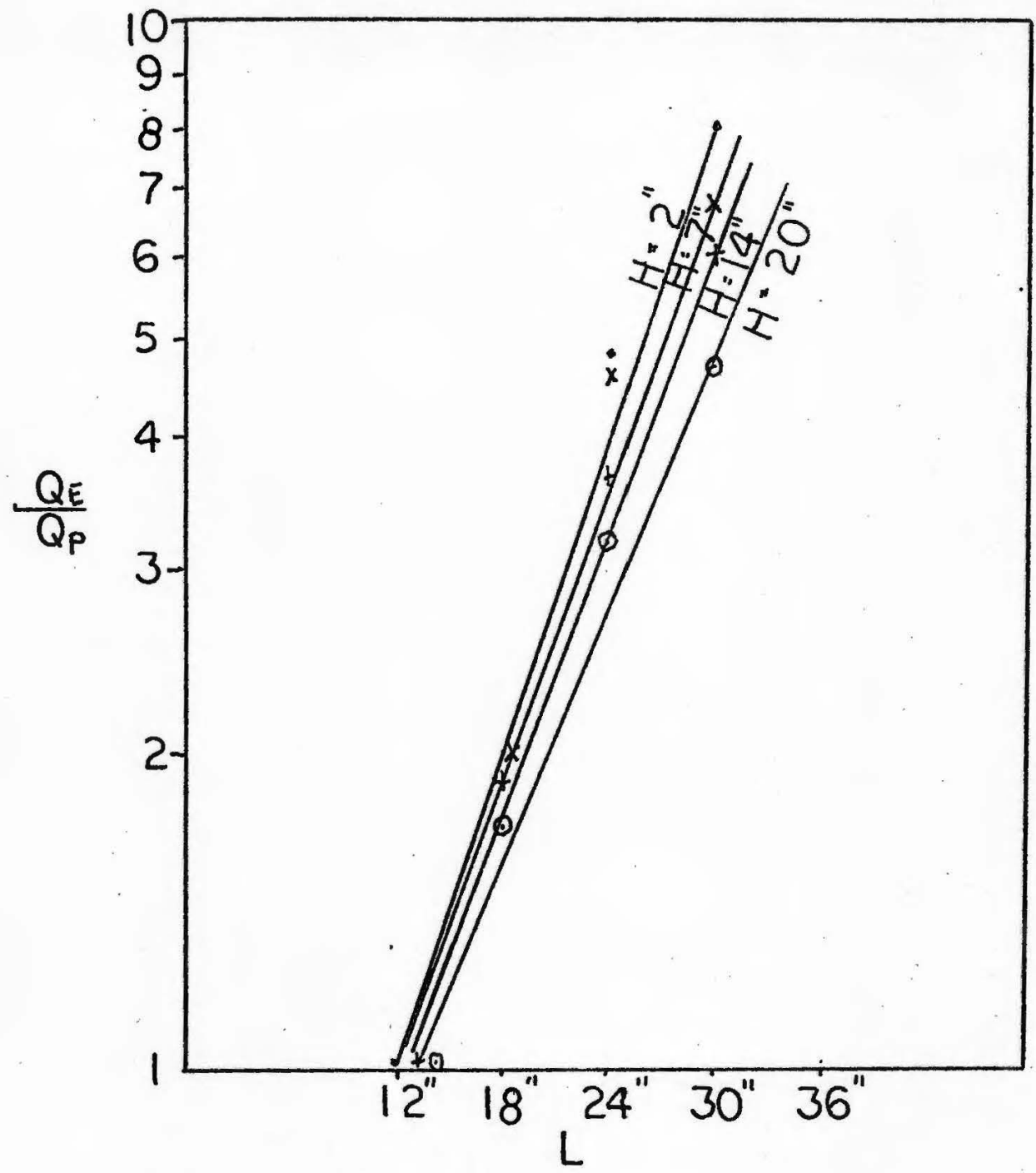

Figure 30. $Q_{E} / Q_{p}$ vs $L, H$ for an $8 " x 10^{\prime \prime}$ plate at $615^{\circ} \mathrm{F}$. 


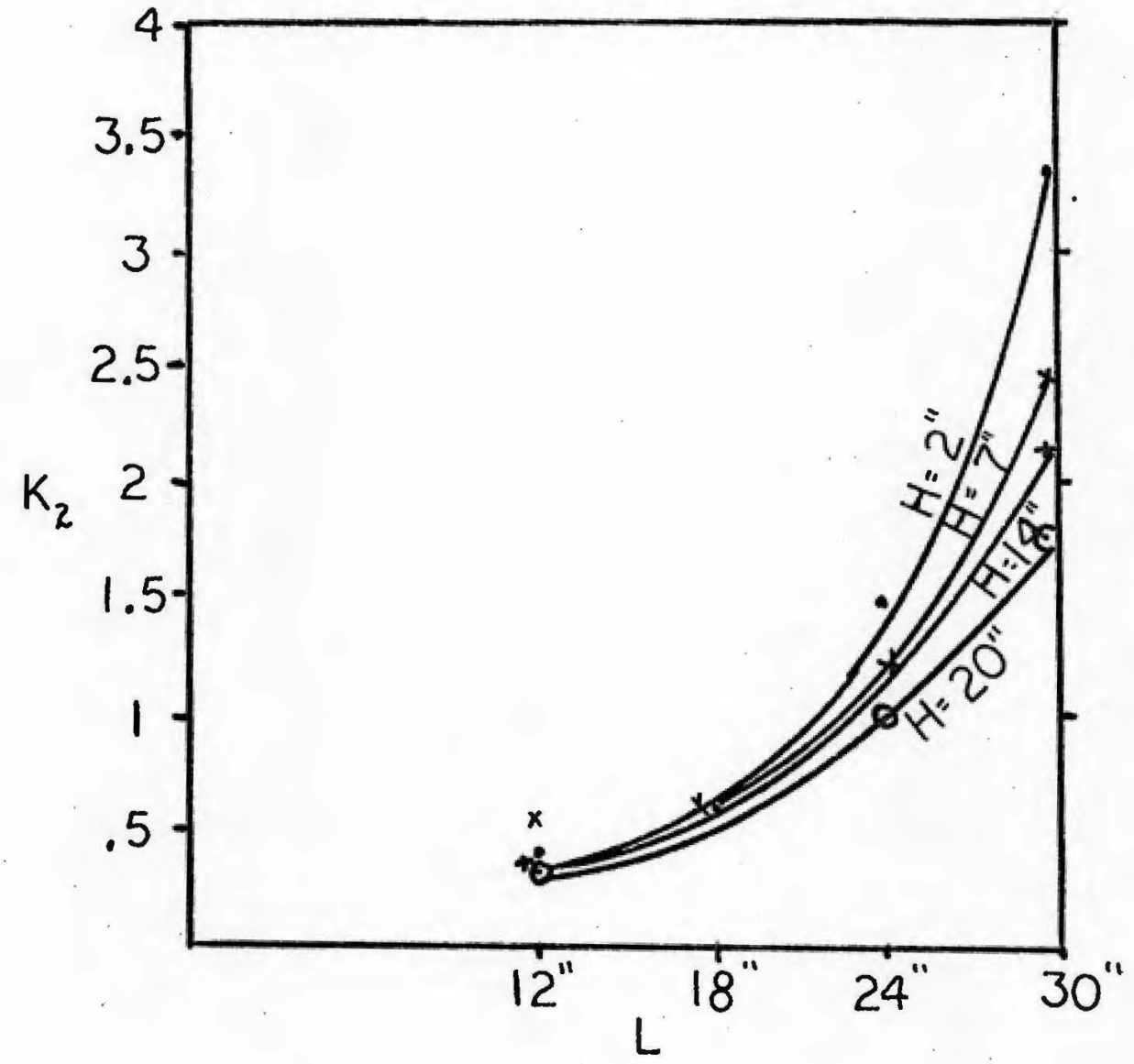

Figure 31. $K_{2}$ expressed as a function of position for an $8^{\prime \prime} \times 10^{\prime \prime}$ plate at $615^{\circ} \mathrm{F}$. 


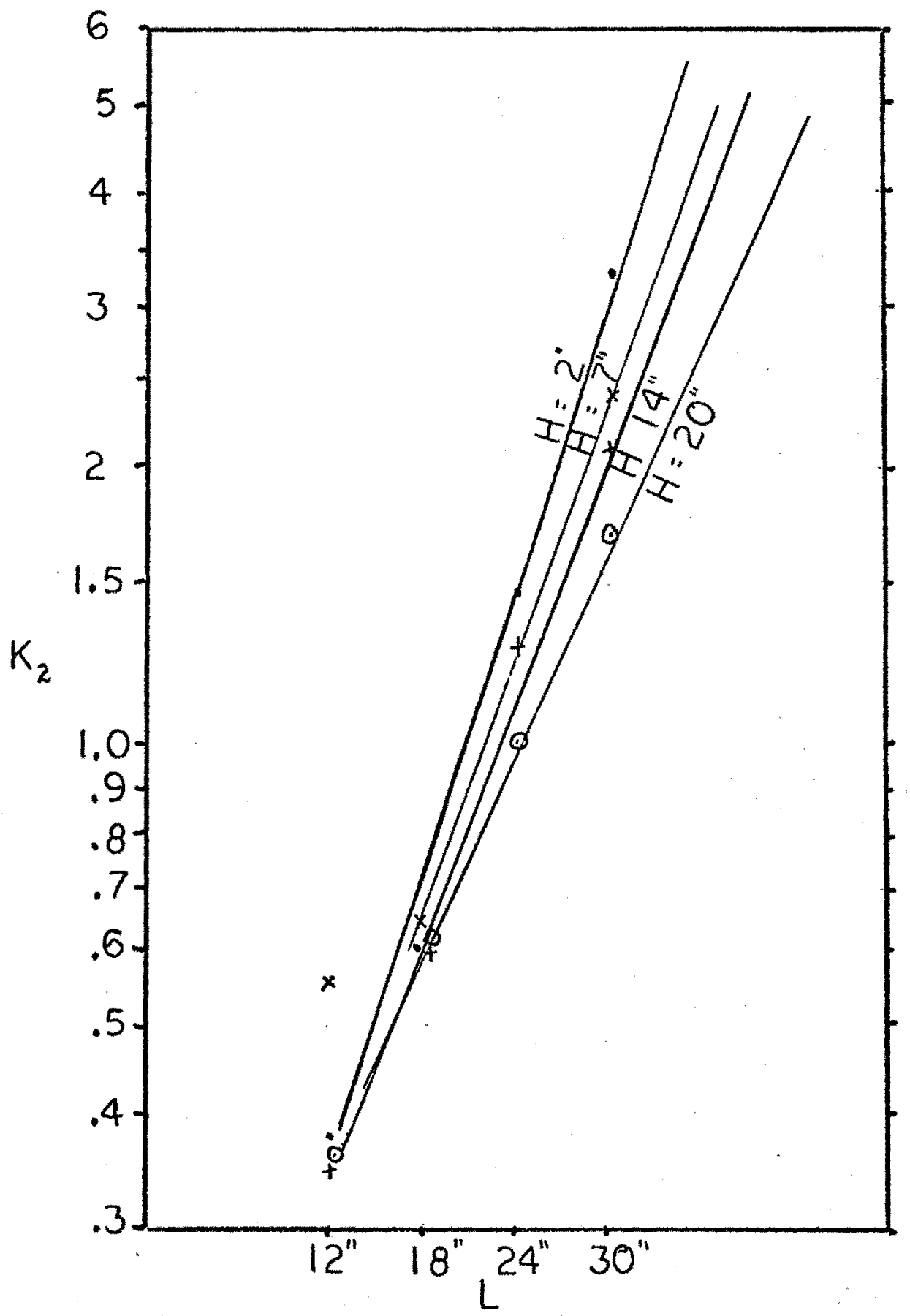

Figure $32 . \mathrm{K}_{2}$ vs $\mathrm{L}, \mathrm{H}$ for an $8^{\prime \prime} \times 10^{\prime \prime}$ plate at $615^{\circ} \mathrm{F}$. 


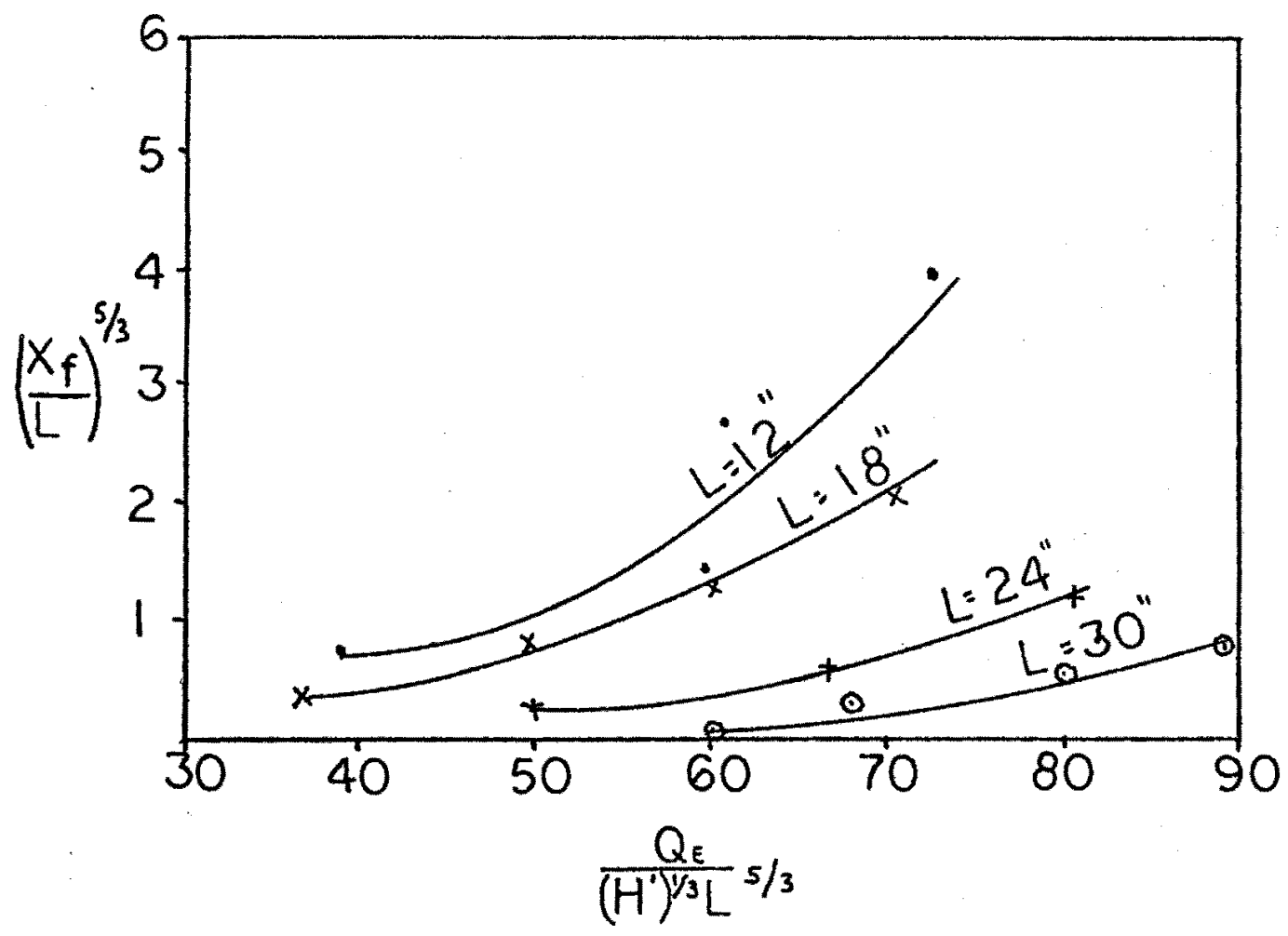

Figure 33. $Q_{E} /\left[\left(H^{\prime}\right)^{1 / 3}(L)^{5 / 3}\right]$ vs $\left(x_{f}^{\prime} / L\right)^{5 / 3}$ for an $8^{\prime \prime} \times 10^{\prime \prime}$ plate tested at $615^{\circ} \mathrm{F}$. 
The results correlating exhaust flow to plume flow are found in Figures 29 to 33; supporting data is referenced in Appendix H, Tables XVII to XXI. It is reemphasized that the procedure used in testing the $8^{\prime \prime} \times 10^{\prime \prime}$ plate differed from that used for the $12^{\prime \prime} \times 20^{\prime \prime}$ plate. Namely, exhaust hood openings were adjusted at each plate height to match the calculated plume diameter, $D_{p}$. In addition plate heights of 2 ", $7 ", 14$ ", and $20^{\prime \prime}$ were tested at distances of $12^{\prime \prime}, 18^{\prime \prime}, 24^{\prime \prime}$, and $30^{\prime \prime}$.

Required exhaust flows are noted in Table XVII and a plot of $Q_{E} / Q_{p}$ as a function of distance and height is noted in Figure 29. The supportive data is noted in Appendix $\mathrm{H}$, Table XVIII. At a distance of 12 "it is noted that $Q_{E} / Q_{p}$ centered around a value of 1.0 (the value of 1.3 noted at the $7^{\prime \prime}$ height was disregarded). At an $18^{\prime \prime}$ distance the values rose to a range of 1.7 to 2.1 . Beyond this range, the values rose rapid1y and dropped off noticeably with increasing height as seen in Figure 29. The same data is plotted in Figure 30 to logarithmic scale, the curves being transformed to straight lines. Within the experimental ranges, the ratio, $\mathrm{Q}_{\mathrm{E}} / \mathrm{Q}_{\mathrm{p}}$, increased to a maximum value of 8 at a $30^{\prime \prime}$ distance and $2^{\prime \prime}$ height; corresponding values at $7^{\prime \prime}, 14^{\prime \prime}$ and $20^{\prime \prime}$ heights were found to be $6.8,6.0$ and 4.6 , respectively.

Exhaust momentums are referenced in Table XIX with the corresponding plume momentums given in Appendix E. More importantly, values of $\mathrm{K}_{2}$ are referenced in Table $X X$ and plotted in Figure 31 . It is seen that values of $k_{2}$ equal 0.4 to 0.5 and 0.6 to 0.65 at corresponding distances of $12^{\prime \prime}$ and $18^{\prime \prime}$. These values compare favorably to those noted for the $12^{\prime \prime} \times 20^{\prime \prime}$ plate at similar distances. However, at a $24^{\prime \prime}$ distance, the $\mathrm{K}_{2}$ values jump to a range of 1 to 1.5 depending on height. These results 
deviate from those obtained from the $12^{\prime \prime} \times 20^{\prime \prime}$ plate where $\mathrm{K}_{2}$ equals 1.0 regardless of height.

The proposed explanation of this discrepancy concerns boundary conditions and is illustrated in Figure 34. It is noted that the flange tips for a 10" hood opening extend to a $23^{\prime \prime}$ radius. It is remembered that in analyzing the $17^{\prime \prime}$ hood opening used for the $12^{\prime \prime} \times 20$ " plate, the flange tip extended to $26.5^{\prime \prime}$. Thus, for the $8^{\prime \prime} \times 10^{\prime \prime}$ plate at a $24^{\prime \prime}$ distance the velocity contours extend beyond the flanges and effect the velocity decay equation as well as the percentage of the exhaust intercepting the plume. It appears that this explanation accounts for the reason that $\mathrm{K}_{2}$ exceeds the expected value at $24^{\prime \prime}$, rather than at $30^{\prime \prime}$ as noted for the $12^{\prime \prime} \times 20^{\prime \prime}$ plate. Furthermore, as height in increased to $7^{\prime \prime}, 14^{\prime \prime}$ and $20^{\prime \prime}$, the hood opening is increased to 12", $15^{\prime \prime}$ and 17", respectively. At these larger heights, the larger hood openings tend to push the flange tips out, therefore reducing the above described boundary effect at a $24^{\prime \prime}$ distance. In fact, at a $20^{\prime \prime}$ height where the hood opening equals $17^{\prime \prime}$ the $\mathrm{K}_{2}$ value of 1 to 1.25 corresponds fairly well to those noted for the $12^{\prime \prime} \times 20^{\prime \prime}$ plate.

At a $30^{\prime \prime}$ distance the values decrease from 3.3 to 1.7 as height increases from $2^{\prime \prime}$ to $20^{\prime \prime}$. It is seen that these values are similar to those noted for the $12^{\prime \prime} \times 20^{\prime \prime}$ plate, it is therefore postulated that the data fits previous results we11, the exception noted at the 24 " distance, being a result of boundary effect.

The momentum ratios are plotted to logarithmic scale in Figure 32 , the curves being straightened to allow extrapolation of results (with some uncertainty) to an industrial scale for use in the fleld. 


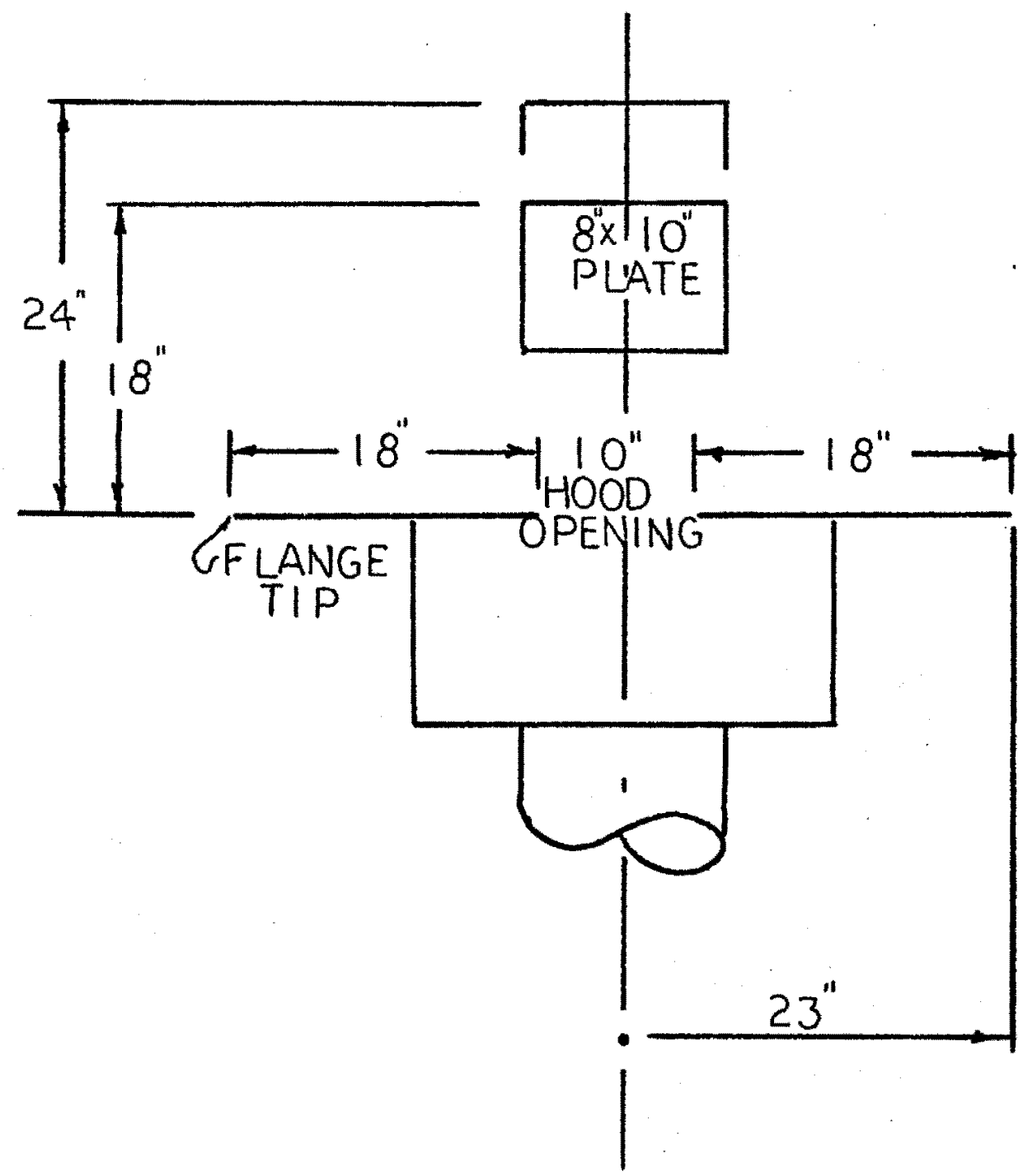

Figure 34. Effect of changing boundary conditions on exhaust velocity field as distance increases from 18" to $24^{\prime \prime}$ for the $8^{\prime \prime} \times 10^{\prime \prime}$ plate. 
A correlation of the Kuz'mina technique is given in Figure 33 and referenced in Appendix $\mathrm{H}$, Table XXI. Although a simflar family of curves results to those found for the $12^{\prime \prime} \times 20^{\prime \prime}$ plate, the curves fit the plotted data much better than in previous results. Still the results conflict with those obtained by Kuz'mina. 
E. APPLICATION OF EXPERIMENTAL RESULTS TO EXISTING SIDE DRAFT HOOD VENTILATING A 48" DIAMETER LADLE OF MOLTEN STEEL 
TABLE VI

APPLICATION OF PLUME MOAENTUM THEORY TO EXISTING

SIDE DRAFT HOOD VENTILATIING A

48" DIAMETER LADLE OF

MOLTEN STEEL

Trial I

$\begin{array}{ll}\text { Source size, } \mathrm{D}_{\mathrm{s}} & 48 \text { inches } \\ \text { Source temperature, } \mathrm{T}_{\mathrm{s}} & 2,700^{\circ} \mathrm{F} \\ \text { Source distance, } \mathrm{L} & 6 \mathrm{ft} . \\ \text { Hood height, } \mathrm{H} & 6 \mathrm{ft} . \\ \text { P1ume volume, } \mathrm{Q}_{\mathrm{p}} & 6,205 \mathrm{cfm} \\ \text { P1ume momentum, } \mathrm{M}_{\mathrm{p}} & 101,464 \\ \text { Exhaust volume, } \mathrm{Q}_{\mathrm{E}} & 40,000 \mathrm{cfm} \\ \text { Exhaust momentum, ME } & 310,880 \\ \text { K } & 3.06 \\ \text { EFFECTIVENESS - SOME FUME LEAKAGE }\end{array}$

Trial II

$\begin{array}{ll}\text { Source size, } D_{s} & 48 \text { inches } \\ \text { Source temperature, } T_{s} & 2,700^{\circ} \mathrm{F} \\ \text { Source distance, } L & 4 \mathrm{ft} . \\ \text { Source height, } \mathrm{H} & 6 \mathrm{ft} . \\ \text { Plume volume, } Q_{p} & 6,205 \mathrm{cfm} \\ \text { Plume momentum, } M_{p} & 101,464 \\ \text { Exhaust volume, } Q_{E} & 40,000 \mathrm{cfm} \\ \text { Exhaust momentum, } M_{E} & 645,161 \\ \text { K } 2 & 6.36 \\ \text { EFFECTIVENESS - GOOD COLLECTION }\end{array}$


The experimental results describing momentum theory and relating $\mathrm{K}_{2}$ as a function of distance were applied to an existing side draft hood ventilating a 48" diameter foundry ladle of molten steel. Exhaust and plume momentums are calculated in Appendix I and resulting values of $\mathrm{K}_{2}$ are summarized in Table VI for ladle distances of $4^{\prime}-0^{\prime \prime}$ and $6^{\prime}-0^{\prime \prime}$.

It is noted that when this distance from hood to the outer edge of the ladle reaches $6^{\prime}-0^{\prime \prime}, K_{2}$ is estimated at 3.06 . The height from ladle surface to hood center line is $6^{\prime}-0^{\prime \prime}$ and no experimental data was generated for these coordinates. Sti11, values of $\mathrm{K}_{2}$ can be extrapolated to a $6^{\prime}-0$ " distance at the $18^{\prime \prime}$ height using Figures 21,27 or 32 and a $\mathrm{K}_{2}$ value of 20 results. Certainly $\mathrm{K}_{2}$ at the $6^{\prime}-0^{\prime \prime}$ height would be lower than 20, but it is estimated that the value would be well above 3.06 . Field observations of the above set up verify the suspected fume leakage; the low value of exhaust to plume momentum, $k_{2}$ provides a clue for predicting this result.

With the ladle relocated adjacent to the hood, the distance was reduced to $4^{\prime}-0^{\prime \prime}$, the height remained the same. However, the calculated exhaust momentum increased dramatically with a $\mathrm{K}_{2}$ value of 6.36 resulting. Experimental values of $k_{2}$ at the $4^{\prime}-0^{\prime \prime}$ distance range from 8 at a $4^{\prime \prime}$ height to 4 at an $18^{\prime \prime}$ height. No results were obtained for the 6'-0" height, but the result should be somewhat less than 4 . It is remembered that the results achieved in the experiments were based on marginal containment by the hood. By comparing a calculated $K_{2}$ value of 6.36 to an expected required value of less than 4, the exhaust would be expected to provide strong containment of the plume. Field observations substantiated expectations and the fume was observed to take a straight, direct path to 
the hood.

The above results appear to add credability to experimental data and the values of $\mathrm{K}_{2}$ found to provide good fume control appear to be within the expected range. However, the results are not definitive. enough to narrow down this range for direct comparison. Experimental testing at heights up to $6^{\prime}-0^{\prime \prime}$ would be required for a better comparison. As a contrast to the above analysis and results, the same ladle was analyzed at the $4^{\prime}-0^{\prime \prime}$ distance using the Kuz'mina technique and Figure 9. As noted in Appendix I, this theory predicted a required exhaust of $14,195 \mathrm{cfm}$, a value which understated the observed required exhaust by a factor of 2.8. Thus, the technique appears unreliable for use in an industrial scale, as well as experimentally. 


\section{CHAPTER VII}

\section{SUMMARY}

In summarizing the study it is recalled that the objective was to relate the exhaust requirements to basic, measurable plume thermodynamics. The ensuing theory, developed from physical observations, related respective momentums of plume and exhaust

$$
\rho_{p} Q_{E T} V_{E}=K_{2} \rho_{p} Q_{p} V_{p}
$$

where momentum was defined as the product of mass flow and velocity. It was recognized that $\mathrm{K}_{2}$ would vary with position and a second objective was to develop curves relating $\mathrm{K}_{2}$ to distance under varying conditions. In evaluating tests run on the $12^{\prime \prime} \times 20^{\prime \prime}$ plate at $550^{\circ} \mathrm{F}$ and $750^{\circ} \mathrm{F}$, the curves relating $\mathrm{K}_{2}$ to position, Figure 20 and Figure 26, can be compared and it is noted that $\mathrm{K}_{2}$ values correlate closely at corresponding position coordinates. For both tests, $K_{2}$ values of $0.5,0.7$ and 1.0 were found at $12^{\prime \prime}, 18^{\prime \prime}$ and $24^{\prime \prime}$ distances. These values appeared to be solely a function of position and as predicted, $\mathrm{K}_{2}$ was found to be a direct function of distance but not height. At distances beyond 24 ", $\mathrm{K}_{2}$ exceeded expected values and decreased with increasing height at a given distance. Thus for the $550^{\circ} \mathrm{F}$ test at a $30^{\prime \prime}$ distance, values dropped from 3.24 to 1.74 as height increased from $4^{\prime \prime}$ to $18^{\prime \prime}$. For the $750^{\circ} \mathrm{F}$ test, values of $\mathrm{K}_{2}$ decreased from 3.3 to 2.15 as height increased from $4^{\prime \prime}$ to $18^{\prime \prime}$. Although these values exceeded the expected value of 1.25 , they were consistent in each test. Values at a $42^{\prime \prime}$ distance ranged from 6.5 to 3 
for the test at $550^{\circ} \mathrm{F}$ and 8 to 2.7 for the test at $750^{\circ} \mathrm{F}$, as height increased from $4 "$ to $18^{\prime \prime}$ in each case. At the $48^{\prime \prime}$ distance these values ranged from 8.0 to 3.5 and 7.6 to 4.75 over the same height and temperature ranges. Although $\mathrm{K}_{2}$ exceeded expected values at distances greater than 30", thus discrepancy was explained by noting a changing boundary condition at the $30^{\prime \prime}$ distance.

In comparing the analysis between the $8^{\prime \prime} \times 10^{\prime \prime}$ and $12^{\prime \prime} \times 20^{\prime \prime}$ plates, it is noted that both plate size and temperature were varied simultaneously, yet comparable $\mathrm{K}_{2}$ values resulted at similar position coordinates where boundary conditions were comparable. The $\mathrm{K}_{2}$ values for the $8^{\prime \prime} \times 10^{\prime \prime}$ plate at $615^{\circ} \mathrm{F}$ centered around 0.4 to 0.5 and 0.6 to 0.65 at $12^{\prime \prime}$ and $18^{\prime \prime}$ distances, respectively. These values compare well to those noted for the $12^{\prime \prime} \times 20^{\prime \prime}$ plate, however, values at the $24^{\prime \prime}$ distance vary from 1.5 to 1.0 as opposed to a constant value of 1.0 noted for the $12 " \times 20$ " plate. The difference in results was explained by noting different boundary conditions in the respective tests. Values at the 30 " distance varied from 3.3 to 1.7 , a good correlation to those noted for the $12^{\prime \prime} \times 20^{\prime \prime}$ plate.

To summarize the experimental results, tests run at three temperatures and two plate sizes yielded consistent curves relating $\mathrm{K}_{2}$ to position, thus, verifying the proposed momentum theory over the ranges tested.

In evaluating the data using the technique developed by Kuz'mina, resulting curves Figure 22, Figure 28 and Figure 33 contradicted published results as given in Figure 9. Rather than one curve describing the exhaust-plume interaction, a family of curves resulted, a new curve 
for each new distance tested.

Curves relating $\mathrm{K}_{2}$ to position were plotted to logarithmic scale, and thus transformed into straight lines which could be cautiously extrapolated to areas outside the experimental range.

The practical significance of this technique was shown in analyzing the foundry ladle hood where locational coordinates fell outside the experimental range. Strong, effective plume capture was observed at an exhaust of $40,000 \mathrm{cfm}$ and $\mathrm{K}_{2}$ value of 6.36 , which fell within the expected range noted by extrapolating the curves. In analyzing the same data using the Kuz"mina technique, a predicted, required exhaust of $14.195 \mathrm{cfm}$ resulted; thus, understating the observed, required exhaust by a factor of 2.8 . 
CHAPTER VIII

CONCLUSION

Tests and field application have shown considerable correlation between exhaust and plume momentums. Variation of plate size, temperature and position resulted in predictable data at relatively close distances; however, $\mathrm{K}_{2}$ became increasingly dependent on hood height as distance increased. This trend is not completely explained and would be an important step for further study. The effect of boundary conditions played a critical role in utilizing the theory and evaluating $\mathrm{K}_{2}$; further evaluation using different hood sizes, shapes and limiting boundary planes is needed to evaluate apparent explanations of discrepancies in data. To better correlate test data to industrial applications, larger hoods and sources and higher source temperatures need to be tested and evaluated to verify conditions which would require extrapolation of present data. In short the above work would test assumptions made in this study and test the analyses of discrepancies.

In conclusion, the curves developed in this paper are applicable within the range of testing. It is remembered that for consistency, $k_{2}$ was evaluated for exhaust values which barely captured the plume. In practice, a safety factor of $15 \%$ to $25 \%$ is recommended to insure good ventilation under normal conditions. 
List of References

1. Engineering Manual for the Control of in Plant Environment in Foundries, American Foundrymen's Society, 1956.

2. Air Pollution Engineering Manual, U.S. Department of Health, Education and Welfare, Public Health Service Publication No. 999-AP-40, 1967.

3. Industrial Ventilation, A Manual of Recommended Practice, 11th Ed., American Conference of Governmental Industrial Hygienists, 1970.

4. Hemeon, W.C.L., Plant Process Ventilation, 2nd Ed., Industrial Press, 1963.

5. ASHRAE Guide and Data Book Systems, American Society of Heating, Refrigerating and Air Conditioning Engineers, 1970.

6. Baturin, V.V., Fundamenta1s of Industrial Ventilation, 3rd Ed., Pergamon Press, 1972.

7. Kreith, Frank, Principles of Heat Transfer, 2nd Ed., International Textbook Co., 1968.

8. Baumeister, Theodore and Marks, Lionel S., Standard Handbook for Mechanical Engineers, 7th Ed., McGraw Hil1 Book Co., 1967.

9. Stanier, William, Plant Engineering Handbook, 2nd Ed., McGraw Hill Book Co., 1959. 
APPENDIX 
APPENDIX A

TEST EQUIPMENT LIST

\section{ITEM}

Test area

Exhaust hooding and ductwork

$10^{\prime \prime} \times 8^{\prime \prime}$ hot

plate

12 " $\times 20^{\prime \prime}$ hot plate

Pitot tube

Vane anemometer

Multi point

thermocouple

Smoke generator
DESCRIPTION

see Chapter IV

see Figure 14

see Chapter IV

Lindberg lab heater, $\mathrm{H}-2$ 115/230 volts

Dwyer mode1 400

slant tube manometer

4" Biram anemometer

8 blade vane -Low

speed, Davis

Instrument Mfg. Co.

Leeds and Northrup

speedomax 12 point

recording thermocouple

ammonia

hydrochloric acid

two ceramic dishes

\section{SOURCE}

Esco Corp.

Acme Metal Inc.,

Portland, Oregon

Esco Corp.

Portland State University

Esco Corp.

Portland State University

Esco Corp.

Portland State University 


\section{APPENDIX B}

TEMPERATURE CALIBRATION $8 " \mathrm{x} 10^{\prime \prime}$ PLATE

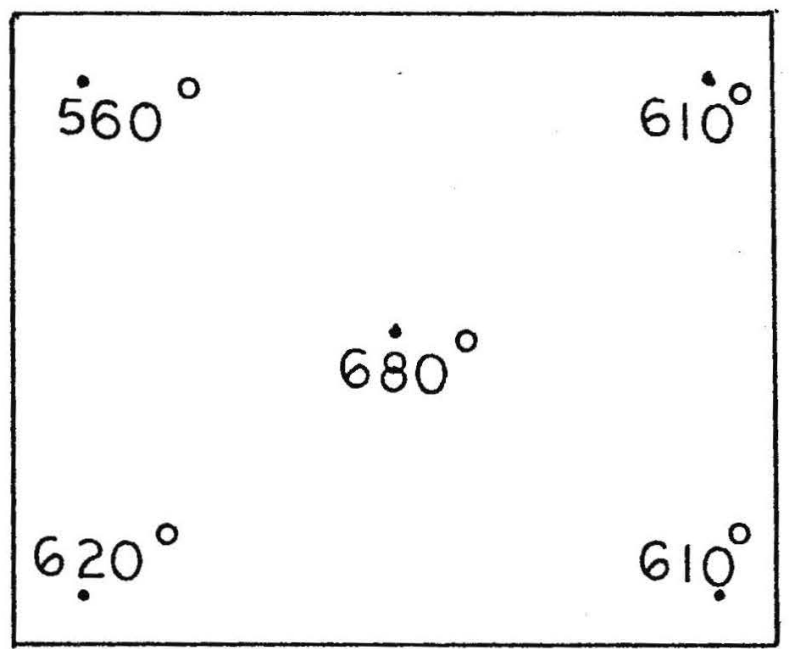

AVERAGE PLATE TEMPERATURE

$615^{\circ} \mathrm{F}$ 
$\therefore$ APPENDIX C

$\because$ TEMPERATURE CALIBRATION

$12 " x 20 "$ PLATE

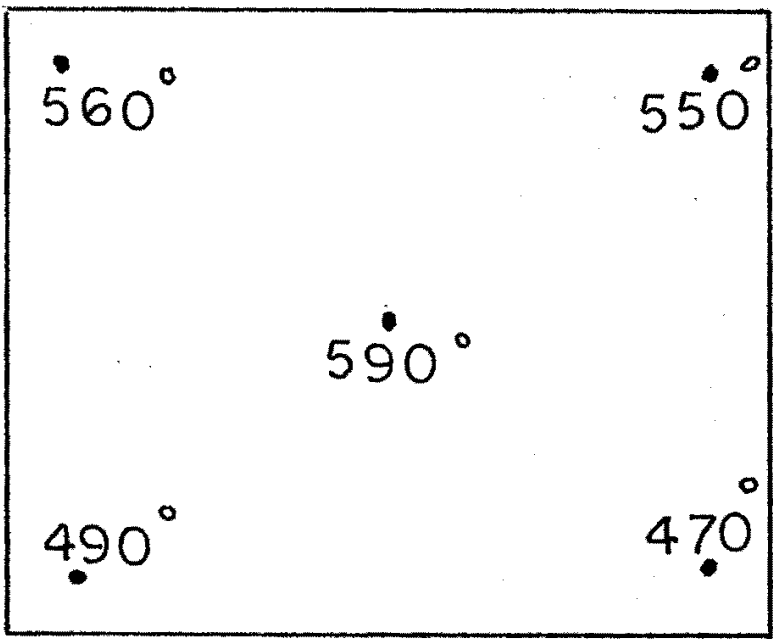

AVERAGE PLATE TEMPERATURE

$532^{\circ} \mathrm{F}$

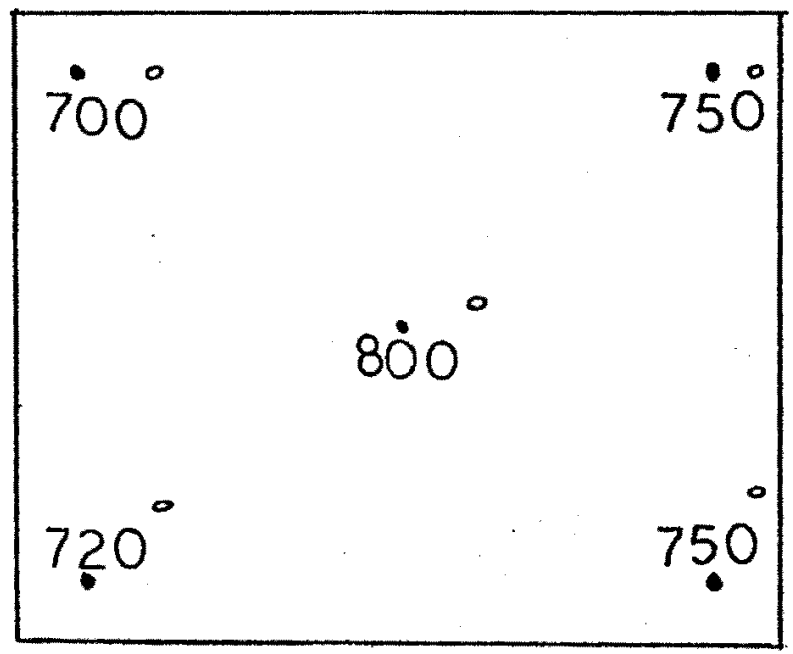

AVERAGE PLATE TEMPERATURE

$744^{\circ} \mathrm{F}$ 


\section{APPENDIX D}

DETERMINATION OF EXHAUST HOOD EQUATIONS 


\section{APPENDIX D}

DETERMINATION OF EXHAUST HOOD EQUATIONS

WITH SOURCE SET AT 2" HEIGHT

$$
\begin{aligned}
& \text { I } \quad Q_{E} \quad=1,163 \mathrm{cfm} \\
& \text { L } \quad=1 \mathrm{ft} \text {. } \\
& v_{E}=352 \mathrm{fpm} \\
& 1,163=K(352)(1)^{2} \\
& \mathrm{~K}=3.3 \\
& \text { II } Q_{E}=1,163 \mathrm{cfm} \\
& \mathrm{L}=1.5 \mathrm{ft} \text {. } \\
& \mathrm{v}_{\mathrm{E}}=167 \mathrm{fpm} \\
& 1,163=K(167)(2.25) \\
& \mathrm{K}=3.07 \\
& \text { III } Q_{E}=1,666 \mathrm{cfm} \\
& \mathrm{L}=2 \mathrm{ft} \text {. } \\
& \mathrm{v}_{\mathrm{E}}=135 \mathrm{fpm} \\
& 1,666=K(135)(4) \\
& \mathrm{K}=3.08
\end{aligned}
$$

Conclusion $\quad Q_{E}=3 V_{E} L^{2}$ 
DETERMINATION OF EXHAUST HOOD EQUATION WITH SOURCE SET AT 14" HEIGHT

I

$$
\begin{array}{ll}
\mathrm{Q}_{\mathrm{E}} & =2,342 \mathrm{cfm} \\
\mathrm{L} & =0.5 \mathrm{ft} . \\
\mathrm{V}_{\mathrm{E}} & =1,760 \mathrm{fpm} \\
2,342 & =\mathrm{K}(1,760)(0.25) \\
\mathrm{K} & =5.3
\end{array}
$$

II

$$
Q_{E} \quad=2,342 \mathrm{cfm}
$$$$
\mathrm{L} \quad=1 \mathrm{ft} .
$$$$
\mathrm{v}_{\mathrm{E}}=554 \mathrm{fpm}
$$

$$
2,342=K(554)(1)
$$$$
\mathrm{K}=4.22
$$

III

$$
\begin{aligned}
& Q_{E} \quad=2,342 \mathrm{cfm} \\
& \mathrm{L} \quad=1.67 \mathrm{ft} . \\
& \mathrm{v}_{\mathrm{E}}=192 \mathrm{fpm} \\
& 2,342=K(192)(2.79) \\
& \mathrm{K} \quad=4.37
\end{aligned}
$$

Conclusion $\quad Q_{E}=5 V_{E} L^{2}$ 
DETERMINATION OF EXHAUST HOOD EQUATION WITH SOURCE SET AT 20" HEIGHT

$$
\begin{aligned}
& \text { I } \quad \mathrm{Q}_{\mathrm{E}} \quad=2,506 \mathrm{cfm} \\
& \mathrm{L} \quad=0.5 \mathrm{ft} \text {. } \\
& \mathrm{v}_{\mathrm{E}}=1,654 \mathrm{fpm} \\
& 2,506=\mathrm{K}(1,654)(0.25) \\
& \mathrm{K}=6.06 \\
& \mathrm{Q}_{\mathrm{E}} \quad=2,506 \mathrm{cfm} \\
& \mathrm{L}=1 \mathrm{ft} \text {. } \\
& \mathrm{v}_{\mathrm{E}} \quad=534 \mathrm{fpm} \\
& 2,506=K(534)(1) \\
& \mathrm{K} \quad=4.69 \\
& \mathrm{Q}_{\mathrm{E}} \quad=2,506 \mathrm{cfm} \\
& \mathrm{L} \quad=1.67 \mathrm{ft} \text {. } \\
& \mathrm{V}_{\mathrm{E}} \quad=170 \mathrm{fpm} \\
& 2,506=K(170)(2.79) \\
& \mathrm{K}=5.28
\end{aligned}
$$

Conclusion

$$
\mathrm{Q}_{\mathrm{E}}=5.25 \mathrm{~V}_{\mathrm{E}} \mathrm{L}^{2}
$$


APPENDIX E

CALCULATED PLATE MOMENTUMS 


\section{APPENDIX E}

CALCULATED PLATE MOMENTUMS

$12^{\prime \prime} \times 20^{\prime \prime}$ PLATE T $T_{S}=550^{\circ} \mathrm{F}$

I $\quad \mathrm{H}=4$ inches $=.33 \mathrm{ft}$.

$\mathrm{z}=\left(2 \mathrm{D}_{\mathrm{s}}\right)^{1.138}=2.2 \mathrm{ft}$.

$x_{f}=2.533 \mathrm{ft}$.

$D_{p}=1 / 2 x_{f}{ }^{0.88}=1.13 \mathrm{ft} . \quad\left[A_{p}=(1.13)(1.66+0.13)\right]$

$A_{p}=2.03 \mathrm{ft} .^{2}$

$v_{p}=8\left(A_{s}\right)^{1 / 3} \Delta T^{5 / 12} / x_{f}{ }^{0.29}=87 \mathrm{fpm}$

$Q_{p}=(87 \mathrm{fpm})\left(2.03 \mathrm{ft} .^{2}\right)=178 \mathrm{cfm}$

$M_{p}=(.075)(178)(87)=1.163$

II $\mathrm{H}=11$ inches

$x_{f}=0.916+2.2=3.1 \mathrm{ft}$.

$D_{p}=0.5(3.1)^{0.88}=1.36 \mathrm{ft}$.

$A_{p}=2.74 \mathrm{ft}^{2}$

$v_{p}=82 \mathrm{fpm}$

$Q_{p}=(82)(2.74)=225 \mathrm{cfm}$

$M_{p}=(.075)(82)(225)=1,382$ 
III $\mathrm{H}=18$ inches

$$
\begin{aligned}
& x_{f}=3.7 \mathrm{ft} . \\
& A_{p}=3.53 \mathrm{sq} . \mathrm{ft} . \\
& v_{p}=78.3 \mathrm{fpm} \\
& Q_{p}=276 \mathrm{cfm} \\
& M_{p}=(.075)(276)(78.3)=1,615
\end{aligned}
$$

Temperatures achieved during test runs at $42^{\prime \prime}$ and $48^{\prime \prime}$ distances were higher than $550^{\circ} \mathrm{F}$; plate momentums were correspondingly adjusted to $1,345,1,623$ and 1,894 for heights of 4", 12" and 18". 
CALCULATED PLATE MOMENTUMS

$12 " \times 20^{\prime \prime}$ PLATE $\mathrm{T}_{S}=750^{\circ} \mathrm{F}$

I $\quad \mathrm{H}=4$ inches $=.33 \mathrm{ft}$.

$\mathrm{x}_{\mathrm{f}}=2.533 \mathrm{ft}$.

$D_{p}=1.13 \mathrm{ft}$.

$A_{p}=2.03 \mathrm{sq} . \mathrm{ft}$.

$v_{p}=8(1.18)(14.6) / 1.3=106 f p m$

$Q_{p}=106 \times 2.03=215 \mathrm{cfm}$

$M_{p}=(.075)(215)(106)=1,710$

II $\mathrm{H}=11$ inches

$x_{f}=3.116 \mathrm{ft}$.

$A_{p}=2.74$ sq. ft.

$v_{p}=8(1.18)(14.6) / 1.39=99 f \mathrm{fm}$

$Q_{p}=(99)(2.74)=271 \mathrm{cfm}$

$M_{p}=(.075)(271)(99)=2,012$

III $\mathrm{H}=18$ inches

$x_{f}=3.7 \mathrm{ft}$.

$A_{p}=3.53 \mathrm{sq} . \mathrm{ft}$.

$v_{p}=8(1.18)(14.6) / 1.46=94.4 \mathrm{fpm}$

$Q_{p}=(94.4)(3.53)=335 \mathrm{cfm}$

$M_{p}=(.075)(335)(94.4)=2,371$ 
CALCULATED PLATE MOMENTUMS

8" $x$ 10" PLATE, $\mathrm{T}_{S}=615^{\circ} \mathrm{F}$

I $\quad \mathrm{H}=2$ inches

$x_{f}=1.94 \mathrm{ft}$.

$A_{p}=0.93 \mathrm{sq} . \mathrm{ft}$.

$v_{p}=78.8 \mathrm{fpm}$

$Q_{p}=73.3 \mathrm{cfm}$

$M_{p}=(.075)(78.8)(73.3)=422$

III $\quad \mathrm{H}=7$ inches

$x_{f}=2.36 \mathrm{ft}$.

$A_{p}=1.29 \mathrm{sq} . \mathrm{ft}$.

$v_{p}=74.5 \mathrm{fpm}$

$Q_{p}=96 \mathrm{cfm}$

$M_{p}=537$

III $\mathrm{H}=14$ inches

IV $\mathrm{H}=20$ inches

$x_{f}=2.95 \mathrm{ft}$.

$x_{f}=3.53 \mathrm{ft}$.

$A_{p}=1.76$ sq.ft.

$A_{p}=2.39 \mathrm{sq} \cdot \mathrm{ft}$.

$v_{p}=68 \mathrm{fpm}$

$v_{p}=66 \mathrm{fpm}$

$Q_{p}=127 \mathrm{cfm}$

$Q_{p}=166 \mathrm{cfm}$

$M_{p}=658$

$\mathrm{M}_{\mathbf{p}}=821$ 
APPENDIX F

TABULAR RESULTS OF $12^{\prime \prime} \times 20^{\prime \prime}$ PLATE TESTED AT $550^{\circ} \mathrm{F}$ 


\section{TABLE VII}

EXHAUST VOLUME (CFM) EXPRESSED AS A FUNCTION

OF POSITION OF $12^{\prime \prime} \times 20^{\prime \prime}$ PLATE

$$
\text { AT } 550^{\circ} \mathrm{F}
$$

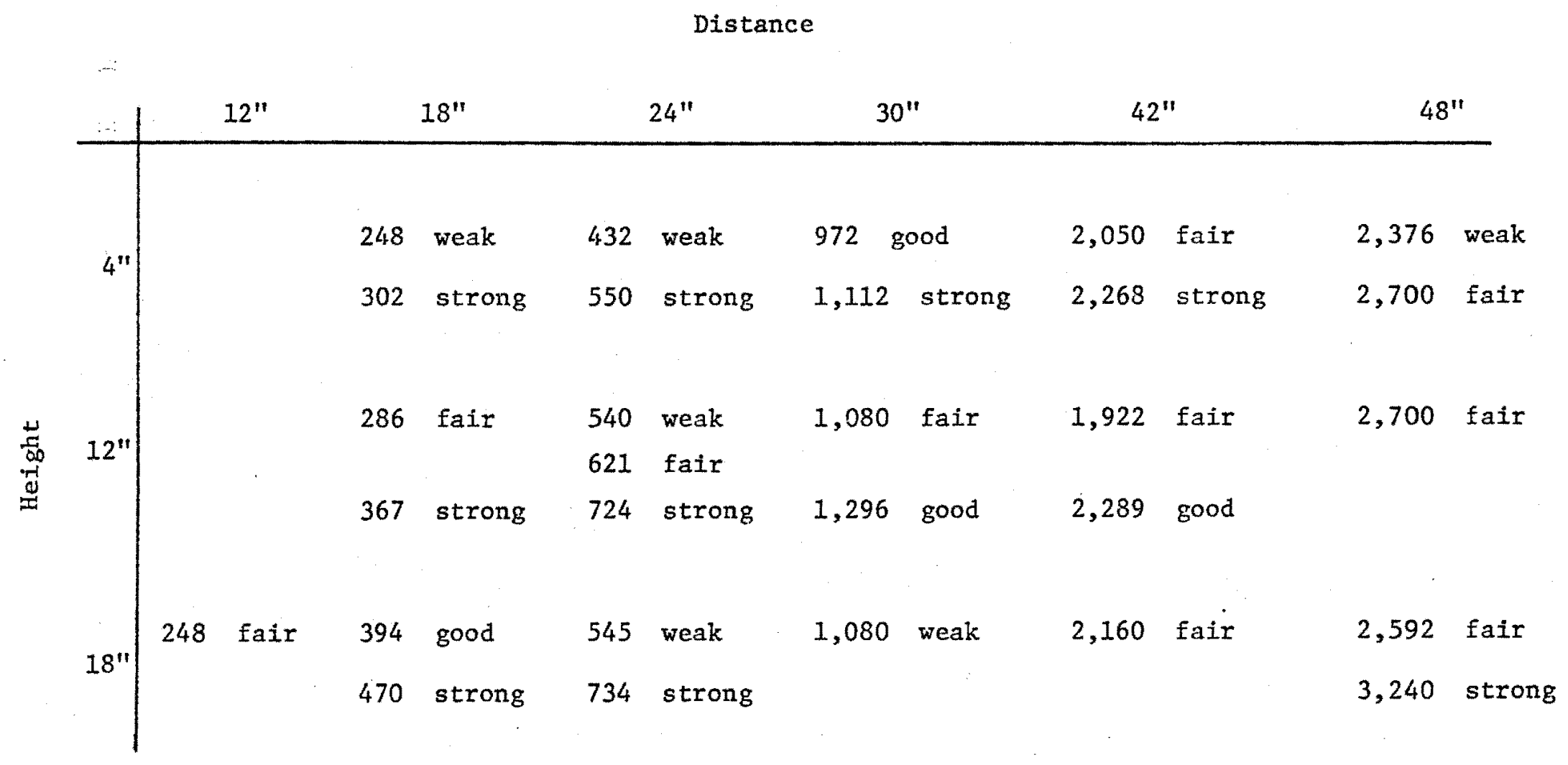




\section{TABLE VIII}

RATIO OF EXHAUST VOLUME TO PLUME VOLUME EXPRESSED

AS A FUNCTION OF POSITION

OF $12^{\prime \prime} \times 20^{\prime \prime}$ PLATE

AT $550^{\circ} \mathrm{F}$

\section{Distance}

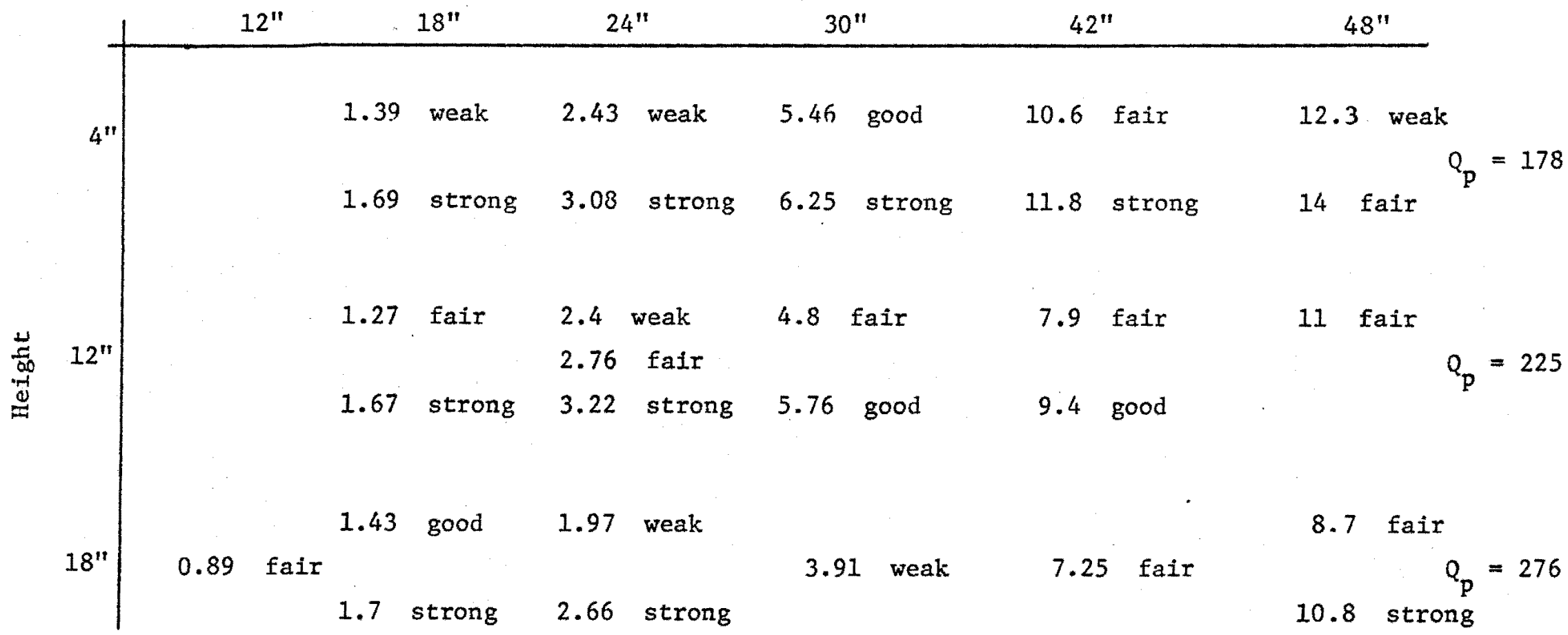


TABLE IX

EXHAUST MOMENTUM EXPRESSED AS A FUNCTION

OF POSITION OF 12" x $20^{\prime \prime}$ PLATE

AT $550^{\circ} \mathrm{F}$

Distance

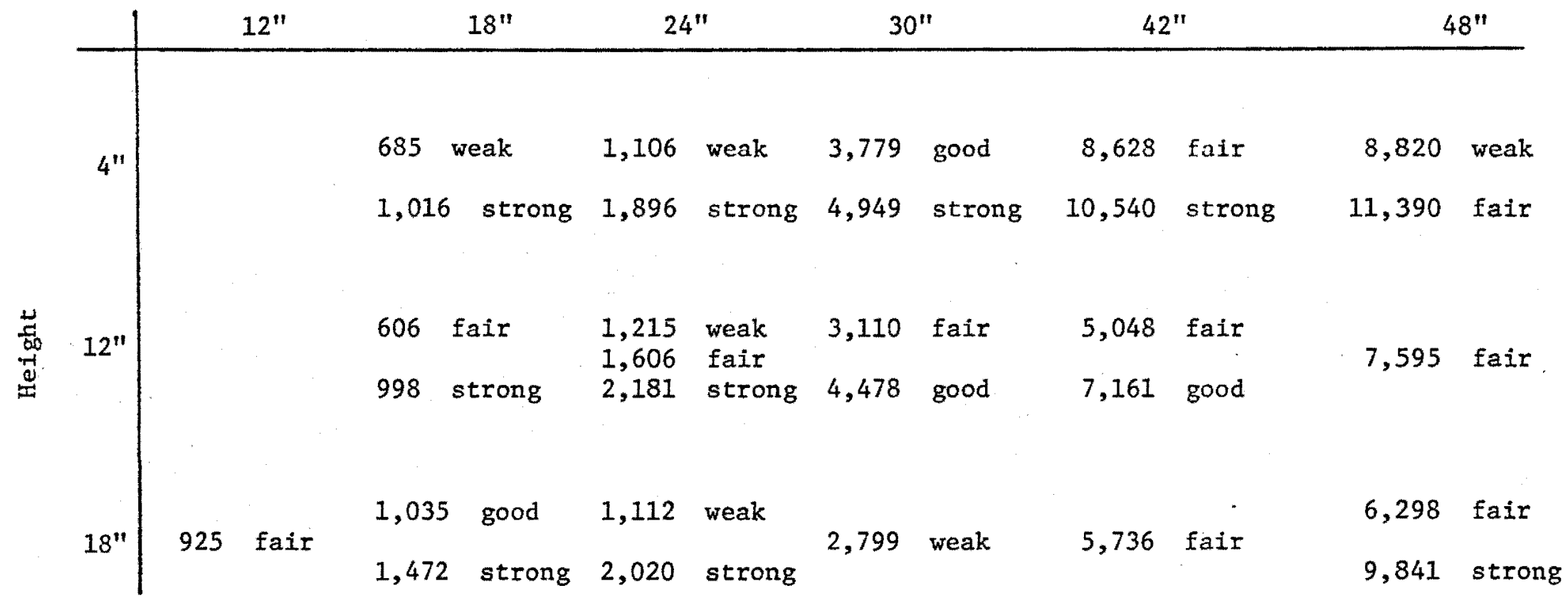


TABLE X

RATIO OF EXHAUST MOMENTUM TO PLUME MOMENTUM, $\mathrm{K}_{2}$,

EXPRESSED AS A FUNCTION OF POSITION

OF $12^{\prime \prime} \times 20^{\prime \prime}$ PLATE AT $550^{\circ} \mathrm{F}$

Distance

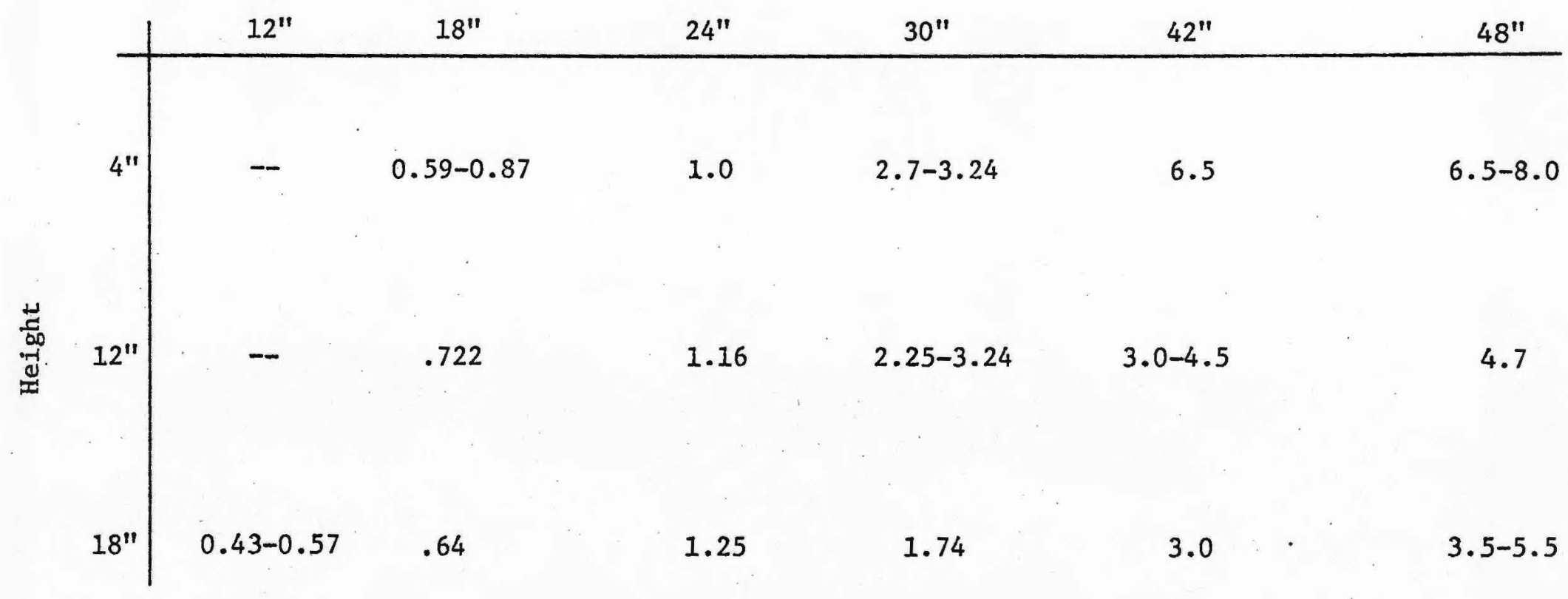


TABLE XI

AN ANALYSIS OF DATA FOR THE $12^{\prime \prime} \times 20^{\prime \prime}$ PLATE AT $550^{\circ} \mathrm{F}$ USING TECHNIQUES PRESENTED

BY KUZ'MINA

\section{Distance}

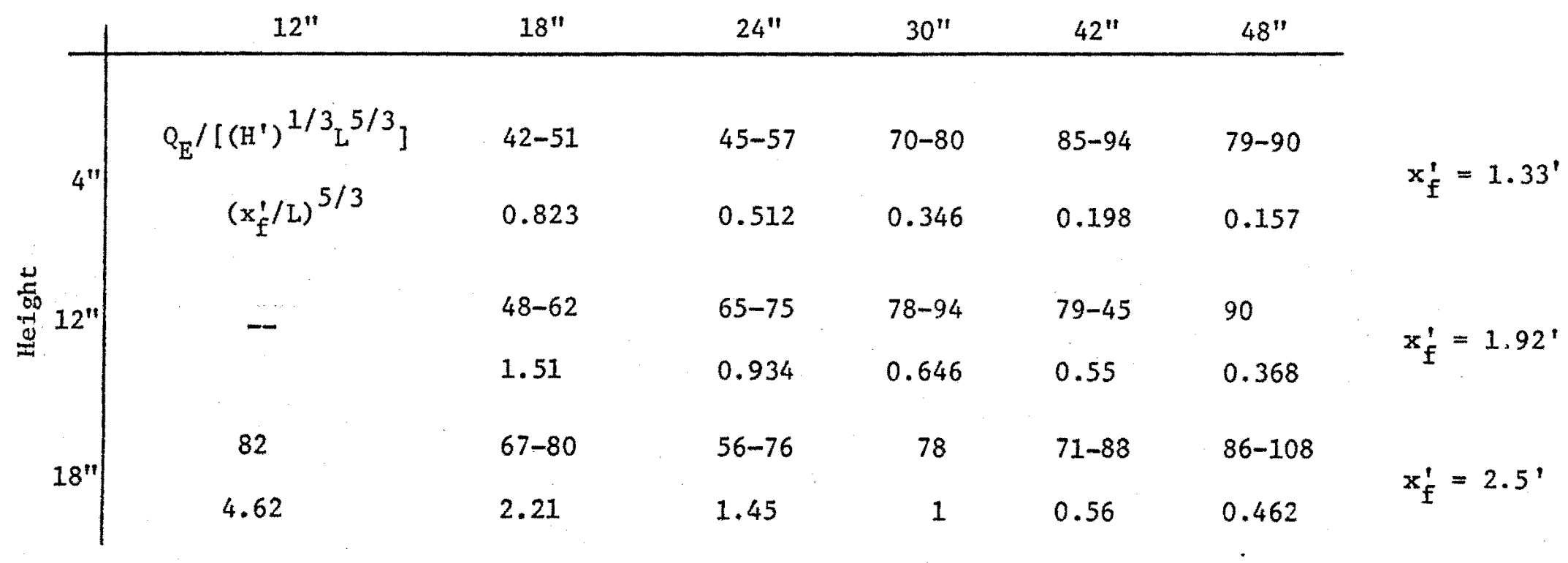


APPENDIX G

TABULAR RESULTS OF $12^{\prime \prime} \times 20^{\prime \prime}$ PLATE TESTED AT $750^{\circ} \mathrm{F}$ 
TABLE XII

EXIHAUST VOLURE (CFM) EXPRESSED AS A FUNCTION

OF POSITION OF $12^{\prime \prime} \times 20^{\prime \prime}$ PLATE

AT $750^{\circ} \mathrm{F}$

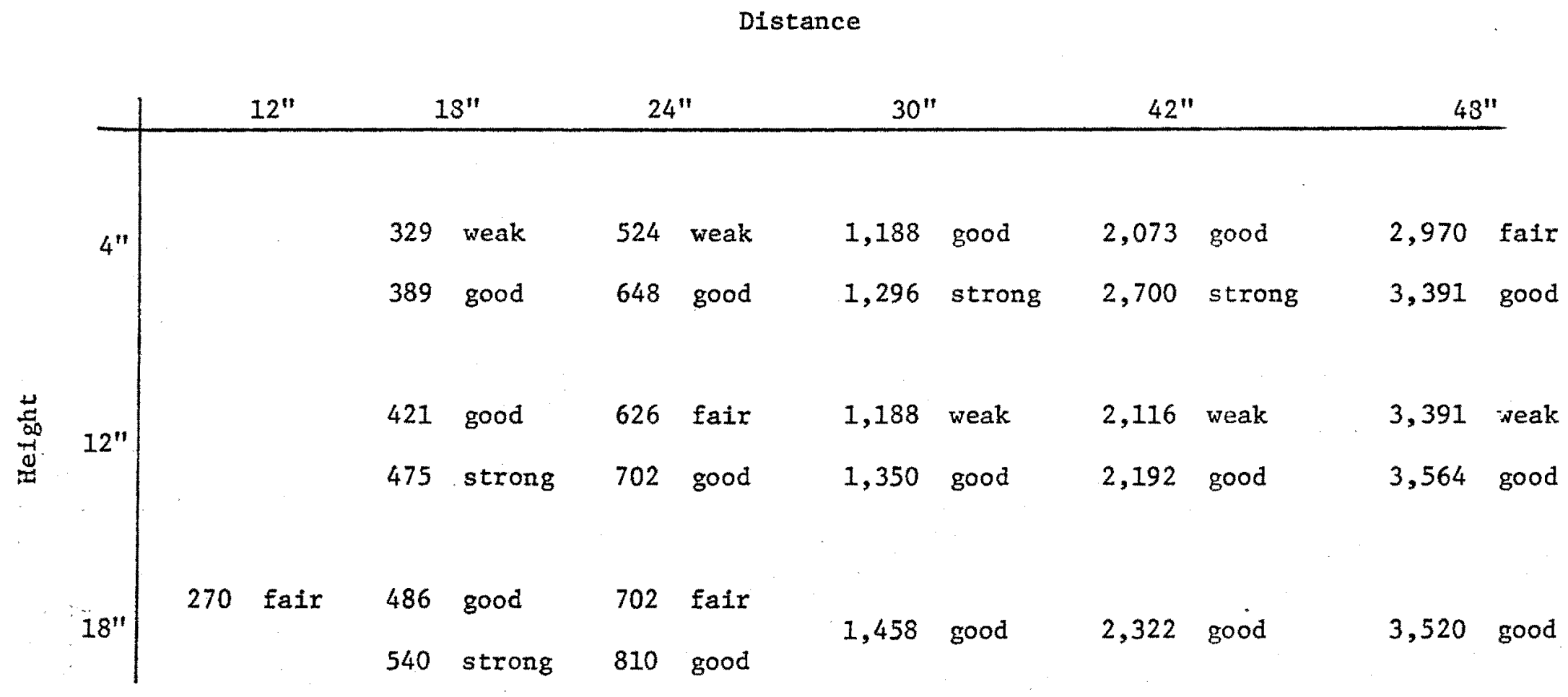


TABLE XIII

RATIO OF EXHAUST VOLUME TO PLUME VOLUME EXPRESSED

AS A FUNCTION OF POSITION

OF $12^{\prime \prime} \times 20^{\prime \prime}$ PLATE

AT $750^{\circ} \mathrm{F}$

Distance

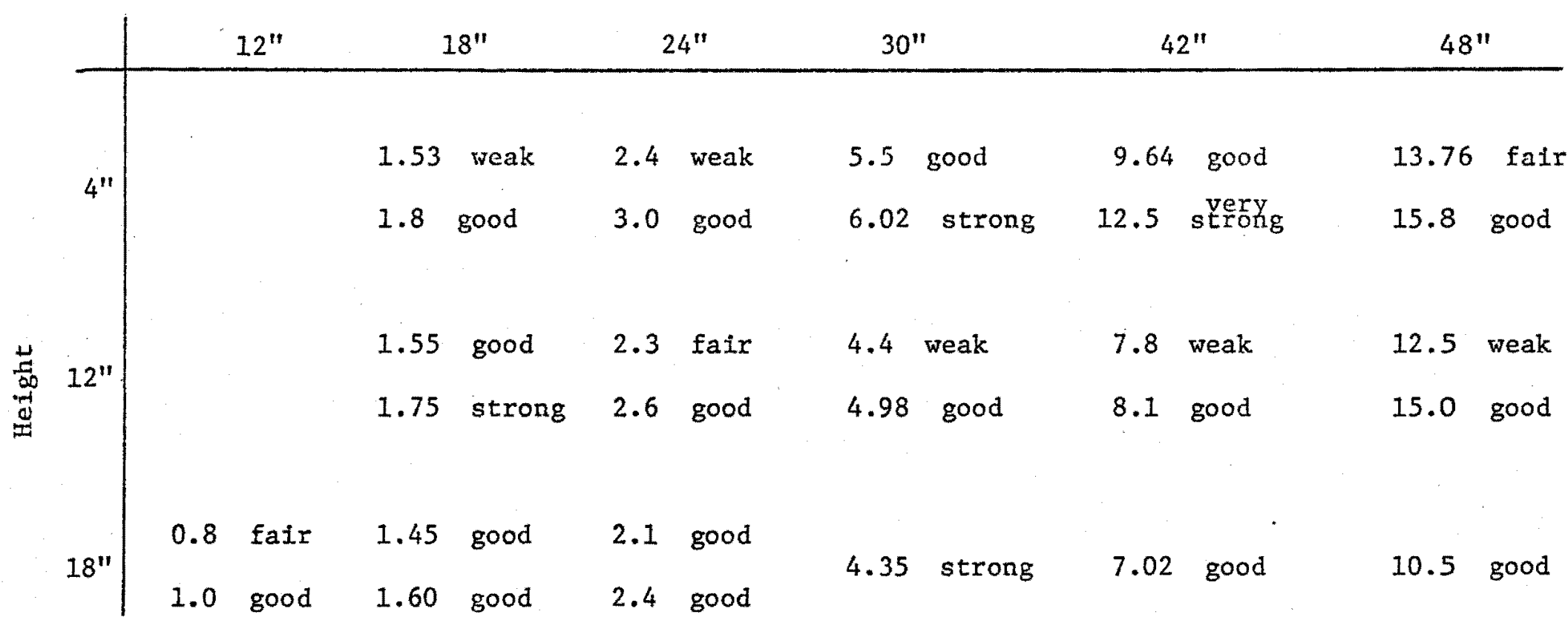


TABLE XIV

EXHAUST MOMENTUM EXPRESSED AS A FUNCTION

OF POSITION OF 12" x 20" PLATE

AT $750^{\circ} \mathrm{F}$

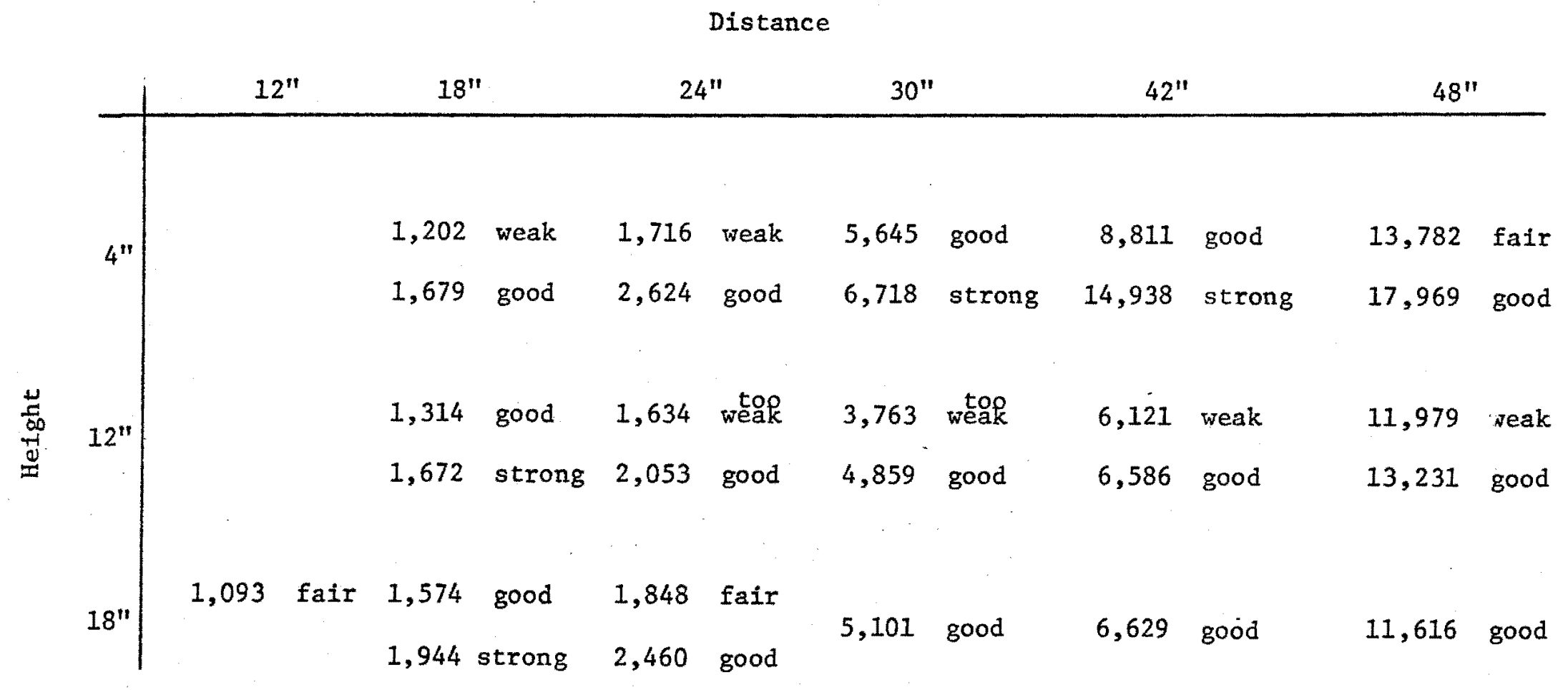




\section{TABLE XV}

RATIO OF EXHAUST MOMENTUM TO PLUME MOMENTUM, $\mathrm{K}_{2}$,

EXPRESSED AS A FUNCTION OF POSITION

OF $12^{\prime \prime} \times 20^{\prime \prime}$ PLATE AT $750^{\circ} \mathrm{F}$

\begin{tabular}{|c|c|c|c|c|c|c|}
\hline & & & Dist & & & \\
\hline & $12^{\prime \prime}$ & $18^{\prime \prime}$ & $24 "$ & $30^{\prime \prime}$ & $42^{\prime \prime}$ & $48^{\prime \prime}$ \\
\hline $4^{\prime \prime}$ & - & 0.7 & $1.0-1.5$ & 3.3 & $4.85-8.0$ & 7.6 \\
\hline $12^{\prime \prime}$ & - & 0.65 & $0.8-1.0$ & 2.4 & 3.1 & $5.6-6.2$ \\
\hline $18^{\prime \prime}$ & 0.46 & 0.66 & $0.8-1.05$ & 2.15 & 2.7 & 4.75 \\
\hline
\end{tabular}




\section{TABLE XVI}

AN ANALYSIS OF DATA FOR THE $12 "$ x $20 "$ PLATE AT $750^{\circ} \mathrm{F}$ USING TECHNIQUES PRESENTED BY KUZ'MINA

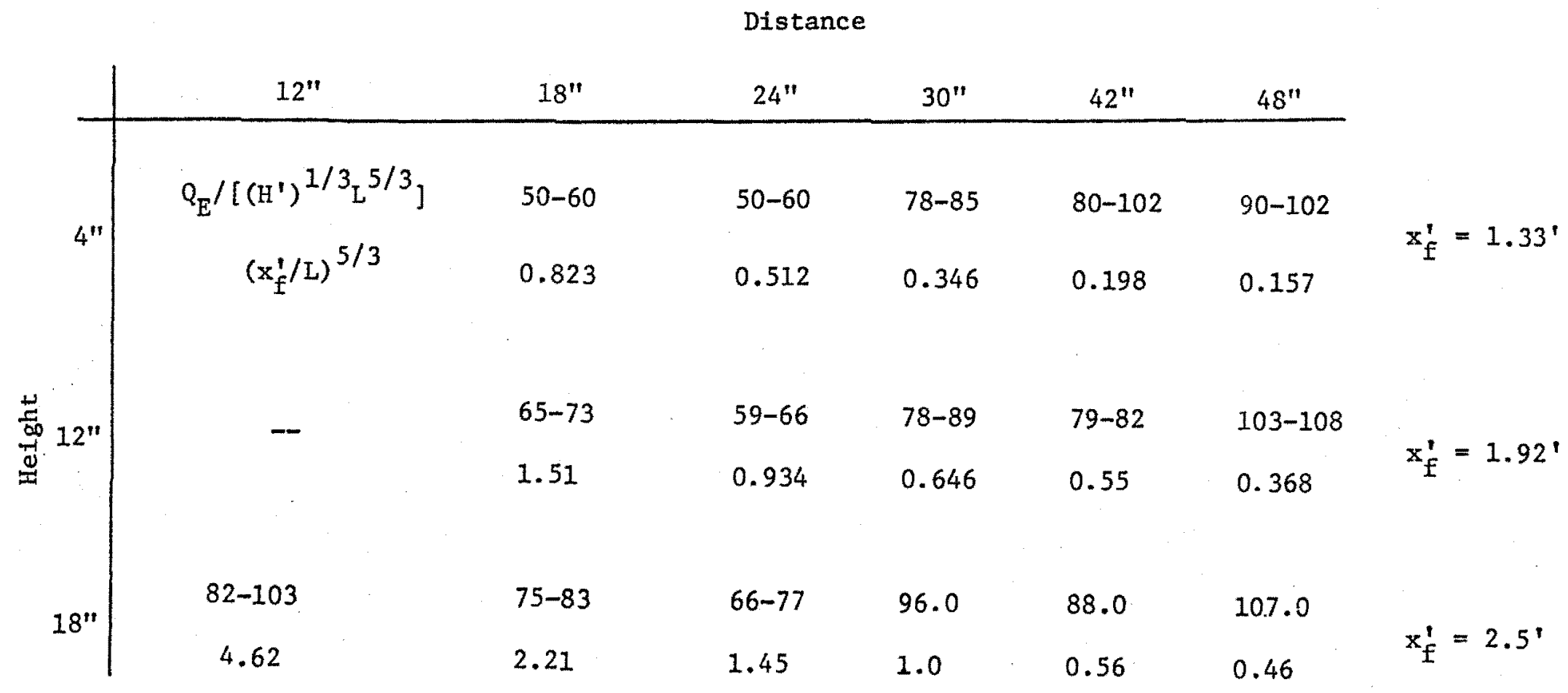


APPENDIX H

TABULAR RESULTS OF $8 " x$ 10" PLATE TESTED AT $615^{\circ} \mathrm{F}$ 
TABLE XVII

EXHAUST VOLUME, (CFM), EXPRESSED AS A FUNCTION

OF POSITION OF 8" $\times 10^{\prime \prime}$ PLATE

AT $615^{\circ} \mathrm{F}$

Distance

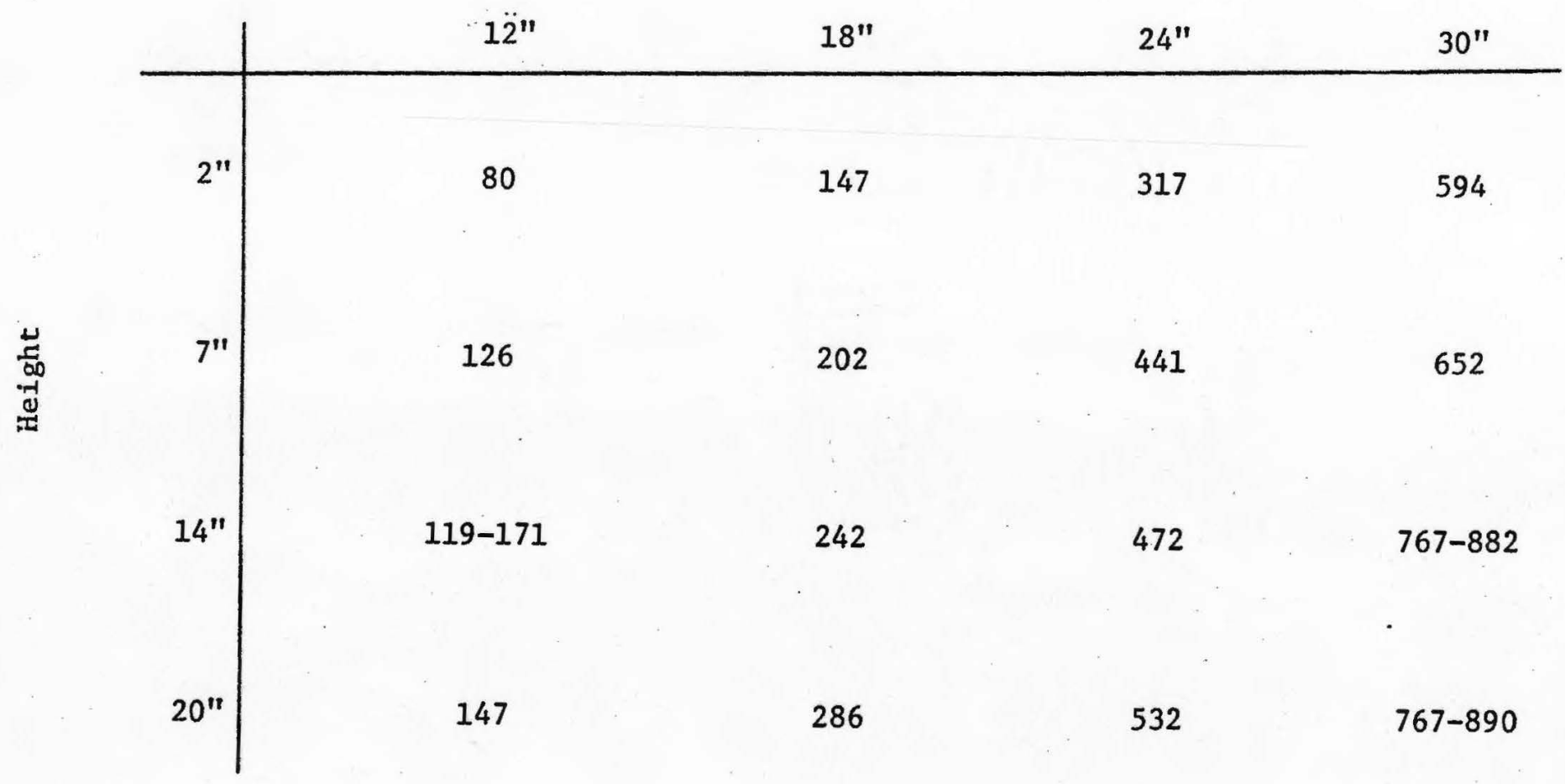




\section{TABLE XVIII}

RATIO OF EXHAUST VOLUME TO PLUME VOLUME

EXPRESSED AS A FUNCTION OF POSITION

OF 8" $x 10^{\prime \prime}$ PLATE AT $615^{\circ} \mathrm{F}$

Distance

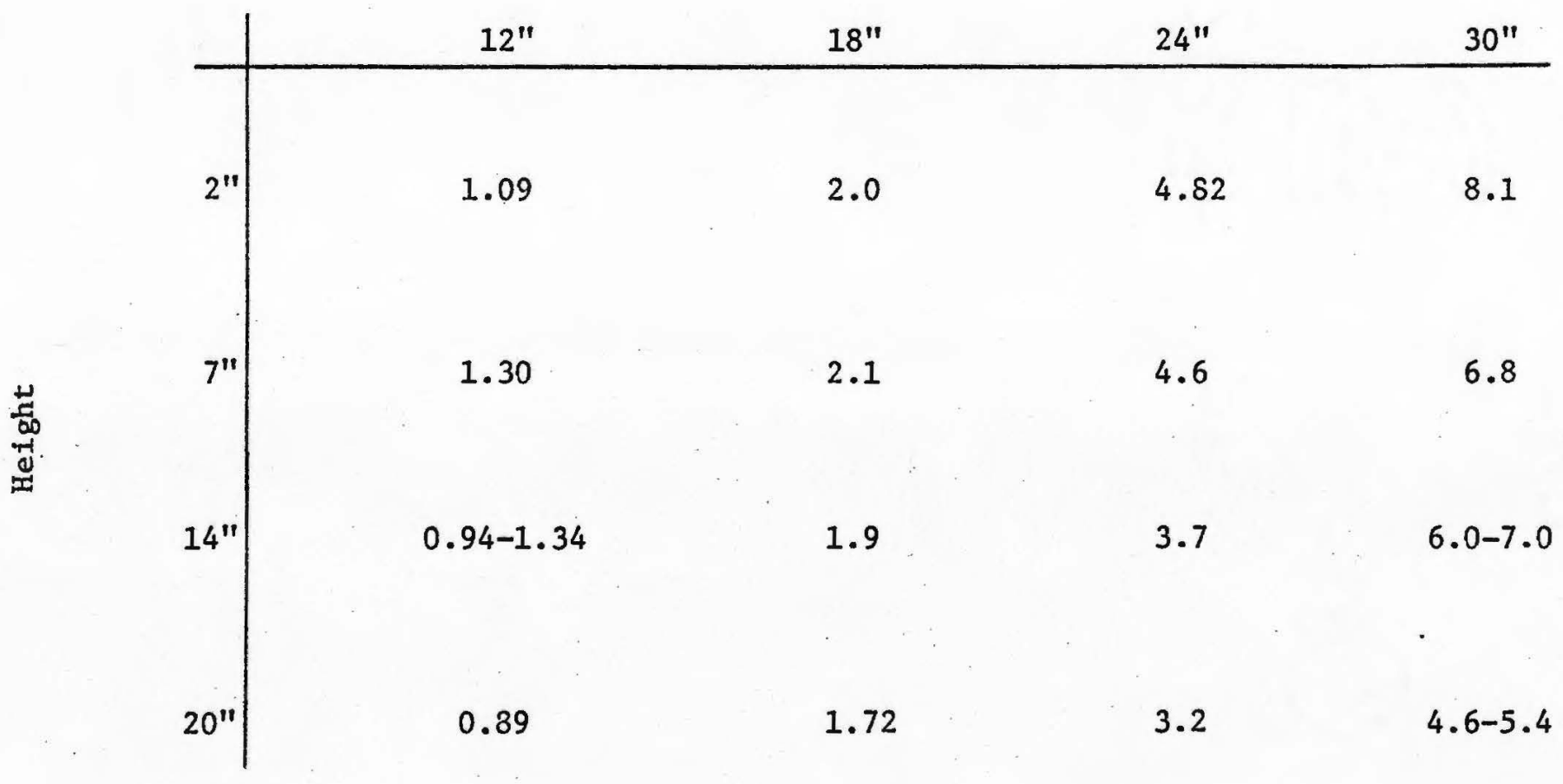


TABLE XIX

EXHAUST MOMENTUM EXPRESSED AS A FUNCTION OF POSITION OF 8 " $x$ 10" PLATE AT $615^{\circ} \mathrm{F}$

Distance

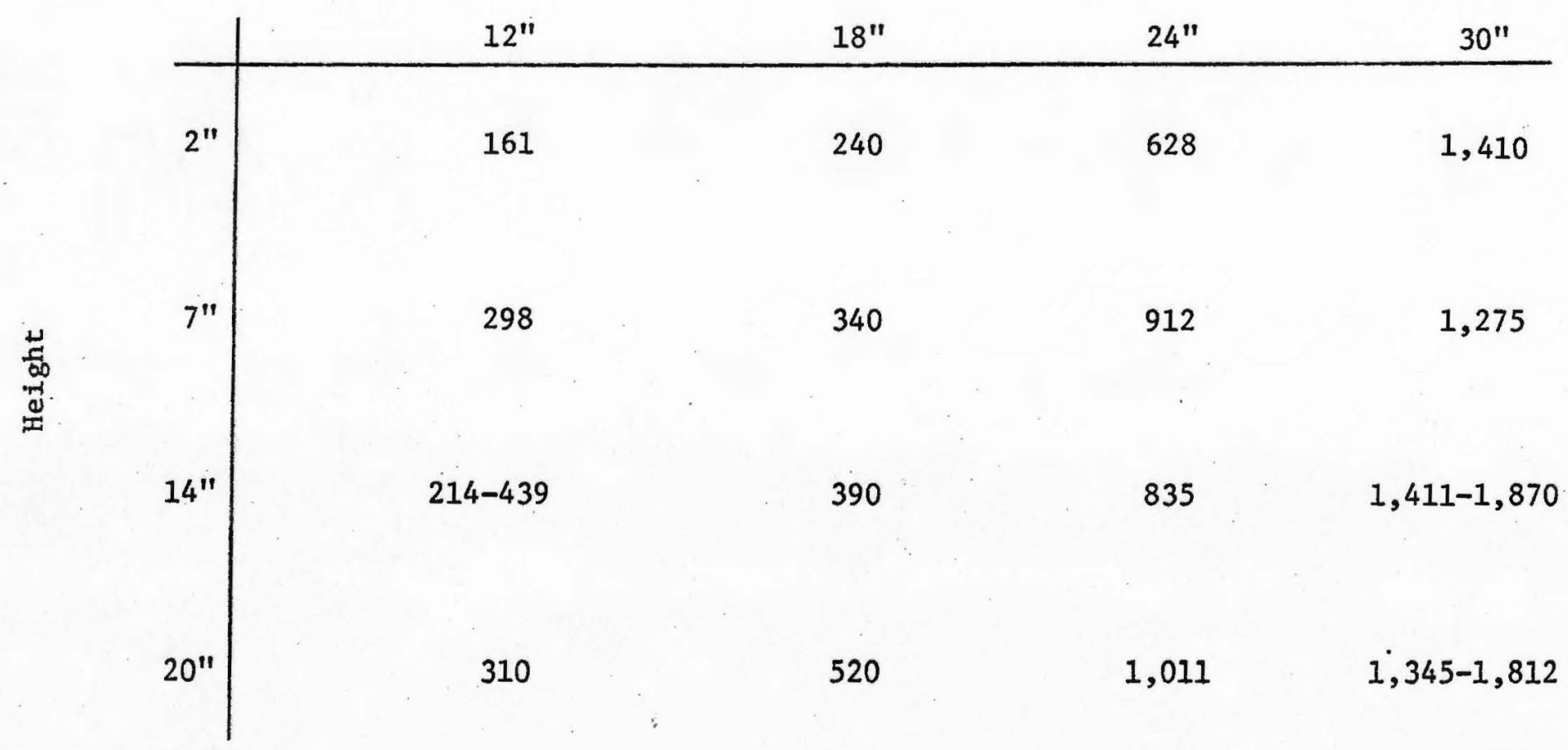


TABLE XX

RATIO OF EXHAUST MOMENTUM TO PLUME MOMENTUM, $\mathrm{K}_{2}$, EXPRESSED AS A FUNCTION OF POSITION OF 8 " $\times 10^{\prime \prime}$ PLATE AT $615^{\circ} \mathrm{F}$

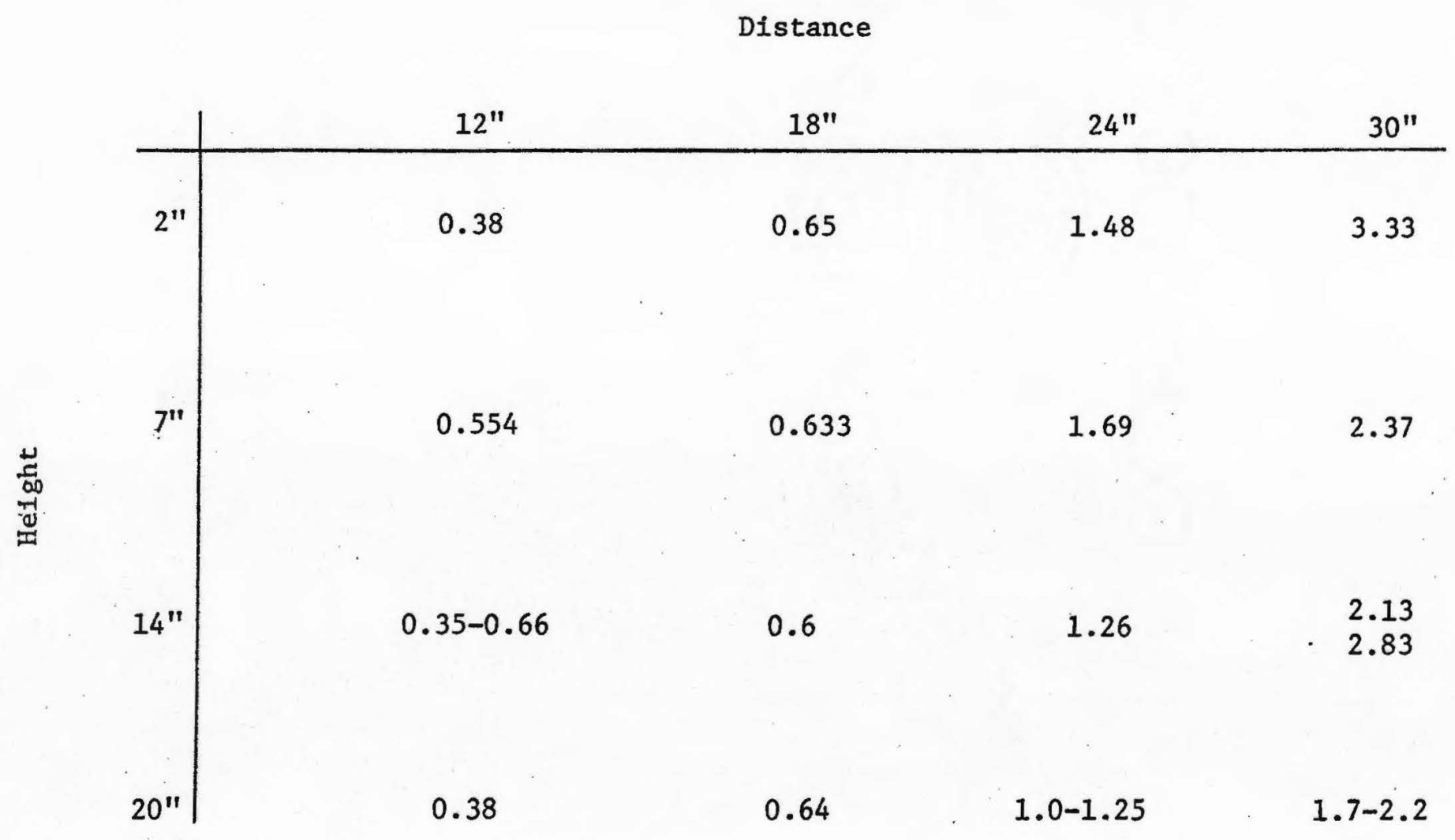


TABLE XXI

AN ANALYSIS OF DATA FOR THE $8^{\prime \prime} \times 10^{\prime \prime}$ PLATE

AT $615^{\circ} \mathrm{F}$ USING TECHNIOUES PRESENTED BY KUZ-MINA

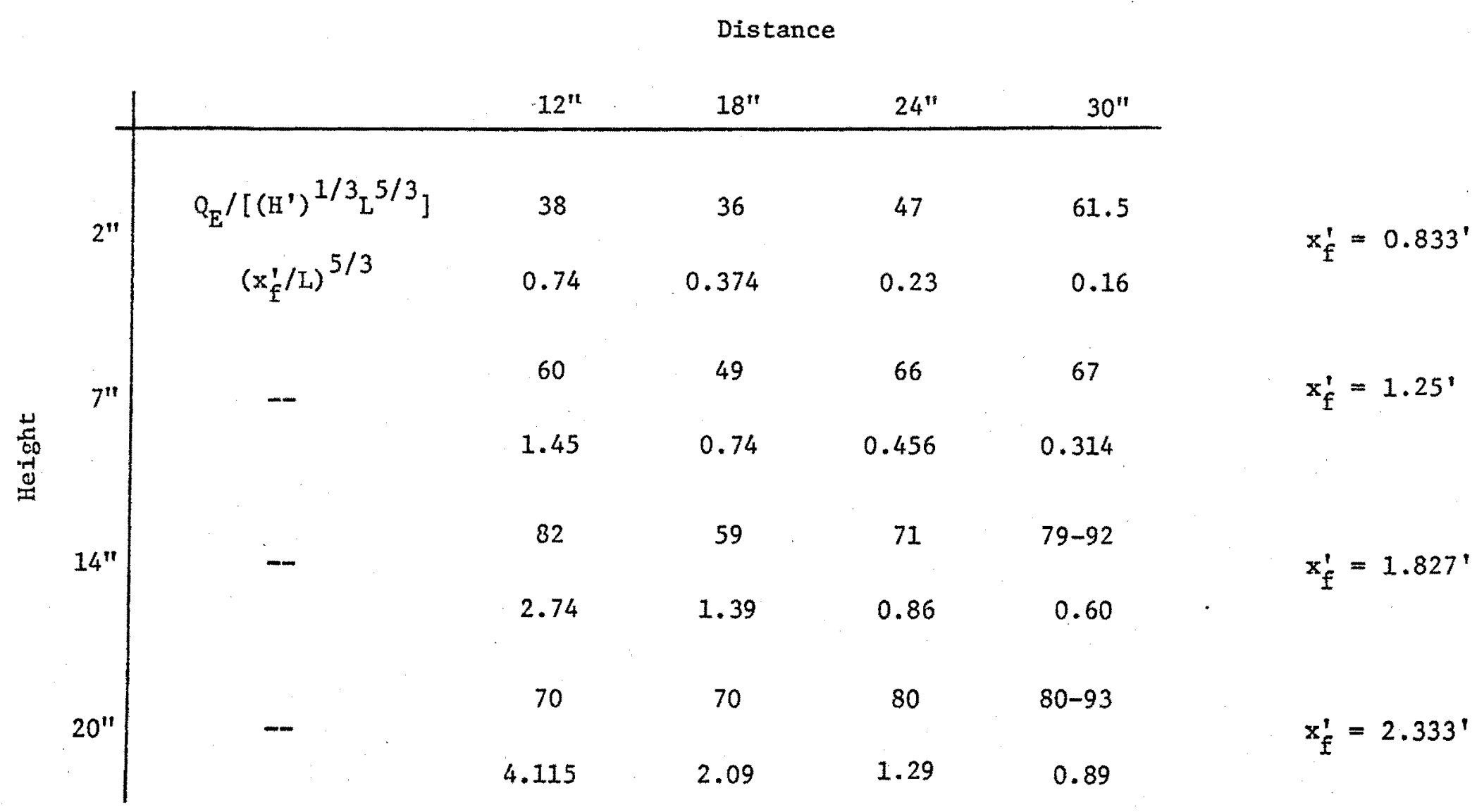




\section{APPENDIX I \\ ANALYSIS OF EXISTING SIDE DRAFT HOOD VENTILATING \\ 48" LADLE OF MOLTEN STEEL}

\section{Trial I}

At present, a 48" diameter ladle is ventilated by side draft hooding. The following are given parameters

$$
\begin{aligned}
& D_{s}=4 \mathrm{ft} . \\
& T_{s}=2,700^{\circ} \mathrm{F} \\
& L=6 \mathrm{ft} . \\
& H=6 \mathrm{ft} .
\end{aligned}
$$

Therefore, $\mathrm{x}_{\mathrm{f}}$ is calculated as

$$
\begin{aligned}
Z=(2 \times 4)^{1.138} & =10.65 \mathrm{ft} . \\
H & =6.00 \mathrm{ft} . \\
x_{f} & =16.65 \mathrm{ft} .
\end{aligned}
$$

Plume diameter can now be calculated as

$$
D_{p}=1 / 2(16.65)^{0.88}=5.9 \mathrm{ft} \text {. }
$$

and plume area is given by

$$
A_{p}=0.785(5.9)^{2}=27.7 \mathrm{ft}^{2}
$$

Plume velocity is calculated as

$$
\begin{aligned}
V_{p}=8\left(A_{s}\right)^{1 / 3}(\Delta \mathrm{T})^{5 / 12} / x_{f}^{0.29} & =8(2.32)(26.75) / 2.22 \\
& =224 \mathrm{f}_{\mathrm{pm}}
\end{aligned}
$$


and flow is then given as

$$
Q_{p}=224 \times 27.7=6,205 \mathrm{cfm}
$$

Momentum 1s given by

$$
\rho_{\mathrm{p}} \mathrm{Q}_{\mathrm{p}} \mathrm{V}_{\mathrm{p}}
$$

therefore, $\rho_{p}$ must be solved.

The heat loss can be found to be

$$
\begin{aligned}
H^{\prime} & =0.38 A_{S} \Delta T^{5 / 4} / 60 \mathrm{Btu} / \mathrm{min} . \\
& =(0.38)(12.56)(19,462) / 60 \mathrm{Btu} / \mathrm{min} . \\
& =1,553 \mathrm{Btu} / \mathrm{min} .
\end{aligned}
$$

This can also be set equal to

$$
\begin{aligned}
H^{\prime} & =\dot{M}_{p}\left(T_{p}-530\right) \\
& =\rho_{p} Q_{p} C_{p}\left(T_{p}-530\right) \\
\text { where } \rho_{p} & =(0.075)\left(530 / T_{p}\right)
\end{aligned}
$$

Therefore, by equating terms and noting that $Q_{p}=6,205 \mathrm{cfm}$,

$$
\begin{aligned}
1,553 & =(0.075)\left(530 / \mathrm{T}_{\mathrm{p}}\right)(6,205)(0.24)\left(\mathrm{T}_{\mathrm{p}}-530\right) \\
.026 & =1-\frac{530}{\mathrm{~T}_{\mathrm{p}}} \\
\mathrm{T}_{\mathrm{p}} & =530 / 0.974=544^{\circ} \mathrm{R}=84^{\circ} \mathrm{F}
\end{aligned}
$$

Therefore, it can be assumed that the plume density remains close to ambient value and equal to $0.073 \mathrm{lbm} / \mathrm{cu} . \mathrm{ft}$. in this case. Plume momentum becomes

$$
M_{p}=(0.073)(6,205)(224)=101,464
$$

Exhaust momentum is found by first determining $\mathrm{V}_{\mathrm{E}}$. In this case

$$
Q_{E}=V_{E}\left(10 L^{2}+A_{H}\right)
$$




$$
Q_{E}=V_{E}(360+26)=386 V_{E}
$$

Thus velocity is given by

$$
V_{E}=40,000 / 386=103 \mathrm{fpm}
$$

Momentum then becomes

$$
(40,000)(103)(0.075)=310,880
$$

The ratio of exhaust to plume momentum is then found to be .

$$
\mathrm{K}_{2}=310,880 / 101,464=3.06
$$

\section{Trial II}

If the distance, $L$, equals $4 \mathrm{ft}$, , better collection results, and $V_{E}$ is determined from

$$
\begin{aligned}
& Q_{E}=V_{E}(10[16]+26)=186 V_{E} \\
& V_{E}=40,000 / 186=215 \mathrm{fpm}
\end{aligned}
$$

Momentum then becomes

$$
(40,000)(215)(0.075)=645,161
$$

and $\mathrm{K}_{2}$ is given as

$$
\mathrm{K}_{2}=645,161 / 101,464=6.36
$$

Trial III Kuz mina Technique

It is noted that

$$
\begin{aligned}
& x_{f}^{\prime}=10 \mathrm{ft} .=3.07 \text { meters } \\
& L=4 \mathrm{ft} .=1.23 \text { meters } \\
& \left(x_{f}^{\prime} / L\right)^{5 / 3}=4.6
\end{aligned}
$$

for the 4'-0" ladle distance.

Thus, from Figure 9 it is seen that

$$
Q_{E} /\left[\left(H^{\prime}\right)^{1 / 3} L^{5 / 3}\right]=600
$$


By noting that

$$
\begin{aligned}
\mathrm{H}^{\prime} & =\left[0.38(2,700)^{1 / 4}(12.6)(2,700)\right] / 60=1,553 \mathrm{Btu} / \mathrm{min} . \\
& =(1,553 \mathrm{Btu} / \mathrm{min} .)(0.25 \mathrm{kCAL} / \mathrm{Btu})(60 \mathrm{~min} . / \mathrm{hr} .) \\
& =23,296 \mathrm{KCAL} / \mathrm{hr} .
\end{aligned}
$$

it is seen that

$$
\begin{aligned}
Q_{E} & =600(23,296)^{1 / 3}(1.23)^{5 / 3} \\
& =24,115 \text { meters }{ }^{3} / \mathrm{hr} .
\end{aligned}
$$

or exhaust flow is given as

$$
\begin{aligned}
& \left(24,115 \mathrm{~m}^{3} / \mathrm{hr}_{.}\right)\left(34.32 \mathrm{ft} .3 / \mathrm{m}^{3}\right)(1 \mathrm{hr} . / 60 \mathrm{~min} .) \\
& =14,195 \mathrm{cfm}
\end{aligned}
$$

